\title{
Application and Construction of Microbial Biosensors in Chemical Forensics
}

\author{
Justine Couper
}

\begin{abstract}
A thesis
Submitted to the Victoria University of Wellington in partial fulfillment of the requirements for the degree of Masters of Science in Molecular Microbiology
\end{abstract}

School of Biological Sciences

Victoria University of Wellington

2008 


\begin{abstract}
Forensic toxicologists are often required to rapidly determine if a suspicious substance, such as a white powder, contain toxins. Preliminary tests usually include screens for a wide range of 'Potentially Toxic Chemicals' (PTCs) such as cyanide, pesticides, herbicides, medicinal and illicit drugs. Subsequent analyses are generally very time-consuming and costly. Any protocol screening for a range of PTC's, prior to more robust chemical analysis, could therefore save significant analytical time.
\end{abstract}

Microbial biosensors are ideal biological tools that can be utilised for these purposes. In vivo bioassays were developed for a range of PTCs using a suite of microbial biosensors, in a variety of complex matrices including water, white powders, soils and vomit to determine the effect of matrix complexities on the biosensors, as well as the toxins.

The lux biosensor, Escherichia coli HB101 pUCD607, showed an $\mathrm{EC}_{50}$, (where $E_{50}$ is the effective concentration of toxin causing $50 \%$ reduction in bioluminescence), of cyanide in water of $20 \mathrm{mg} / \mathrm{L}$. This biosensor still detected cyanide, in talc and flour, at $\mathrm{EC}_{50}$ values of $589 \mathrm{mg} / \mathrm{L}$ and $700 \mathrm{mg} / \mathrm{L}$ respectively. Vibrio harveyi showed good sensitivity to cyanide in initial water bioassays with an $\mathrm{EC}_{50}$ of $9.66 \mathrm{mg} / \mathrm{L}$. The $V$. harveyi biosensor did not detect cyanide spiked in talc or flour when tested up to a maximum concentration of $10,000 \mathrm{mg} / \mathrm{L}$. The Mycena citricolor ATCC 34884 fungal biosensor, showed lower sensitivity levels however it detected the presence of sodium monofluoroacetate (1080) at a concentration $1000 \mathrm{mg} / \mathrm{L}$.

Preliminary investigation of a novel, faster, solid-phase sample preparation method was also undertaken and its potential proven, particularly in PTC spiked white powders. Here the biosensor showed sensitivity to arsenate, arsenite, copper, cyanide and PCP at $1000 \mathrm{mg} / \mathrm{L}$. 
This project highlighted the inability of current biosensors to reliably detect 1080 and the difficulty in constructing a specific biosensor. The utilisation of a reliable vector and inducible promoter are pivotal in biosensor construction. 


\section{Acknowledgements}

I would like to express my sincere thanks and appreciation to a fantastic and supportive team of supervisors: Dr Jacqui Horswell and Dr Ronan O'Toole. Their doors were always open for me. A special thanks to Jacqui, my day-to-day supervisor, who gave me this opportunity and didn't laugh, sigh or cry at stupid questions.

I would also like to thank the students and staff at Vic Uni Lab 817 (Shahista Nisa, Jeremy Owen, Gareth Prosser and David Ackerley) for the advice, fun and coffees. Thanks to the staff and students at the Population and Environmental Health research lab at ESR; especially my room buddies Melanie Goucher and Alice Johnstone - Alice was like the concierge in our office - she just knows everything!!!!. Professor Anne Glover \& Dr Hedda Weitz deserve mention for sending me the fungi used to achieve the fungal bioassay results and answering my questions.

Zac, Jake and Teagan, my three children, have sometimes felt mother-less and have only ever known their mother to be studying therefore the biggest thanks must also go to them and my husband, David, who invariably picked up the pieces and without his support I would never have tried to do this.

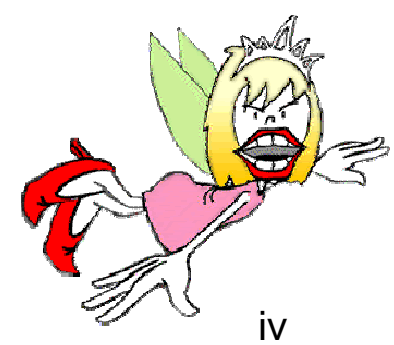




\section{Table of Contents}

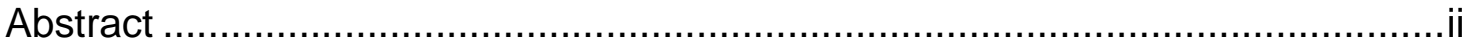

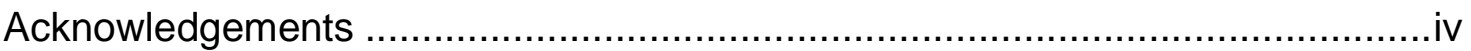

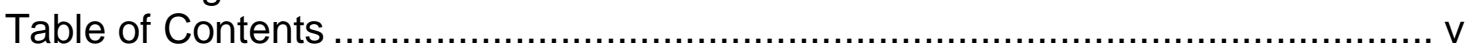

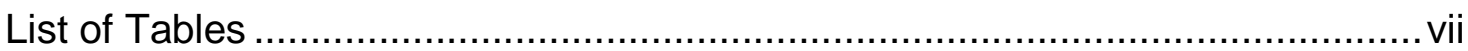

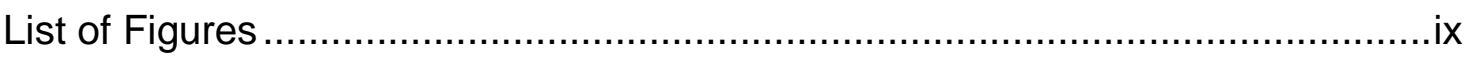

CHAPTER ONE: INTRODUCTION …...................................................... 1

1.2.1 Investigation of a Suite of General Biosensors ................................. 2

1.2.2 Development of a Specific Bacterial Biosensor .............................. 2

1.3.1 Microbial Biosensors ............................................................... 5

1.3.1.1 lux-Based Bacterial Biosensors (non-specific) ...................... 8

1.3.1.2 Genetically Modified Non-Specific Biosensors ...................... 11

1.3.1.3 Biosensor Case Study: Vomit Bioassay. .............................. 13

1.3.1.4 Naturally Luminescent Fungi........................................... 14

1.3.2 The Development of a Specific Bacterial Biosensor: '1080-lux' . ....... 19

CHAPTER TWO: MATERIALS AND METHODS ......................................... 28

2.1.1 Bacterial Biosensor Preparation Methods ..................................... 28

2.1.2 Fungal Biosensor Preparation Methods. .................................... 31

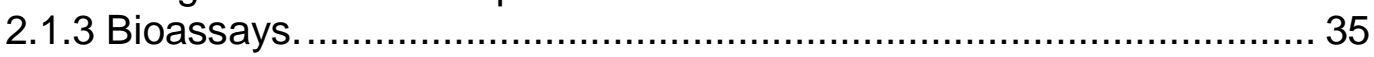

2.1.3.1 White Powder Bioassays.............................................. 37

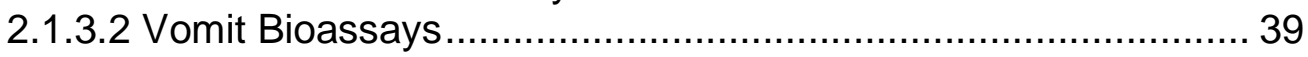

2.2.1 Method of Solid-Phase sample Preparation .................................. 40

2.2.2 Statistical Analysis and Data Interpretation ................................... 45

2.3.1 Methods of Construction of the Specific Bacterial Biosensor. ........... 46

2.3.2 Construction of 1080-lux and JlacO-lux constructs. ......................... 51

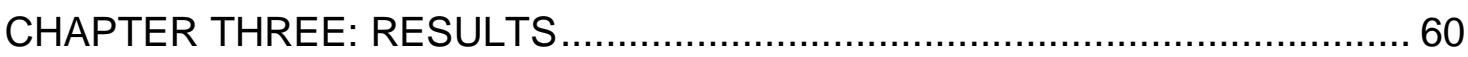

3.1.1 Characterisation of Bacterial Biosensors......................................6 60

3.1.2 Characterisation of Fungal Biosensors.......................................... 62

3.3.1.1 PTC Methanol Extraction. ............................................... 78

3.3.1.2 Case Study: Vomit Bioassay ....................................... 80

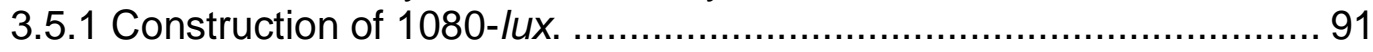

3.5.2 Screening for Positive Insert Clones. ........................................... 93

3.5.3 Construction of positive control JlacO luxCDABE constructs. ........... 98

3.5.4 Screening for JlacO promoter positive insert clones. ....................... 99

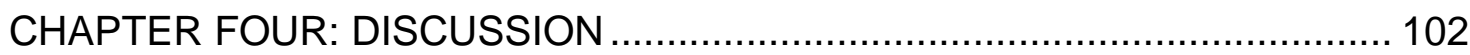

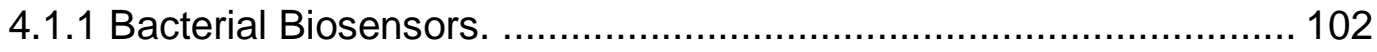

4.1.1.1 Case Study: Vomit Bioassay ........................................ 106

4.1.2 Fungal Biosensors. ........................................................... 107

4.5.1 Metabolic Biosensor Bioassays............................................... 117

4.5.2 Solid-Phase Sample Preparation. ........................................... 118

4.5.3 Specific 1080-lux biosensor. ................................................. 119 
REFERENCES. 
List of Tables

Table 1-1:Traditional approaches to measuring the presence of toxins. 3

Table 1-2: Types and characteristics or biosensors used in environmental monitoring.

Table 1-3: E. coli HB101 pUCD607 biosensor response to a range of toxins in comparison to concentrations found in samples from fatal poisonings........ 12

Table 1-4: Comparison of bacterial biosensors and potential of naturally luminescent fungi as biosensors.

Table 1-5: Oral Toxicity of 1080 for susceptible species.

Table 2-1: Basidiomycete fungi isolates chosen for investigation of bioluminescence and globular mycelial growth patterns.

Table 2-2: PTCs used in this non-specific biosensor investigation including uses, application rates and $L D_{50}$ s where applicable.

Table 2-3: Optimal pH range for bioluminescence of microbial biosensors used in PTC bioassays.

Table 2-4: Bacterial strains and plasmids used in the construction of specific '1080-Iux' bacterial biosensor and the 'J/acO-positive control' bacterial biosensor.

Table 2-5: Primers used in PCR amplification.

Table 2-6: PCR protocols used for the amplification of the 1080 dehalogenase promoter and the JlacO positive control promoter fragments.

Table 2-7: PCR protocols used for the amplification of inserts for determination of promoter orientation in trannsformants.

Table 3-1: Luminescence of sourced potential fungal biosensors on three different agars and in three different broths, screened for desired growth and luminescence patterns.

Table 3-2: Initial bioassays of PTCs in water using the three microbial biosensors; E. coli HB101 pUCD607, V. harveyi and M. citricolor...

Table 3-3: Bioassays of PTC spiked flour and talc using the two bacterial biosensors; E. coli HB101 pUCD607 and V. harveyi.

Table 3-4: E. coli HB101 pUCD607 biosensor sensitivity to three PTCs in different spiked matrices. 
Table 3-5: Bioluminescence measurement of positive 1080-lux colonies 98

Table 3-6: Bioluminescence screening of JlacO-lux construct. 101

Table 4-1: Microbial bioassay results showing the $\mathrm{LD}_{50}$ and the E. coli HB101 pUCD607 biosensor response in PTC spiked water, vomit, talc and flour. 105

Table 4-2: Summary table comparing the biosensor ability to detect PTCs spiked into different matrices using different sample preparation methods.113 
List of Figures

Figure 1-1: The rationale behind metabolic and catabolic biosensors. .............. 6

Figure 1-2: The E. coli HB101 pUCD607 luxCDABE operon.............................. 9

Figure 1-3: The regenerative process of autocatalysis ................................ 11

Figure 1-4: (i) Chemical structure of 1080 (ii) The haloacetate dehalogenase reaction

Figure 1-5: The Krebs Cycle (Tricarboxylic Acid Cycle -TCA Cycle) .................26

Figure 1-6: The structural similarity between citrate and fluorocitrate................27

Figure 2-1: M. citricolor ATCC 34884 and Mycena sp. ICMP 16534.................. 33

Figure 2-2: Globular mycelium of $M$. citricolor ATCC 34884 cultured in PD

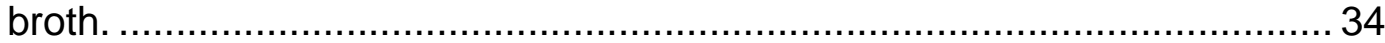

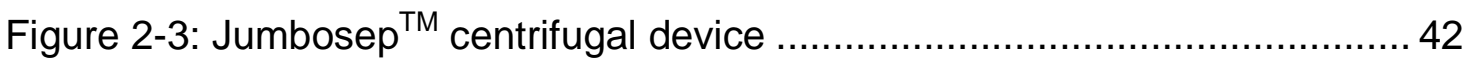

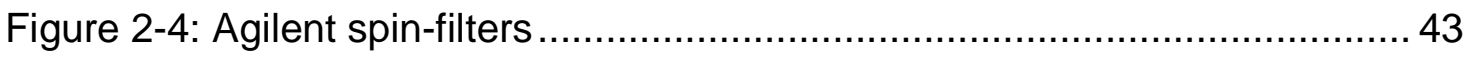

Figure 2-5: Overview of solid-phase bioluminescence bioassay using spin

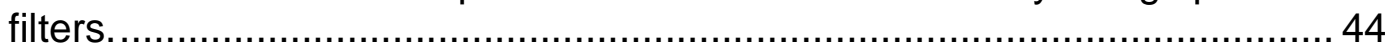

Figure 2-6: (A) luxCDABE transposon (B) pUT mini-Tn5 luxCDABE................ 48

Figure 2-7: Flow chart illustrating steps involved involved in constructing the specific bacterial biosensor plasmid construct........................................... 49

Figure 2-8: The rationale behind the design of the promoter orientation colony screening PCR. ................................................................................ 57

Figure 3-1: Growth and bioluminescence patterns of the two bacterial biosensors. (A) E. coli HB101 pUCD607 and (B) V. harveyi. .....................61

Figure 3-2: Dose-response curves of quality assurance of the bacterial biosensors, E. coli HB101 pUCD607 $(\mathrm{A})$ and $V$. harveyi $(\mathrm{B})$ using TCP ${ }^{\mathrm{TM}}$ as a test solution

Figure 3-3: Characterisation experiments of Mycena sp. ICMP 16534 64

Figure 3-4: Graph depicting differing growth efficiencies of the U.K sourced $M$. citricolor ATCC 34884 and the New Zealand Mycena sp. ICMP 16534. ..... 65

Figure 3-5: Comparisons of the effect of copper on M. citricolor. 66 
Figure 3-6: Initial acephate bioassays of E. coli HB101 pUCD607 and V. harveyi biosensors.

Figure 3-7: M. citricolor ATCC34884 bioassay dose response curves for acephate, arsenate, copper, cyanide, zinc and 1080.

Figure 3-8: M. citricolor ATCC34884 dose response curves indicating the biosensors inability to detect carbaryl, arsenite and difenacoum...

Figure 3-9: V. harveyi white powder dose-response curves 73

Figure 3-10: Comparison of the E. coli HB101 pUCD607 and V. harveyi biosensor dose-response curve shapes.

Figure 3-11: Comparison of the E. coli HB101 pUCD607 biosensor doseresponse curve shapes.

Figure 3-12: Comparison of dose-response curve shapes with different PTCs used.

Figure 3-13: Preliminary methanol bioassay results 79

Figure 3-14: Dose-response curves showing the E. coli HB101 pUCD607 response to the organic pesticides acephate and carbaryl following methanol extraction.

Figure 3-15: Vomit and water controls. 81

Figure 3-16: Spiked vomit bioassays using three PTCs; (A) arsenate, (B) arsenite and $(\mathrm{C})$ carbaryl. 82

Figure 3-17: E. coli HB101 pUCD607 bioassays with arsenate 84

Figure 3-18: E. coli HB101 pUCD607 bioassays with arsenite. 85

Figure 3-19: E. coli HB101 pUCD607 bioassays with cyanide. 86

Figure 3-20: E. coli HB101 pUCD607 bioassays with copper. 87

Figure 3-21: E. coli HB101 pUCD607 bioassays with PCP. 88

Figure 3-22: $1 \%$ agarose gel electrophoresis showing a $14.2 \mathrm{~kb}$ band corresponding to $\mathrm{pUT}$ mini-Tn5 luxCDABE plasmid.

Figure 3-23: 1\% agarose gel showing the 550 bp PCR amplified region of dehRI promoter.

Figure 3-24: Fragment analysis using BLAST for the PCR amplified dehRI promoter region. 
Figure 3-25: The successful ligation of the 550bp dehRI promoter segment into the mini-Tn5 luxCDABE............................................................ 93

Figure 3-26: 1080-lux orientation screening. .................................................. 94

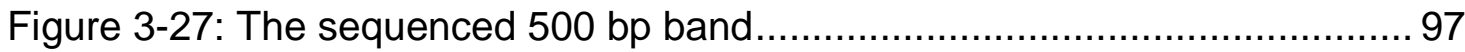

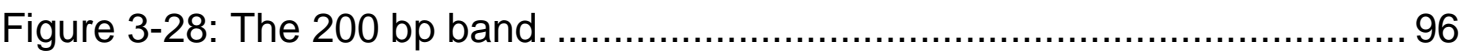

Figure 3-29: 1\% agarose gel shows the $147 \mathrm{bp}$ JlacO promoter insert .............. 99

Figure 3-30: The confirmed presence of the JlacO promoter ligated into pUT

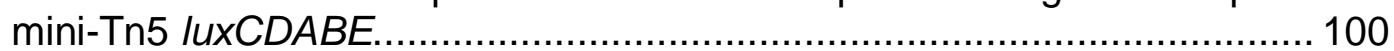

Figure 3-31: Insert orientation screening of JlacO promoter in pUT mini-Tn5 I $\mathrm{x}$ CDABE vector............................................................................. 100 
List of Symbols, Abbreviations and Nomenclature

\section{Symbol}

ATCC

CDC

CIAP

CSIRO

CYP

DNA

$\mathrm{EC}_{50}$

GC

GCMS

GFP

HPLC

HSNO

ICMP

IPTG

$\mathrm{KCl}$

$\mathrm{LD}_{50}$

ME

$\mathrm{MeOH}$

$\mathrm{PAH}$

PCP

$P D$

RHDV

RLU

SAP

SDW

TCA

TCP

TNT

WHC

WHO

YM

\section{Definition}

American Type Culture Collection

Centre for Disease Control

Calf intestine alkaline phosphatase

Commonwealth Scientific and Industrial Research Organisation

Cytochrome P450

Deoxy-ribose nucleic acid

Effective concentration of toxin causing $50 \%$ reduction in bioluminescence

Gas chromatography

Gas chromatography mass spectrometry

Green fluorescent protein

High performance liquid chromatography

Hazardous substances new organisms

International collection of microorganisms from plants

Isopropyl B-D-1-thiogalactopyranoside

Potassium chloride

Concentration/dose where $50 \%$ mortality of the population occurs

Malt extract

Methanol

Polycyclic aromatic hydrocarbons

Pentachlorophenol

Potato dextrose

Rabbit haemorrhagic disease virus

Relative light unit

Shrimp alkaline phosphatase

Sterile distilled water

Tricarboxylic acid cycle

Brand name of liquid antiseptic

2,4,6 - trinitrotoluene

Water holding capacity

World Health Organisation

Yeast malt 


\section{Chapter One: INTRODUCTION}

\subsection{Rationale.}

Incidents such as the September 11 World Trade Centre attacks in 2001 (United States of America) and the illegal introduction of Rabbit Haemorrhagic Disease Virus (RHDV) in 1997 into New Zealand, illustrate the continued concern over threats from terrorists and extremists. These types of incidents occur worldwide and highlight the need for reliable, portable, cost-effective and simple detection systems for potentially toxic chemicals (PTCs). As a result many nations are now investing in counter terrorism strategies. Underpinning 'biodefence' strategies is the development of biotechnology-based analytical tools.

Microbial biosensors are ideal biological tools that can be used for rapid and sensitive initial screening of suspicious substances. Their stability and low cost contribute to their advantage over chemical analysis. The investigation of microbial biosensors, prokaryotic and eukaryotic, naturally bioluminescent and genetically modified, provides an expansive portrayal of sensitivity to a diverse range of PTCs.

In this thesis work the responses of non-specific (metabolic) microbial biosensors, both bacterial and fungal, were analysed using bioassays with a variety of PTCs. This highlighted 1080 as a PTC that non-specific biosensors have been unable to reliably detect in low concentrations. Therefore the 
construction of a 1080-specific bacterial biosensor was investigated as an alternative method for developing a more sensitive biosensor.

\subsection{Aims.}

\subsubsection{Investigation of a Suite of General Biosensors.}

Non-specific bacterial biosensors have been previously used to assess metal toxicity in environmental samples. This project aimed to develop a suite of biosensors and investigate their sensitivity to several classes of PTCs in a variety of complex matrices. Two bacterial biosensors were investigated, including a naturally bioluminescent, non-genetically modified bacterium ( $V$. harveyi) and a genetically modified biosensor (E. coli HB101 pUCD607). To assess eukaryotic relevance and expand current knowledge of fungal biosensor responses and sensitivities, bioassays were carried out using the fungal isolate Mycena citricolor ATCC 34884.

This thesis also aimed to develop a novel solid-phase bioluminescent bioassay protocol as an initial screening method in white powders and soils, thereby providing a preliminary evaluation of the potential of the protocol for suspicious powders and soils contaminated with PTCs with low solubility.

\subsubsection{Development of a Specific Bacterial Biosensor.}

New Zealand has a heavy reliance on the manufacture and production of primary products. Agricultural and horticultural chemicals such as 1080, 
organophosphate and carbamate pesticides and herbicides, are of a highly toxic nature if used inappropriately. This project therefore, aimed to design and construct a specific bacterial biosensor that detects such chemicals and has particular relevance to New Zealand.

\subsection{Background.}

Traditional and more classical approaches to determining and quantifying the presence of toxins include chemical analysis methods such as High Performance Liquid Chromatography (HPLC), Gas Chromatography (GC) and Gas Chromatography Mass Spectrometry (GCMS), each having advantages and disadvantages [1], [2] (Table 1-1).

Table 1-1:Traditional approaches to measuring the presence of toxins. Listed are the advantages and disadvantages of each.

\begin{tabular}{|l|l|l|}
\hline \multicolumn{1}{|c|}{ Method } & \multicolumn{1}{c|}{ Advantage } & \multicolumn{1}{c|}{ Disadvantage } \\
\hline $\begin{array}{l}\text { HPLC } \\
\text { (High Performance Liquid }\end{array}$ & Most sensitive & $\begin{array}{l}\text { Interference } \\
\text { Chromatography) }\end{array}$ \\
GC & Not widely available \\
(Gas Chromatography) & Reliable & Interference \\
GCMS & Inexpensive & Not as sensitive as HPLC \\
(Gas Chromatography Mass & Positive identification & Not as sensitive as HPLC \\
Spectrometry) & & Relatively expensive \\
\hline
\end{tabular}

An alternative to these approaches are microbial biosensors. Microbial biosensors can be defined as analytical devices, incorporating a biological sensor, such as a micro-organism or an enzyme, which can provide an 
information-linked response to a specific property (e.g. the presence of a toxic chemical), via a suitable transducer (e.g. electrochemical, optical) [1].

Table 1-2: Types and characteristics or biosensors used in environmental monitoring.

The mechanisms of various types of catabolic and metabolic biosensors, their advantages and disadvantages. Metabolic biosensors are fast and effective however they are also non-specific. Catabolic biosensors are specific but the range available is currently limited [1].

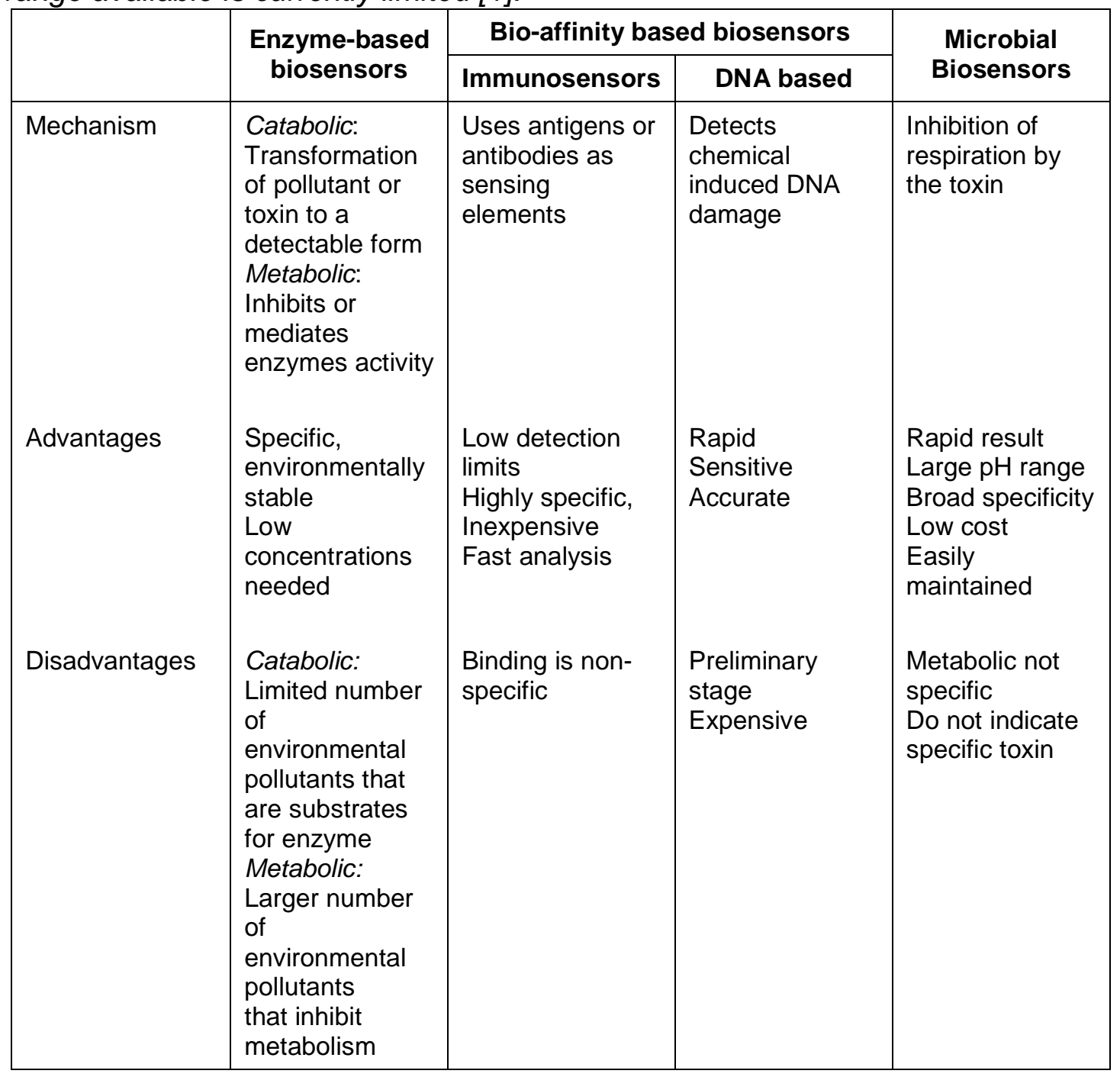


Biosensors have applications in numerous fields, including medicine [1], therapeutics, environmental testing [3], [4], [5], [6] [1] and food quality testing [7], [8], [9], clearly demonstrating their diversity and value as biological tools. A number of these different types of biosensors along with their mechanisms, relative advantages and disadvantages are shown in Table 1-2.

\subsubsection{Microbial Biosensors.}

Non-specific (metabolic) bioluminescent microbial biosensors encompass two broad categories; naturally luminescent, for example $V$. harveyi, and genetically modified, for example E. coli HB101 pUCD607 [10]. Non-specific biosensors exploit the microorganisms stress response and produce a measurable response, in the presence of a metabolic toxin [1]. Non-specific biosensors require a strong constitutive promoter and any increase or decrease in the luminescence response quantitatively indicates toxicity to the cells metabolism [1] (Figure 1-1(i)). Metabolic lux biosensors have been applied to the detection of heavy metals in soil samples [11].

Genetically modified microbial biosensors may be either non-specific (metabolic) or specific (catabolic). Specific biosensors contain reporter genes downstream of a strong constitutive promoter. Genetic modification may increase these metabolic responses. Specific biosensors require an inducible promoter and light emitted by this class of biosensor is induced only in the presence of the specific 
substance, frequently achieved by linking the lux genes to a degradation pathway [10], [12] (Figure 1-1 (ii)). Specific metabolic biosensors have applications to the assessment of toxicity in environmental samples based on a reduction in bioluminescence in the presence of toxic compounds including the detection of arsenic and copper in soils [3] and cadmium and lead in soils [5].

(i) Metabolic

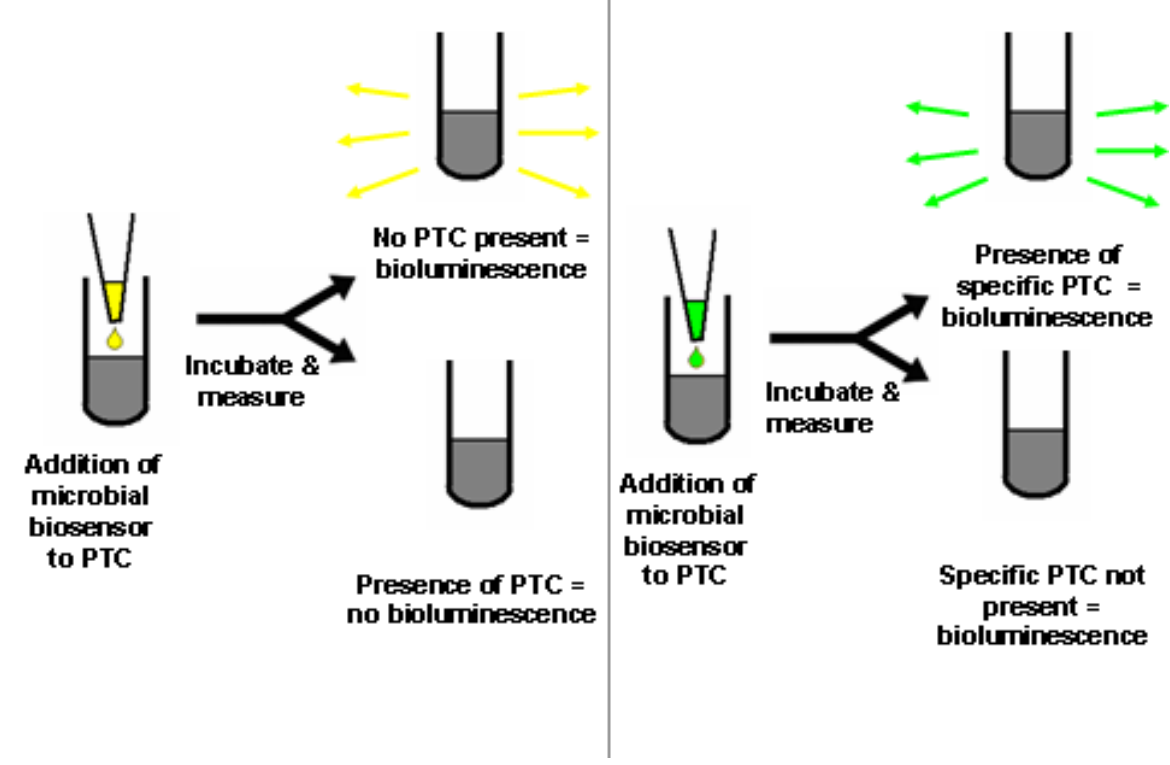

Figure 1-1: The rationale behind metabolic and catabolic biosensors.

(i) In metabolic biosensors following the addition of the microbial biosensor to the prepared PTC the biosensor is incubated and measured for luminescence. The presence of luminescence indicates no toxicity. If limited or no luminescence occurs toxins are likely to be present. (ii) In catabolic biosensors the presence of a specific PTC will induce bioluminescence. If the specific PTC is not present or other PTCs are present the biosensor will not luminesce.

Perhaps the foremost advantage of microbial biosensors is they permit rapid and continuous control of measurement, that is, they provide real time information [1], 
contrasting with the more periodic sampling in traditional analytical methods. Furthermore, the application of biosensors allows determination of analyte concentration of compounds difficult or expensive to detect including dioxins, pesticides and metabolites [13].

Microbial biosensors have advantages in terms of their exploitation of biological recognition molecules such as enzymes or antibodies, imparting a high specificity and relevance to higher organisms [1]. Biosensors have the advantage over chemical analysis in that they are able to address whether PTCs are biologically available; bioavailability being defined as the measurement of the extent to which a PTC is available at the active site of the biosensor [11]. Conventional chemical analysis, by comparison, exclusively measures the concentration of the contaminant. Additional biosensor advantages include their ease of use, economy and ability to operate in complex matrixes, for example, contaminated soils [14], urine [15] or stomach contents [16]. Crucially, this ability reduces the need for sample preparation providing faster response times, a feature particularly advantageous in forensic applications [17],[18].

Because biosensors are generally relatively small, they can be used separately or as detectors within larger systems [1]. They are stable, easily maintained and a large number of cells can be exposed to an individual toxin in a single investigation. The overall toxicity of a sample can be measured and requires no pre-knowledge about the nature of toxicity in the sample, as is necessary when 
employing standard chemical analysis [17]. Their shelf stability has been improved by freeze-drying and the microorganism can be immediately reconstituted and used [14].

\subsubsection{1 lux-Based Bacterial Biosensors (non-specific).}

Several types of reporter gene systems have been documented [19]. While some bio-reporters require the presence of secondary substrates (IuxAB, Luc and aequorin) others, for example, green fluorescent protein ( $g f p)$, require an external light source and others still have self-induced signals [18]. Differences in assay conditions using different biosensor constructs, necessarily reflect differences in reporter constructs [20]. Although each construct functions differently, the end result is the same; a measurable signal that is proportional to the concentration of the chemical or physical agent [14]. A decrease in metabolic activity leads to decreased cellular respiration and adenosine triphosphate (ATP) production equating to a decline in luminescence (Figure 1-1).

Luciferase is a generic name used for an enzyme that catalyses a light emitting chemical reaction, such as is characteristic of bacterial bioluminescence. These enzymes can be found in a variety of organisms, including bacteria, algae, fungi, jellyfish and insects, and the light emitted from them is termed bioluminescence [19]. The lux operon that encodes luciferase consists of 5 genes; luxA, luxB, $\operatorname{lu} x C, \operatorname{lu} x D$ and $\operatorname{lu} E$; where $\operatorname{lu} A$, IuxB synthesise the $\alpha$ and $\beta$ subunits of 
luciferase and $\operatorname{lu} x C$, IuxD and $\operatorname{lu} x E$ synthesise or recycle the aldehyde substrate [19], [21] (Figure 1-2).

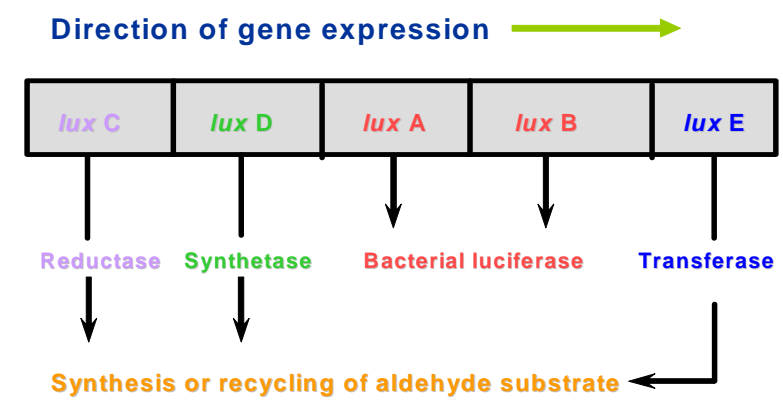

Figure 1-2: The E. coli HB101 pUCD607 luxCDABE operon.

This operon contains two genes for luciferase, the enzyme that catalyzes the lightemitting reaction (luxA and luxB) and three genes for the enzymes that produce the luciferins, the substrates for the light-emitting reaction (IuxC, luxD, IuxE).

If solely luxAB genes are inserted into a plasmid construct, the sensor requires the exogenous addition of $n$-decanal as it is unable to synthesise this component of the luminescence reaction [19]. If the complete lux cassette, luxCDABE, encoding for light production is utilised the sensor requires no exogenous substances [19]. In lux-based metabolic biosensors, luminescence is directly proportional to metabolic activity such that any toxin inducing metabolic stress, results in a quantitative decline in luminescence proportional to the concentration of the toxin [22]. Light output is measured by a luminometer or scintillation counter. 
The complete luxCDABE cassette has been inserted into numerous environmentally relevant terrestrial microorganisms for use in ecotoxicity bioassays [23], [24]. Shaw and Kado [21] cloned bioluminescent (lux) genes from Vibrio fischeri into the broad host range vector, pUCD4. The resulting recombinant plasmid (pUCD607) has been mobilised into a variety of bacterial species, including E.coli HB101 pUCD607 [14], Rhizobium leguminosarum biovar trifolii [23], Pseudomonas fluorescens [11] and Salmonella typhimurium [16]. The lux constitutively bioluminesces and is relatively stable in the absence of selective pressure [11].

Light emission is highly dependant on growth and environmental conditions. Several elements are critical to bacterial bioluminescence. It is essential that the external cellular environment provides molecular oxygen [24]. Without this, the microorganism is unable to emit light. The second factor critical to the emission of luminescence is quorum sensing [22]. The machinery involved is under stringent regulatory control. For the brightest light emission to occur, a high level of luxCDABE expression is required to form bacterial luciferase and fatty acid reductase [22]. Also required is the continued synthesis of the substrates over long time periods. The increased expression of luxCDABE genes occurs through autocatalysis (Figure 1-3), where the products of the reaction (autoinducers) also catalyse the reaction from which they were derived, leading to the generation of more products and then more catalysts [25]. 


\section{Autocatalysis}

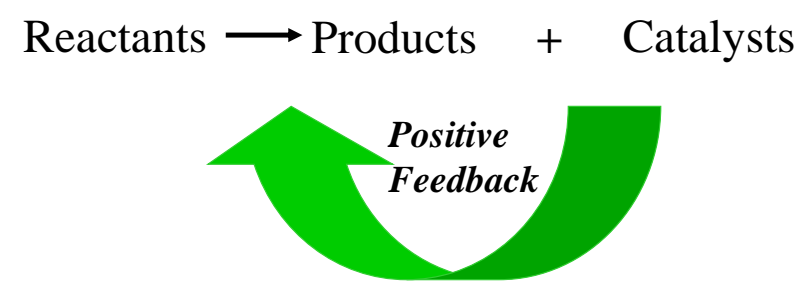

Figure 1-3: The regenerative process of autocatalysis.

The products of the reaction catalyse the reaction from which they were derived from.

At low cell density the autoinducers produced, diffuse through the bacterial cell membrane into the growth media. As cell growth continues the level of autoinducers in the media increases in the confined environment. At this stage a very low light emission can be detected. Higher levels of autoinducers activate the luminescent systems of the bacteria. This regulatory response to the changing concentration of auto-inducer is called quorum sensing [26].

\subsubsection{Genetically Modified Non-Specific Biosensors.}

As stated in Section 1.3.1, genetic modification can greatly enhance the sensitivity of the microbial biosensor response, primarily through the use of reporter genes. Paton et al. [14], investigated the detection of environmental toxins including copper, nickel, cadmium and zinc. The lux plasmid construct used in his study, pUCD607, was determined to be more sensitive than a 
chromosomal construct [14]. The potential of microbial biosensors has been explored to detect PTCs as listed in Table 1-3 and furthermore, it has been established that biosensors remain sensitive in a variety of complex media including urine [15], stomach contents [16], soil [14] as well as water and are therefore useful to this study.

Table 1-3: E. coli HB101 pUCD607 biosensor response to a range of toxins in comparison to concentrations found in samples from fatal poisonings.

Comparisons of concentrations of PTCs that have occurred in published fatal poisonings and biosensor responses to the toxins. $E C_{50}$ is defined as the effective concentration of toxin causing $50 \%$ reduction in bioluminescence.

\begin{tabular}{|c|c|c|}
\hline $\begin{array}{c}\text { Potentially Toxic } \\
\text { Compound }\end{array}$ & $\begin{array}{c}\text { Range Concentrations (mg/L) } \\
\text { in Fatal Poisonings }\end{array}$ & $\begin{array}{c}\text { Biosensor Response } \text { EC }_{50} \\
\text { (in water) }\end{array}$ \\
\hline Glyphosate & $11,200[13]$ & 316.3 \\
$2,4-D$ & $314[27]$ & 23.7 \\
Cyanide & $37[27]$ & 3.9 \\
Arsenate & $0.2[28]$ & 0.2 \\
Arsenite & $0.2[28]$ & 6.9 \\
Mercuric & $\begin{array}{c}0.5-1.6 \text { for vapour inhalation as } \\
\text { mercury [29] } \\
214[29]\end{array}$ \\
Phenol & \multicolumn{2}{|c|}{0.4} \\
\hline
\end{tabular}

Previous studies have discussed the difficulties encountered with the detection of PTCs with limited solubility, for example pentachlorophenol (PCP), in environmental samples, such as soil [30]. In their study investigating the use of recombinant luminescent bacteria as biosensors specific for cadmium and lead in 
soils, Ivask et al. [5] developed an approach that enabled the detection of bioavailable metals in solid-phase samples [5]. Previous studies using contact biotests (where the biosensor organism is in contact with solid matrix during the bioassay), have been undertaken using worms [31], plants [32] and soil bacteria [33]. On comparison of results from solid-phase and aqueous bioassays, Ivask et al. [5], determined that approximately 90 fold more cadmium and 21 fold more lead was available to the biosensor in contact assays compared to water extract assays [5]. By their nature, solid-phase bioassays require robust controls as pollutants in complex matrices may interfere with assay results. The inhibition of light output by the biosensor, due to quenching of emitted light by colour or turbidity of the soil matrix must be considered [5].

\subsubsection{Biosensor Case Study: Vomit Bioassay.}

Forensic toxicologists are frequently asked to implicate or exclude chemical poisoning in suspicious deaths or unexplained illnesses [34]. A number of analyses are used depending on the circumstances of the case, with primary tests usually looking for medicinal or illicit drugs. Subsequent testing may include individual or groups of poisons making screening for such a range of PTCs time consuming [16].

Although, as previously mentioned, earlier studies have investigated the successful use of bacterial biosensors in urine and stomach contents [16], [15] 
their use has not, to our knowledge, been investigated in vomit, which is frequently the matrix in which chemical toxins are presented to the toxicologist.

The bioavailability of PTCs and the presence of organic compounds in spiked matrices influences the response of the biosensor [16]. Binding of PTCs to organic matter in vomit is synonymous with the binding of PTCs to organic matter in soil. Bundy et al. [35], used microbial biosensors to assess the ecological toxicity of organotins in soils and established that toxicity decreased by an order of magnitude in soil extracts compared to distilled water [35]. This was deemed to be due to the binding of organotins to the soluble colloids in the soil solutions.

\subsubsection{Naturally Luminescent Fungi.}

Bioluminescence production in fungi is less well understood than in bacteria and the molecule, or molecules, acting as a fungal luciferin remains unidentified [36]. However, as with bacterial luminescence, luminescence in fungi occurs in optimum conditions and is therefore an indicator of cell health both before and after exposure to a toxin [37]. In the event of decreased number of cells, such as cell death due to toxic agents, luminescence decreases. There are currently thought to be naturally bioluminescent fungi in 42 species within 9 genera, all of which are basidiomycetes making this phylum a viable option in the selection of fungi to be screened for potential biosensor applications [38]. 
A limited number of studies have been carried out characterising the growth and bioluminescence of naturally bioluminescent fungi. Weitz et al. [37], established that a general relationship exists between mycelial growth and bioluminescence, as lower levels of luminescence were associated with poor growth. Most bacterial biosensors are genetically modified in order to aid the detection of the sensor response, for example, E. coli HB101 pUCD607 and Salmonella typhimurium pUCD607 [16]. It is due to this genetic modification, that their potential for use "out-in-the-field" as a portable rapid detection system, is considered to be limited, especially in New Zealand. Although there is negligible possibility of escape and subsequent environmental risk from genetically modified bacterial biosensors, public perception is a consideration and current HSNO regulations (AS/NZS2243.3, 1995, Safety in Laboratories, Part 3: Microbiology) prohibit their use outside a PC2 laboratory in New Zealand.

Most biosensor development to date has concentrated on bacterial biosensors however they do have limitations. Bacterial biosensors may be relatively fragile in the sensors environment leading to a reduced in-use life [37]. In addition, limited osmotic and temperature tolerances of individual species may consequently lead to limitations in operating parameters [37]. Parry et al. [39], reviewed the use of yeast and other fungi for the detection of carcinogens and noted the physical robustness of these eukaryotes in comparison to bacterial biosensors. He, and others, have also noted crucial optimal $\mathrm{pH}$ ranges, temperature, osmolytic and/or ion strength tolerances of bioluminescent fungi [39], [40]. 
It is significant that cellular responses of eukaryotes to some molecule(s) may differ from the responses of prokaryotes to the same molecule(s). This limits the application of bacterial biosensors in toxicity evaluation of higher organisms [41]. The utilisation of eukaryotes in biosensor analysis of PTCs imparts information of increased relevance to other eukaryotes, consequently making it potentially more accurate at predicting responses in higher organisms to toxins [39], [42].

Desirable characteristics for naturally luminescent fungi, enabling their potential use in biosensor bioassays, include ease of cultivation, bioluminescent stability, bioluminescence linked to metabolic activity, the production of soft globular mycelia and measurable luminescence [37]. In her study Weitz [43], examined four fungal species including; Mycena citricolor ATCC 34884, Armillaria mellea, Omphalotus olearius and Panellus stipticus, for their potential as biosensors. Of these four, two species (M. citricolor ATCC 34884 and A. mellea), were further investigated for their biosensor ability [43]. Weitz [43], considered both A. mellea and M.citricolor ATCC 34884 to be the most stable and easily cultivated of the naturally bioluminescent fungi examined. Their important ecological functions of nutrient cycling and biodegradation, make fungi an important taxonomic group for the detection and monitoring of toxins.

Weitz [43], also found both M. citricolor ATCC 34884 and A. mellea showed sensitivity towards 3,5-dichlorophenol (3,5-DCP), pentachlorophenol (PCP) and copper. However, there was some variation in sensitivity between fungal species. 
Notably, the $\mathrm{EC}_{50}$ values (the concentration of a toxin which induces a response halfway between the baseline and maximum) for $A$. mellea and $M$. citricolor ATCC 34884 for 3,5-DCP, PCP and copper were similar to those for bioluminescent bacterial biosensor E.coli HB101 pUCD607 (Table 1-4).

Table 1-4: Comparison of bacterial biosensors and potential of naturally luminescent fungi as biosensors. (Amended from Weitz $H \mathrm{~J}$, 2002)

\begin{tabular}{|l|c|c|c|}
\hline \multirow{2}{*}{$\begin{array}{l}\text { Potentially Toxic } \\
\text { Compound }\end{array}$} & \multicolumn{2}{|c|}{$\begin{array}{c}\text { Fungal Biosensors } \\
\text { EC }_{50} \text { (mg/L) }\end{array}$} & $\begin{array}{c}\text { Bacterial Biosensors } \\
\text { EC }_{50} \text { (mg/L) }\end{array}$ \\
\cline { 2 - 3 } & A. mellea & M. citricolor & \\
\hline $3,5-\mathrm{DCP}$ & $13.6 \pm 1.1$ & $9.16 \pm 0.31$ & $2.8-8.2[44]$ \\
$\mathrm{PCP}$ & $8.08 \pm 0.68$ & $0.356 \pm 0.016$ & $0.0077[44]$ \\
$\mathrm{Cu}$ & $0.080 \pm 0.016$ & $2.25 \pm 0.62$ & $0.09[14]$ \\
\hline
\end{tabular}

Several researchers have investigated basidiomycete ability to minimise the effect of environmental toxins and successfully colonise contaminated soils, specifically soils contaminated with polycyclic aromatic hydrocarbons (PAHs) [45], [46], [47]. These studies focussed on basidiomycete mycelial degradation of PAHs in compost [46] and their use as an on-farm pesticide bioremediation system [45]. Polycyclic aromatic hydrocarbons are common persistent and recalcitrant soil contaminants that are of public health concern due to their cytotoxic, mutagenic and carcinogenic characteristics. McNamara et al. [48] examined fungi as bioremediators in an olive oil mill wastewater determining that fungi proved effective in reducing high chemical oxygen demand and toxicity. Other researchers studied basidiomycete resilience to other environmental toxins 
including 2,4,6,-trinitrotoluene (TNT) [49], pulp and paper mill effluent [50] and metals including nickel, copper and zinc [51].

It should also be noted that some bacterial species may exhibit resilience to toxins. A study undertaken by Kelly et al. [52] demonstrated that fungi may have more cytochrome P450s (CYPs) than bacteria. The cytochrome P450 (CYP) superfamily of genes and proteins are well known for their involvement in pharmacology and toxicology in addition to their importance in diversity of microbes. Although functional genomic investigation of fungal CYPs is preliminary, initial sequencing suggests variations in the of number coding genes between species. For example, E. coli has no CYPs (as is the case with many bacteria) whilst Mycobacterium smegmatis have 40 CYPs representing $1 \%$ of its coding genes and a basidiomycete fungi Phanerochaete chrysosporium contains more than one hundred CYPs. The degradation abilities and resilience of basidiomycetes to several environmental toxins, afforded to them by the CYPs superfamily, suggests their potential as bioremediators but also suggests their use as biosensors requires substantial investigation and validation.

Although some studies have been undertaken investigating the potential of fungi as biosensors, this work has been preliminary and few organic (pentachlorophenol and 3,5-dichlorophenol) and heavy metal (copper and zinc) PTCs have been investigated to date [43]. In order to determine the appropriateness of fungal biosensors for in-the-field analysis of toxins, further 
validation is required. The availability of a naturally luminescent fungus that has the ability to produce the desired globular mycelium in a timely fashion, is key to being able to utilise fungi as biosensors in PTC bioassays.

\subsubsection{The Development of a Specific Bacterial Biosensor: '1080-Iux'.}

Despite their advantages over traditional chemical analysis, the inability of nonspecific biosensors to identify a specific compound or even a class of compound, limits their usefulness. To create specificity and increase sensitivity, a link between a specific cellular response (for example, degradation), a particular PTC and the reporter system is necessary [17]. The design of a specific (catabolic) biosensor, and its construction through genetic modification, involves the fusion of a specific promoter sequence to a reporter gene [53]. The genetically modified biosensor subsequently responds to the specific compound or gene product and luminesces only in the presence of that gene product or toxin, as shown in Figure 1-1(ii)), [53]. Specific biosensor constructs have been achieved by the fusion of lux-based reporter genes to heavy metal resistance promoters including mercury [4], [6], copper [3], cadmium [5], lead [5] as well as naphthalene degradation [54]. Systems are also available for arsenic and antimonite to measure the bioavailability of these environmental toxins and pollutants [55].

Tuariainen et al. [55], examined biosensor sensitivity to arsenic by transforming an arsenic specific biosensor plasmid into three bacterial species ( $E$. coli MC1061, Bacillus subtilis BR151 and Staphlococcus aureus). Variation in both 
sensitivity and induction efficiencies between the transformed species was demonstrated. This study suggested that these differences in sensitivity may be due to differing regulatory functions, the roles of genes specifying the transport or metabolism of the target compound within the different species [55]. Their use of firefly luciferase (as opposed to the more commonly used bacterial luciferase) may also have impacted on variability in biosensor sensitivity possibly due to either the use of a eukaryotic luciferase inserted into a prokaryotic species or simply the differences in luciferases themselves.

Bioavailability is used to describe the concentration of an unchanged substance that is biologically usable [56], potentially influencing biosensor sensitivity. Ivask et al. [57], measured the bioavailability of cadmium and lead in metal smelter polluted soils using specific biosensors and determined that the bioavailability of metals was dependent on soil types [57]. Flynn et al. [3], in their study of bioavailability of arsenic and copper in soils of Northern Chile, used an arsenic specific biosensor (Eshericheria coli CM1166 pC200) constructed by Corbisier et al. [58] and a metabolic whole cell biosensor (E. coli HB101 pUCD607) [3]. Flynn's study determined that matrices with high organic matter can complicate the interpretation of results due to toxins binding to organic matter in both specific and metabolic biosensors [3].

Variations in sensitivity between bacterial biosensor species to PTCs may be influenced by resistance mechanisms. Bontidean et al. [59] investigated bacterial 
metal-resistance proteins and their use in detection of bioavailable heavy metals. Bacteria are simple cells and when resistance occurs it is usually specific to one or a few metals [59]. Mechanisms of resistance include; efflux pumps, modification of the speciation of the metal, sequestering of the metal or a combination of these mechanisms [59].

The selection of host bacteria is significant to the efficiency and usefulness of the biosensor. In order to optimize the use of whole cell biosensors, it is essential that organism ecophysiology, transcriptional switch and reporter gene construct can be related to the biosensor performance [60]. A host bacterium ideally has low pathogenicity, is easy to genetically modify and has the ability to withstand a wide range of conditions. Many Pseudomonads and related genera have the ability to utilise a wide range of natural and synthetic hydrocarbon compounds. As a consequence members of this genus are relatively tolerant to a variety of conditions and would therefore be an appropriate option for host species.

There are numerous PTCs for which it would be desirable to have a specific and rapid detection test, due to the difficulties or expense involved in current traditional testing protocols. In counter terrorism, PTCs that have relevance include those that have a relative ease of acquisition and have the potential to cause large-scale destruction and/or panic. Such PTCs are not solely those wellknown compounds given media exposure. They also include more accessible substances like vertebrate pesticides ('1080'), organophosphate pesticides and 
herbicides that have the ability to contribute to a public health emergency. The most notorious of these, although used by licensed personnel, are more readily available but still highly toxic to humans. Because of this, these chemical agents are considered to be potential chemical warfare agents by both the Centre for Disease Control (CDC) and The World Health Organization (WHO).

Since the 1950s, sodium monofluoroacetate (1080), (Figure 1-4) has been used in New Zealand as a vertebrate pesticide for the control of possums, stoats, ferrets and rats. All of these vertebrate pests have no natural predators in New Zealand compounding their destructive capacity. 1080 is used specifically against arboreal foraging possums, introduced from Eastern Australia [61]. The possums' destructive impact on New Zealand native plants and birds threatens the fragile native ecosystem and New Zealand currently accounts for around $80 \%$ of global consumption of 1080 protecting this ecosystem [62]. Because of its relative ease of acquisition and its toxicity to vertebrates (Table 1-5), there is concern in New Zealand over the environmental fate and non-target exposure of 1080. Dogs are particularly susceptible to 1080 and at risk of secondary poisoning due to scavenging of poisoned carcasses [62].

It is due to these concerns, the use of 1080 as a vertebrate pesticide in New Zealand is under strict legislative control [62]. Despite this, its ease of acquisition, characteristics of being tasteless and odourless, and being a 
colourless to white powder, denotes the potential of 1080 for aberrant "spiking" of food sources or water supplies.

(i)<smiles>O=C([OH+])CF</smiles>

Sodium

(ii)

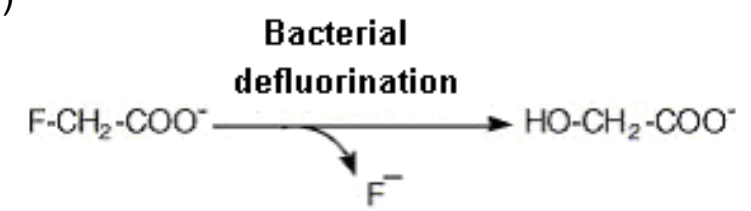

haloacetate $+\mathrm{H}_{2} \mathrm{O}$

glycollate $+\mathrm{H}^{+}$

monofluoroacetate

Figure 1-4: (i) Chemical structure of 1080 (ii) The haloacetate dehalogenase reaction.

The bacterial degradation of 1080 reaction shows the hydrolytic defluorination of fluoroacetate by bacterial enzymes producing glycollate, a hydrogen ion and fluoride ion [63].

A recent Royal Commission reviewed generic issues associated with continued 1080 use in New Zealand. In addition the Royal Commission called for assessment of scientific information on its use including positive and negative effects on flora and fauna [62]. The Royal Commission reported deeply divided communities with regard to the use of 1080 and opinions ranged from active support to passionate opposition over its continued use [62]. The continued use of 1080 as a vertebrate pesticide to protect native flora and fauna is subject to the implementation of more stringent controls [62]. The Royal Commission stipulated the implementation of a watch-list to monitor 1080 operations, 
provision of a channel for the public to register complaints and has encouraged further scientific research [62].

Table 1-5: Oral Toxicity of 1080 for susceptible species.

Dogs are particularly susceptible to secondary poisoning by 1080. The same amount of 1080 required to kill a three kilogram possum (0.0021 grams) would kill an average 35 kilogram labrador dog (0.0024 grams).

\begin{tabular}{|l|c|c|}
\hline Species & $\begin{array}{c}\text { LD }_{50} \\
(\mathbf{m g} / \mathbf{k g} \text { bodyweight })\end{array}$ & Reference \\
\hline Human & $2-5$ & {$[61]$} \\
Dog & 0.06 & {$[61]$} \\
Pat & $0.3-0.35$ & {$[64]$} \\
Norway Rat & $0.4-1.0$ & {$[65],[66]$} \\
Possum & $0.2-3.0$ & {$[65]$} \\
\hline
\end{tabular}

Nonetheless, regardless of ecological concerns, to maintain consistent dosing concentrations has also been a longstanding issue. The application of 1080 is carried out by ground controlled bait stations (in more accessible regions) or by aerial drops of spiked cereal pellets or carrots in less accessible areas. Carrot baits are usually prepared at the site of operation by coating with a soluble concentrate of 1080 . If 1080 dosing concentrations are inadequate and a nonlethal dose is administered there is a subsequent likelihood of possums becoming bait shy, while an unnecessarily high dose is simply uneconomical. 
Biodegradation of 1080 occurs within several common soil bacterial species including Pseudomonas sp., Pseudomonas fluorescens, Delftia acidvorans, Moraxella sp B. [68] and Burkholderia sp. [63]. These organisms are either able to use 1080 as a sole carbon source or are capable of cleaving the normally stable C-F bond in 1080 when there is an alternative carbon source available for growth (Figure 1-4). In 1080 degrading microorganisms, 1080 is defluorinated by fluoroacetate dehalogenase. The gene, designated dehl, encodes an enzyme specific for the mono-halogen substituted acetates with the regulatory region termed dehRI. A second dehalogenase gene is present, dehll, (in some bacterial species) but it lacks homology and it has been shown that dehl preferentially degrades fluorine substrates while dehll prefers other halogens, specifically bromine and chlorine [68].

Dehalogenase enzymes' primary role is dehalogenation [69] and they are a member of the haloacid dehalogenases (HAD) superfamily. Classical haloacid dehalogenases are usually regulated which is not unexpected as they act on naturally occurring compounds [69]. Fluoroacetate, the active compound of 1080 , is one of the most toxic compounds for mammals and occurs in some plants in Australia, Africa and Central America [70].

The degradation of 1080 in soil occurs within approximately two weeks, in optimal conditions [71], and 1080 has only been found to persist in sterilised soil [72]. Lien et al. [73], suggests that there seems little likelihood of a long term 
build up of 1080 residues in soils, as most New Zealand soils would be expected to contain sufficient populations of some or all of these microbial species [73]. Nonetheless, public concern and perception demands immediate remedial measures be undertaken, should contamination occur. The use of specific biosensors as analytical tools will potentially give sensitive, rapid confirmation of the presence or absence of 1080 in soils, foodstuffs or water supplies.

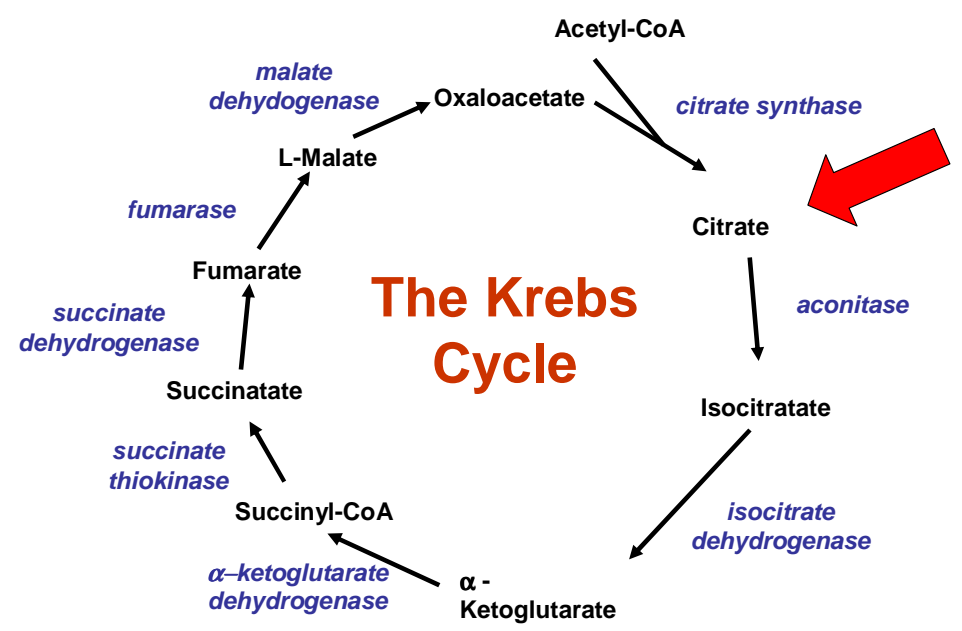

Figure 1-5: The Krebs Cycle (Tricarboxylic Acid Cycle -TCA Cycle).

Metabolic pathways for cellular energy production. The arrow indicates where in the TCA cycle fluorocitrate interferes in the TCA cycle shutting down vital downstream functions.

The pathways of mammalian exposure to 1080 include inhalation, ingestion, dermal and ocular contact as well as absorption. Death occurs as a result of an imbalance in the Krebs Cycle (Tricarboxylic Acid Cycle or TCA cycle), an essential mechanism of energy production in mammalian cells. Although 1080 
does not affect oxygen activity within a cell, it shuts down vital steps within the Krebs Cycle (Figure 1-5).

Fluoroacetate is converted through a series of reactions to fluorocitrate which blocks the Krebs Cycle (Figure 1-5) [61] [61, 74]. It is likely that fluorocitrate acts as a competitive inhibitor to citrate, given that its structure closely resembles that of citrate (Figure 1-6) and fluoro-substitution can result in significant effects on biological activity, particularly effects on energy generation [75].

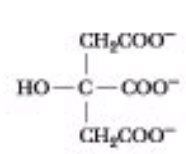

Citrate

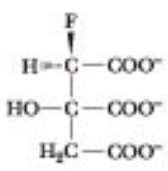

Fluorocitrate

Figure 1-6: The structural similarity between citrate and fluorocitrate.

Similarities in chemical structure suggest that when 1080 is broken down and fluoro-substitution occurs, the resultant fluorocitrate is likely to act as a competitive inhibitor to citrate in the Krebs Cycle. 


\section{Chapter Two: MATERIALS AND METHODS}

\subsection{Microbial Biosensor Bioassays.}

\subsubsection{Bacterial Biosensor Preparation Methods.}

Glycerol stocks of the marine bacterium $V$. harveyi were streaked onto LuriaBertani agar (tryptone $10 \mathrm{~g}$, yeast extract $5 \mathrm{~g}$, sodium chloride $10 \mathrm{~g} / \mathrm{L}$ and $1.5 \%$ agar) (LB agar) with an extra $2 \% \mathrm{NaCl}$ and cultured for 2 to 4 days at $22{ }^{\circ} \mathrm{C}$. For short term storage the agar plates were stored at $4{ }^{\circ} \mathrm{C}$. For long term storage single colonies were selected and inoculated into $50 \mathrm{~mL}$ LB broth with an extra $2 \% \mathrm{NaCl}$ added. The culture was incubated shaking at $180 \mathrm{rpm}$ at $22{ }^{\circ} \mathrm{C}$ overnight. Aliquots of $100 \mathrm{uL}$ of overnight culture was added to $400 \mathrm{uL}$ of $80 \%$ glycerol and stored at $-80^{\circ} \mathrm{C}$.

E. coli HB101 pUCD607 was grown on LB agar with ampicillin (100 mg/L) and kanamycin (50 mg/L) (LB Amp100kan50 agar), incubated at $25{ }^{\circ} \mathrm{C}$ and grown for 2 to 4 days. For culture in broth the plates were subsequently examined in the dark room for luminescence and the single brightest colony inoculated into $50 \mathrm{~mL}$ $\mathrm{LB}_{\text {Amp100Kan50 }}$ broth. The culture was incubated overnight shaking at $180 \mathrm{rpm}$ and $25{ }^{\circ} \mathrm{C}$. For long term storage freezer stocks were prepared as stated above for V. harveyi.

For growth curve experiments of $1 \mathrm{~mL}$ of both E. coli HB101 pUCD607 and $V$. harveyi overnight cultures were inoculated separately into $100 \mathrm{~mL}$ of 
$\mathrm{LB}_{\text {Amp100Kan50 }}$ broth and LB $2 \% \mathrm{NaCl}$ broth respectively, in $250 \mathrm{~mL}$ schott bottles, in triplicate. The cultures were incubated at $25{ }^{\circ} \mathrm{C}$ shaking at $180 \mathrm{rpm} . \mathrm{A} 1 \mathrm{~mL}$ sample from each triplicate flask was taken at 60 minute intervals for measurement of optical density and bioluminescence [14]. Optical density was measured at 600 nanometers (OD $600_{\mathrm{nm}}$ ) on a Helios Alpha UV-Vis spectrophotometer (Thermo Electron Corporation). Initially one serial dilution was carried out (1/10) but it was later necessary to do 1 in 100 or 1 in 1000 dilutions. Bioluminescence was measured as relative light units (RLUs) on LumiSkan TL (Labysystems).

For use in bioassays, E. coli HB101 pUCD607 from freeze-dried cells (provided by Aberdeen University) were utilized in bioassays as they provided for a more standardised analysis than using glycerol stocks or batch culture. In addition, using freeze-dried cultures decreased the bioassay time. Ten $\mathrm{mLs}$ of sterile phosphate buffered $0.1 \mathrm{M} \mathrm{KCl}$ (add $100 \mathrm{~mL}$ of sterile distilled water (SDW) to a $250 \mathrm{~mL}$ volumetric flask, $2.5 \mathrm{~mL}$ acetate buffer, $\mathrm{pH} 5.89,1.864$ grams $\mathrm{KCl}$, make up to $250 \mathrm{~mL}$ with SDW) was added to the freeze-dried ampoules of $E$. coli HB101 pUCD607 cells which were incubated shaking at $180 \mathrm{rpm}$ at $25^{\circ} \mathrm{C}$ for one hour [16].

As freeze-dried cells were not available, a single $V$. harveyi colony was inoculated from short term storage plates into $10 \mathrm{~mL} \mathrm{LB}$ broth $2 \% \mathrm{NaCl}$ and incubated at $25^{\circ} \mathrm{C}$ for approximately 20 hours or to an OD of $0.8_{600 \mathrm{~nm}}$. Cells were 
refrigerated at $4{ }^{\circ} \mathrm{C}$ until required. One $\mathrm{mL}$ of the cells were sub-inoculated into $10 \mathrm{~mL}$ LB broth $2 \% \mathrm{NaCl}$ and grown for 4 hours, harvested and washed.

Prior to the bioassay it was necessary to remove growth media substrates by washing, as these can complex some compounds and alter speciation and bioavailability of toxins giving ambiguous results. However, multiple washing reduces the viability of the bacterial cells affecting bioluminescence [14]. The cells were washed twice by centrifugation at $3000 \mathrm{rpm}$ for 3 minutes, the supernatant removed and cells re-suspended in $5 \mathrm{~mL}$ of $0.1 \mathrm{M} \mathrm{KCl}$. The cells were once again centrifuged at $3000 \mathrm{rpm}$ for 3 minutes and re-suspended in 5 $\mathrm{mL}$ of $0.1 \mathrm{M} \mathrm{KCl}$. Finally the supernatant was once again removed, resuspended in $5 \mathrm{~mL}$ of $0.1 \mathrm{M} \mathrm{KCl}$ making the washed cells ready for use in the bioassay. Immediately before use, $100 \mathrm{uL}$ of washed cells was placed in a luminometer cuvette and luminescence measured to ensure sufficient bioluminescence for the bioassay.

To assure standardisation and reproducibility of the response of the biosensor organisms, each were exposed to test solutions containing serial dilutions of $\mathrm{TCP}^{\mathrm{TM}}$ liquid antiseptic (Pfizer Ltd, UK), an aqueous glycerol solution of halogenated phenols $(0.68 \% \mathrm{w} / \mathrm{v})$ and phenol $(0.175 \% \mathrm{w} / \mathrm{v})$, which gives known results [14]. Into each luminometer cuvette, $100 \mathrm{uL}$ cell suspension of the resuscitated or prepared cells was added to $900 \mathrm{uL}$ of each TCP concentration ( 0 $\%, 0.1 \%, 0.2 \%, 0.4 \%, 0.6 \%, 0.8 \%, 1 \%$ and $10 \%)$ at $10 \mathrm{~s}$ intervals. The 
mixture was pipetted up and down 5 times to mix. After 15 minutes exposure to the TCP, light output is measured at $10 \mathrm{~s}$ intervals in a LumiSkan TL (Labysystems). Each concentration was carried out in triplicate and data was expressed as a percentage of the luminescence measured in control samples.

\subsubsection{Fungal Biosensor Preparation Methods.}

The ten Armillaria species, Mycena citricolor ATCC 34884 and Mycena sp. ICMP 16534 isolates (Table 2-1) were sub-cultured for short term storage, long term storage and for growth and luminescence measurement. For short term storage the fungi were separately sub-cultured onto Difco Malt Extract agar (ME agar), Difco Potato Dextrose agar (PD agar) and Yeast Malt Agar (YM agar) (peptic digest of animal tissue $5 \mathrm{~g}$, yeast extract $3 \mathrm{~g}$, malt extract $3 \mathrm{~g}$, dextrose $10 \mathrm{~g}$, agar $15 \mathrm{~g}$, make up to $1 \mathrm{~L}$ with SDW and autoclave at $121^{\circ} \mathrm{C}$ for 15 minutes at $15 \mathrm{psi}$ ), incubated at $22{ }^{\circ} \mathrm{C}$ in 12 hour light/12 hour dark cycles. Once sufficient growth was established, agar plates were refrigerated at $4{ }^{\circ} \mathrm{C}$. For long term storage, fresh $5 \mathrm{~mm}$ agar plugs were placed in $500 \mathrm{uL} 10 \%$ glycerol and stored at ${ }^{-} 80^{\circ} \mathrm{C}$. Additional agar plugs were placed into $5 \mathrm{~mL}$ SDW and stored at $4{ }^{\circ} \mathrm{C}$ [43].

For measurement of growth on agar, the stored cultures were sub-cultured onto PD agar, YM agar and ME agar. The cultures were incubated at $22{ }^{\circ} \mathrm{C}$ in 12 hour light/12 hour dark conditions. Mycelial growth was measured every 2 to 3 days using a caliper gauge along two diameters at right angles to one another and the 
average diameter for each plate calculated [43]. The mean mycelial growth was calculated from 5 replicates of each treatment (Figure 2-1 (A) and (C)).

Table 2-1: Basidiomycete fungi isolates chosen for investigation of bioluminescence and globular mycelial growth patterns.

\begin{tabular}{|l|l|l|}
\hline Isolate name & Isolate Identification & Source \\
\hline Armillaria novae-zelandiae & LU872, LU874, LU878 & Lincoln University \\
LU881, LU887, LU904 & \\
LU906, LU911, LU916 & \\
LU917 & \\
Mycena citricolor & ATCC 34884 & $\begin{array}{l}\text { Dr Hedda Weitz via } \\
\text { Landcare Research } \\
\text { Mycena sp. }\end{array}$ \\
& ICMP 16534 & Landcare Research \\
\hline
\end{tabular}

To measure bioluminescence during growth on agar, the fungi isolates were subcultured onto fresh PD agar, YM agar and ME agar. Bioluminescence was measured and plate positions were randomised every 2 to 3 days until all treatments reached the edge of the plate. To measure bioluminescence agar plugs of $5 \mathrm{~mm}$ diameter were removed from the plates, the top $1 \mathrm{~mm}$ was removed from the plugs and placed into a luminometer cuvette with $700 \mathrm{uL}$ of $1 / 4$ strength Ringers solution (consisting of $\mathrm{NaCl} 2.25$ g., $\mathrm{KCl} 0.075$ g., $\mathrm{CaCl}_{2} .2 \mathrm{H}_{2} \mathrm{O}$ 0.0625 g., $\mathrm{NaHCO}_{3} 0.05$ g., SDW 1 L., autoclave for 15 minutes at $\left.121^{\circ} \mathrm{C}\right)$. The cuvettes were vortexed ( 1 s) 3 times and luminescence was measured using a luminometer (LumiSkan TL, Labysystems). Background readings were obtained using the same method with un-inoculated agar plates. The mean bioluminescence was calculated from 5 replicates of each treatment. 


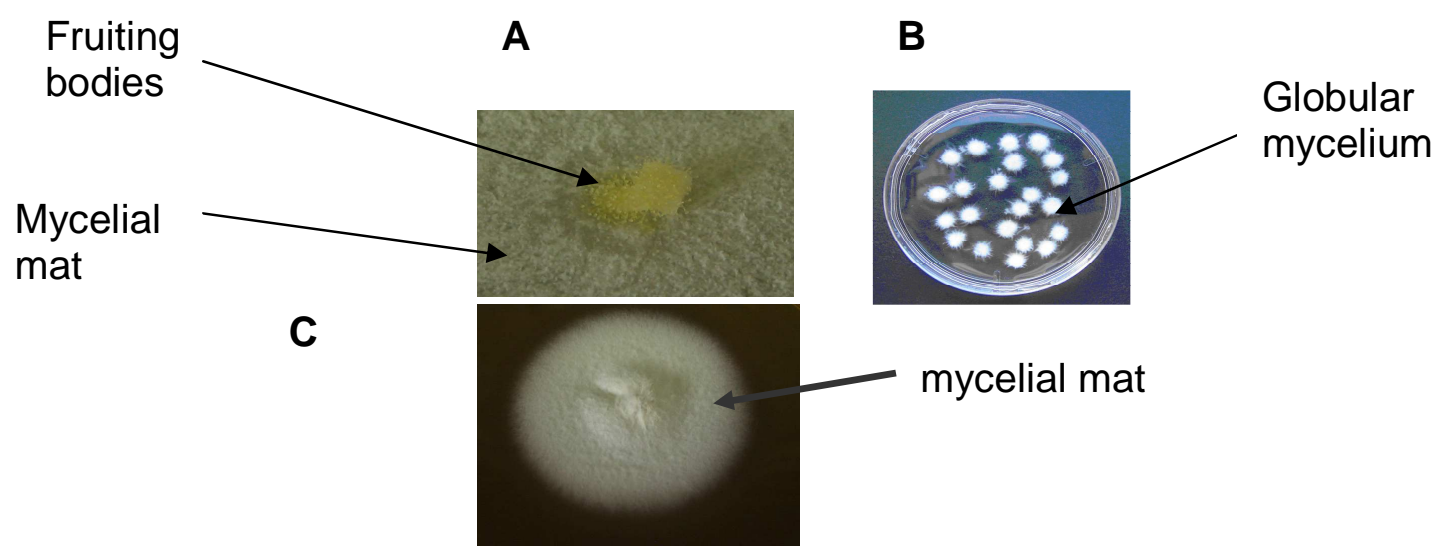

Figure 2-1: Mycena citricolor ATCC 34884 and Mycena sp. ICMP 16534.

Sourced from Aberdeen University. (A) Growth after 7 to 10 days on PD agar, showing fruiting bodies and mycelial mat. (B) The globular mycelium after 7 days in PD broth ready for use in the fungal bioassay. (C) This photograph demonstrates the growth of a mycelial mat on malt extract agar (sourced from Landcare Research).

In order to measure the formation of globular mycelium and bioluminescence in broth, $205 \mathrm{~mm}$ agar plugs were removed, the top $1 \mathrm{~mm}$ removed, quartered and inoculated into PD broth. This protocol was repeated twice more inoculating the quartered plugs into $\mathrm{YM}$ broth and ME broth. All cultures were performed in triplicate and incubated at $22{ }^{\circ} \mathrm{C}$ shaking at $150 \mathrm{rpm}$ (Figure 2-2). Bioluminescence of the quartered plugs in broth were measured daily for up to 30 days. Three globular mycelia were removed from each triplicate and placed into separate luminometer cuvettes containing $700 \mathrm{uL} 1 / 4$ strength Ringers solution. The cuvettes were vortexed (1 s) 3 times and measured using a luminometer (LumiSkan TL, Labysystems). Vortexing was necessary and is 
consistent with fungal luminescence requirement for oxygen [76], [77] similar to bacterial bioluminescence [24].

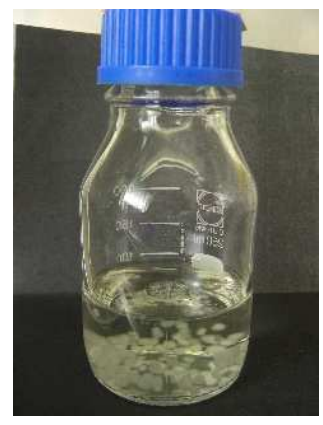

Figure 2-2: Globular mycelium of M. citricolor ATCC 34884 cultured in PD broth.

Globular mycelium growth following growth in broth for 7 days. The mycelia were checked for bioluminescence and used in bioassay.

Due to slow growth of Mycena sp ICMP 16534, only the M. citricolor ATCC 34884 species was used in bioassays in this study. The naturally bioluminescent M. citricolor ATCC 34884 has previously been investigated for growth and luminescence patterns as well as characterised for usefulness as a biosensor [43]. To assure the reproducibility and standardise the biosensor response to PTCs, M. citricolor ATCC 34884 was exposed to test solutions containing serial dilutions of copper metal in the form of copper sulphate $\left(\mathrm{CuSO}_{4}\right)$. Weitz et al. [43], has previously investigated the effect of $\mathrm{CuSO}_{4}$ on $M$. citricolor ATCC 34884, thus by the comparison of results it is possible to standardise the biosensor response. 
When required for use in bioassays, $205 \mathrm{~mm}$ agar plugs were removed from stored petri dishes. The top $1 \mathrm{~mm}$ taken off, quartered and inoculated into PD broth, YM broth and ME broth. The cultures were incubated in 24 hour darkness at $22{ }^{\circ} \mathrm{C}$ shaking at 150 rpm for 7 days (Figure 2-2). After 7 days, the globular mycelium were harvested using a $1.18 \mathrm{~mm}$ sieve, rinsed in deionised water, luminescence levels of individual globular mycelium were checked to maximise standardisation of the bioassay and the globular mycelia kept in $1 / 4$ strength Ringers until ready for use in the bioassay. Aliquots of $700 \mathrm{uL}$ of the prepared PTCs (Table 2-2) were placed into luminometer cuvettes and a single globular mycelia was added to each cuvette at $10 \mathrm{~s}$ intervals. De-ionised water was used as a non-toxic control in all samples. After 15 minutes of exposure to the PTC each cuvette was vortexed (1 s) 3 times and bioluminescence measured at $10 \mathrm{~s}$ intervals.

\subsubsection{Bioassays.}

Previous studies have found that $\mathrm{pH}$ is a consideration for the microbial biosensors, particularly those that are not genetically modified [14]. The $\mathrm{pH}$ of the diluents, and the PTC stock solutions used to make up the PTC dilutions, were checked (Thermo Orion perpHecT LogR meter, Model 310) and where necessary altered (using $\mathrm{HCl}$ or $\mathrm{NaOH}$ ) to fall within the optimal range for each biosensor (Table 2-3). 
Table 2-2: PTCs used in this non-specific biosensor investigation including uses, application rates and $L D_{50} S$ where applicable.

\begin{tabular}{|c|c|c|c|}
\hline Toxin & Use of Toxin & Application Rate & $\mathrm{LD}_{50}(\mathrm{mg} / \mathrm{kg})$ \\
\hline Acephate & $\begin{array}{l}\text { Organophosphate } \\
\text { insecticide }\end{array}$ & 1000 ppm & 866 [29] \\
\hline \multirow[t]{2}{*}{ Arsenate } & Insecticides & & \multirow{2}{*}{$\begin{array}{l}87[29] \\
\text { (mouse) }\end{array}$} \\
\hline & $\begin{array}{l}\text { Herbicides } \\
\text { Insecticides }\end{array}$ & & \\
\hline \multirow[t]{2}{*}{ Arsenite } & Insecticides & & \multirow{2}{*}{$\begin{array}{c}41[29] \\
\text { (rat) }\end{array}$} \\
\hline & $\begin{array}{l}\text { Herbicides } \\
\text { Insecticides }\end{array}$ & & \\
\hline Carbaryl & Insecticide & $2.4 \mathrm{ppm}$ & $400[29]$ \\
\hline Copper & $\begin{array}{l}\text { Piping, electronics } \\
\text { Environmental toxin }\end{array}$ & & 472 [29] \\
\hline Cyanide & $\begin{array}{l}\text { Possum baits, mining } \\
\text { (gold) }\end{array}$ & & 6.4 [29] \\
\hline Difenacoum & $\begin{array}{l}\text { Rodenticide, anti- } \\
\text { coagulant }\end{array}$ & & \\
\hline PCP & $\begin{array}{c}\text { Insecticide, } \\
\text { herbicide, biocide, } \\
\text { fungicide (wood } \\
\text { treatment) }\end{array}$ & & $74-130$ [29] \\
\hline 1080 & Vertebrate pesticide & $\begin{array}{l}2-5 \mathrm{ppm}^{2} \\
\text { per m}{ }^{2}\end{array}$ & $2-10[78]$ \\
\hline Zinc & $\begin{array}{c}\text { Metallurgical } \\
\text { processes } \\
\text { Environmental toxin }\end{array}$ & & 221 [29] \\
\hline
\end{tabular}

Stock solutions of the PTCs were made up to a concentration of $1111 \mathrm{mg} / \mathrm{L}$ so that when $100 \mathrm{uL}$ of prepared bacterial biosensor cells are added to $900 \mathrm{uL}$ of the diluted PTC working solution the final PTC concentration will be the required concentration [14]. All PTC bioassays included a water control for E. coli HB101 pUCD607 and $0.1 \mathrm{M} \mathrm{NaCl}$ control for $V$. harveyi. 
Table 2-3: Optimal $\mathbf{p H}$ range for bioluminescence of microbial biosensors used in PTC bioassays.

\begin{tabular}{|c|c|c|}
\hline Microbial Biosensor & Optimal pH Range & Reference \\
\hline E. coli HB101 pUCD607 & $4-7$ & {$[14]$} \\
V. harveyi & $7-7.5$ & {$[79]$} \\
M. citricolor ATCC 34884 & $5-6$ & {$[43]$} \\
\hline
\end{tabular}

Aliquots of $900 \mathrm{uL}$ of each PTC dilution and the control were added to luminometer cuvettes, in triplicate. For each diluted 900 uL PTC sample, $100 \mathrm{uL}$ of the washed cell suspension (Section 2.1.1) was added at $10 \mathrm{~s}$ intervals pipetting up and down 5 times to mix. After 15 minutes of exposure to the PTC, light output of the biosensors was measured at $10 \mathrm{~s}$ intervals in a LumiSkan TL (Labysystems). Data was expressed as a percentage of the luminescence measured in control samples.

\subsubsection{White Powder Bioassays.}

Previous work with bacterial bioassays has mostly been focused on environmental samples such as soils and sediments [17], [14] and water [80], where protocols have been developed to expose the biosensor to the PTC. In white powder incidents commonly used carrier powders include flour, salt, sugar, icing sugar and talc [34]. Only flour and talc were used here, as preliminary investigations found that salt was toxic to the biosensor and both sugar and icing sugar gave false negative results. 
Two grams each of flour (Pams High Grade) and analytical talc (BDH Laboratory Supplies) were spiked with $2 \mathrm{~mL}$ of serial diluted PTCs. The powders were left to dry overnight. Once dry the spiked powders were ground using a Phillips Coffee Grinder (Type HR2175). The ground powders were stored at room temperature for 14 days to allow the PTCs to bind to the powders and equilibrate, before being used in bioassays. Ten $\mathrm{mLs}$ of either SDW or $0.1 \mathrm{M} \mathrm{NaCl}$ (for $E$. coli HB101 pUCD607 and $V$. harveyi respectively) was added to the ground spiked powders. The slurry was shaken for 15 minutes at $3000 \mathrm{rpm}$ on a benchtop shaker (Lab-Line Instruments Inc., Model No. 3521). The slurry was filtered through Whatmans Glass Fibre Paper and the $\mathrm{pH}$ of the filtrate checked (Thermo Orion perpHecT LogR meter, Model 310), to ensure it was within the optimal range of the biosensor (Table 2-3). If necessary the $\mathrm{pH}$ was altered using $\mathrm{HCl}$ or $\mathrm{NaOH}$. The bacterial biosensors were prepared and bioassays performed as outlined in Section 2.1.1.

Previous studies have shown that for some PTCs, biosensor sensitivity can be increased by extracting the PTC from the carrier with methanol [16]. Two $\mathrm{mL}$ of individual organic PTCs (carbaryl, acephate) were aliquoted into a thick walled universal and placed into heat block at $40{ }^{\circ} \mathrm{C}$. Nitrogen gas was gently blown in a steady stream onto the universal $1 \mathrm{~cm}$ from the surface. Once all the methanol had evaporated $2 \mathrm{~mL}$ SDW was added to the residue and used for bioassays. 


\subsubsection{Vomit Bioassays.}

Redshaw et al. [16] spiked stomach contents with PTCs and highlighted the importance of using optimal $\mathrm{pH}$ when using biosensors. Their study cited the possibility of the presence of hydrolytic enzymes in stomach contents (e.g. pepsin) inactivating the biosensor. Increasing the $\mathrm{pH}$ of the stomach contents to $\mathrm{pH} 7$ alleviates the toxic effect and inactivates any peptic enzymes present. This also applies to the vomit matrix which would also be expected to contain hydrolytic enzymes.

Dog vomit was kindly provided by Judgeford Kennels, Judgeford, Wellington. The vomit was centrifuged for 30 minutes at $3000 \mathrm{rpm}$ to remove solids. The supernatant was diluted by half and the $\mathrm{pH}$ checked (Thermo Orion perpHecT LogR meter, Model 310), to ensure it was within the optimal range of the biosensor (Table 2-3) and altered if necessary (using $\mathrm{HCl}$ or $\mathrm{NaOH}$ ). The vomit was spiked with PTC dilutions to ascertain $\mathrm{EC}_{50}$ values. The PTCs used for the vomit bioassays included arsenate, arsenite and carbaryl. The bacterial biosensors were prepared and bioassay performed as outlined in Section 2.1.1. Due to the limited availability of dog vomit only preliminary investigations were able to be performed. 


\subsection{Solid-Phase Extraction Bioluminescence Bioassay.}

\subsubsection{Method of Solid-Phase Sample Preparation.}

Two separate soils (Waitarere and Templeton) were chosen for PTC spiking to investigate potential differences that occur within different soil types. Waitarere is classified as a sandy loam while Templeton is a sandy silt loam based on Hewitts Soil Classification Method [81].

Soils were collected and passed through a $1 \mathrm{~mm}$ sieve. The percentage moisture content and the water holding capacity (WHC) for each soil was calculated. Most WHCs are reported on an oven-dry basis but as oven-drying causes changes in several chemical properties of soils, analyses are carried out on air-dried samples (where soil is dried at temperatures of no more than $30^{\circ} \mathrm{C}$ ). In order to convert air-dry results to an oven-dry basis, a moisture factor is applied in the calculation of results. To determine the moisture factor a $10 \mathrm{~g}$ sample of soil was placed into a weighed dish with a lid. The weighed soil was dried in an oven at $105{ }^{\circ} \mathrm{C}$ for $8-24$ hours. The dried soil was then removed from the oven, the lid fitted and the set up was cooled and reweighed without delay. This ensures the soil picks up minimal moisture from the atmosphere (all weighing should be made to the nearest $10 \mathrm{mg}$ ). The moisture factor was then calculated as follows:

$$
\frac{\text { Weight of air dry soil }(\mathrm{g})}{\text { Weight oven-dry soil }(\mathrm{g})}=\text { Moisture Factor }
$$


The calculated moisture factor was used to determine the amount of PTC solutions required to bring the soils to $80 \%$ water holding capacity (WHC). Fifty grams of each soil, in triplicate, was spiked with PTC solution to obtain a final PTC concentration of $1000 \mathrm{mg}$ per kilogram of soil. The high spike concentration was used to compensate for any potential binding of the PTC to the complex matrices. All bioassays were also carried out in triplicate. The PTCs were mixed into each soil or white powder treatment and left to equilibrate for 30 days before being prepared for use in solid-phase bioluminescence bioassays.

For the centrifugation sample preparation method, a Jumbosep ${ }^{\mathrm{TM}}$ centrifugal device (Pall Filtron Corporation, U.S.A) was used for collecting the spiked soil solution (Figure 2-3). Whatman No. 42 filter paper of $42.5 \mathrm{~mm}$ diameter was placed over the bottom of the Jumbosep ${ }^{\mathrm{TM}}$ sample reservoir to prevent the transfer of tiny particles to the extracted solution. Fifty grams of the spiked soil was packed into the reservoir and then centrifuged for one hour at $800 \mathrm{~g}$. After centrifugation the soil solutions were collected and used directly in the bioassay. 


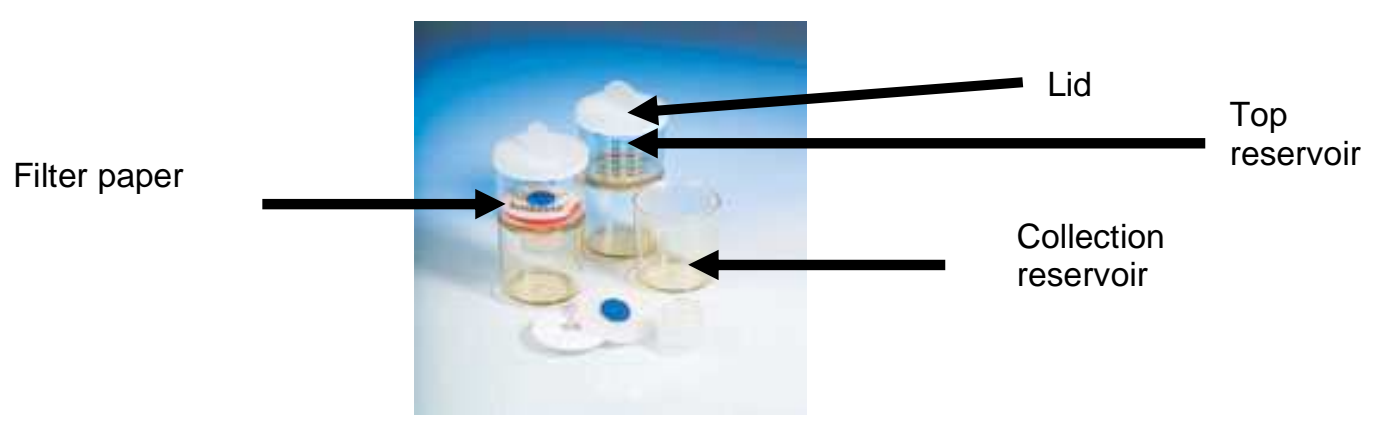

Figure 2-3: Jumbosep ${ }^{T M}$ centrifugal device.

Used for collecting spiked soil filtrates for use in bioassays.(Pall Corporation).

For the filtration method, the centrifuged soil or white powder solutions that had been collected, were passed through Whatmans Glass Fibre Paper. 900 uL of the filtrate was aliquoted into each luminometer cuvette and used in the bioassays.

The third sample preparation method was the solid-phase bioluminescence bioassay. The soil/white powder slurries were centrifuged at $3000 \mathrm{rpm}$ for 30 minutes and the resultant supernatant used in the bioassay. For each triplicate, $450 \mathrm{uL}$ of the supernatant or filtrate was aliquoted into the Agilent Spin Filter column (Agilent Technologies), (Figure 2-4). The E. coli pUCD607 biosensor cells were prepared (Section 2.1.1) and $450 \mathrm{uL}$ of the prepared cells was added to the filtrate in the spin filters at $10 \mathrm{~s}$ intervals. The spin filters were centrifuged at $3000 \mathrm{rpm}$ for 30 minutes. 


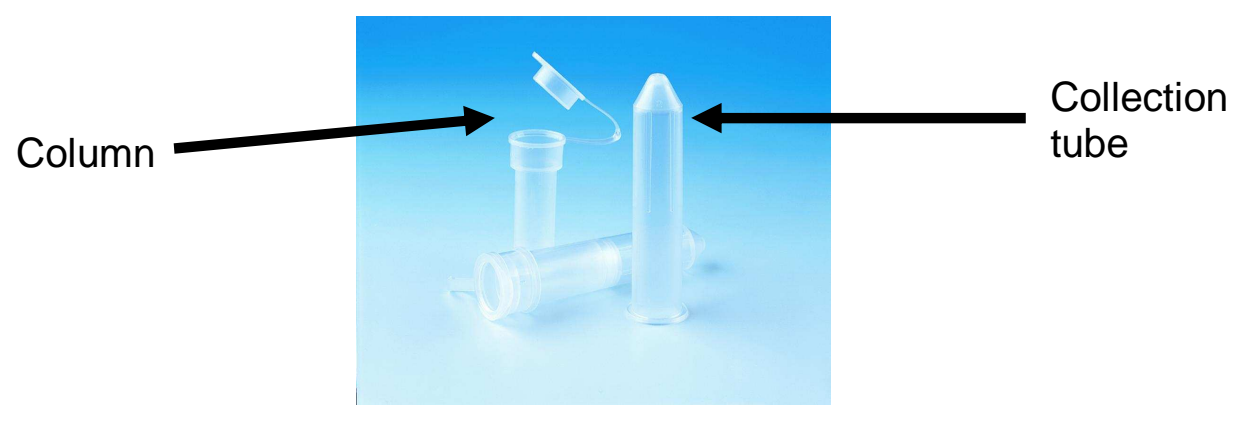

Figure 2-4: Agilent spin-filters.

(catalogue number 5185-5990) used for the novel solid-phase PTC extraction sample preparation method.

A thin soil layer is formed on top of the filter and the contact between the cells and soil particles is established through centrifugation (Figure 2-5). The spin filter columns are removed and placed into luminometer cuvettes and bioluminescence measured in a luminometer (LumiSkan TL, Labysystems) at $15 \mathrm{~s}$ intervals. The total contact time between the biosensor cell addition and measurement of light output from each soil is 30 minutes. 


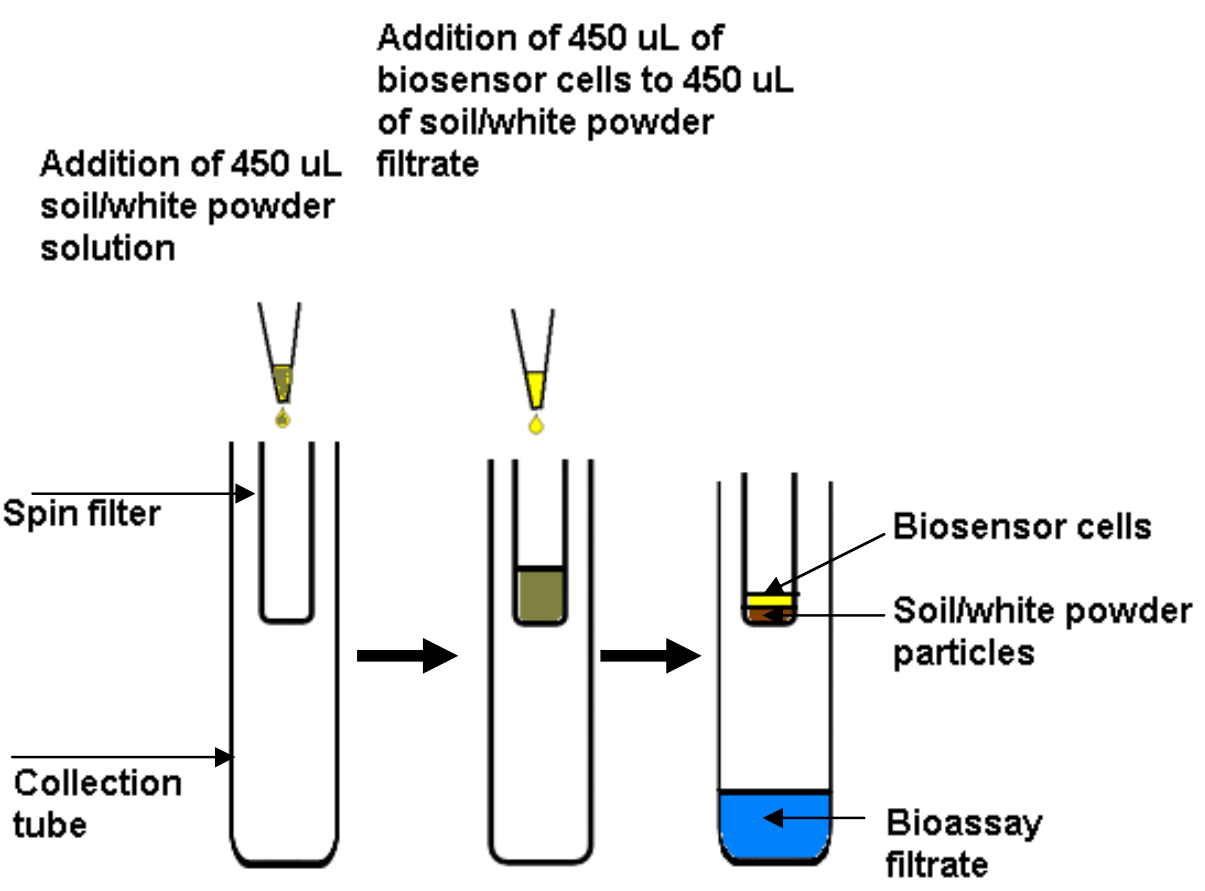

Figure 2-5: Overview of solid-phase bioluminescence bioassay using spin filters.

The spiked soil solution is added to the spin filter, following the addition of biosensor cells, the spin filter is centrifuged. The biosensor cells sit on top of and through the spiked soil solution. The spin filter is removed and luminescence measured.

The solid-phase bioassay filtrates are collected and background luminescence is measured to determine if the cells or toxin have passed through the filter. The liquid-phase bioassay is performed by adding $10 \mathrm{uL}$ of resuscitated cells to $90 \mathrm{uL}$ of each filtrate sample. Bioluminescence was measured after 15 minutes at $10 \mathrm{~s}$ intervals. The control of deionised water was measured as a reference. Toxicity results are expressed as a percentage of the maximum bioluminescence for the different PTC concentrations using the control soil (unspiked) as $100 \%$. 


\subsubsection{Statistical Analysis and Data Interpretation.}

Statistical analysis of the bacterial biosensor bioassay required the data be subjected to sigmoidal dose-response analysis using the equation developed by CSIRO, Australia [82], [83], based on the model developed by Haanstra et al. [84]. The equation is:

$$
Y=\frac{C}{1+\mathrm{e}^{\left(-H\left(\log X-\log \mathrm{EC}_{50}\right)\right)}}
$$

Where $\mathrm{Y}$ is the bioluminescence; $C$ is the calculated maximum value of $Y ; X$ is the log of the toxin concentration; $\mathrm{EC}_{50}$ is the toxin concentration at which the bioluminescence is inhibited by $50 \%$; and $H$ is the Hill slope. The CSIRO calculator is also able to determine any EC value and the equation is a logarithmic approximation of Michaelis-Menten Model I as described by Speir et al. [85].

The data points obtained from some bioassays, specifically the fungal bioassays, did not adhere to the data points of the traditional sigmoidal dose-response curve used by CSIRO to interpret $\mathrm{EC}_{50}$ values. This is likely to be due to the nature and inherent variability of the fungal bioassay. Where the data points did not fit those of the CSIRO model, luminescence (RLUs) was expressed as a percentage of 
the control and the $\mathrm{EC}_{50}$ values were determined by reading from graphs. The control that was included in each sample set was taken as being a maximum value and therefore calculated as $100 \%$ luminescence. This was considered sufficient given the inherent variability of the bioassay and its potential utilisation as a preliminary screening tool. In all bioassays, error bars were calculated using standard error data calculated in Microsoft Excel using the following formula:

$S E=\frac{\text { sample standard deviation }}{\sqrt{ } \text { number of replicates }}$

\subsection{Construction of Specific Bacterial Biosensors.}

\subsubsection{Methods of Construction of the Specific Bacterial Biosensor.}

The pUT mini-Tn5 luxCDABE plasmid was obtained from Aberdeen University

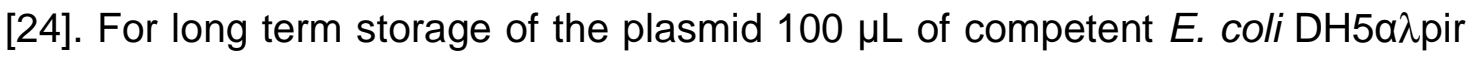
cells were thawed on ice for 5 minutes. An aliquot of $1 \mathrm{uL}$ of plasmid was added to the thawed competent cells and the reaction incubated on ice for 30 minutes. The cells were heat-shocked at $42{ }^{\circ} \mathrm{C}$ for 3 minutes, placed on ice for $90 \mathrm{~s}$, after which $900 \mu \mathrm{L}$ LB was added and the transformation mixture was incubated at $37^{\circ} \mathrm{C}$ for 1 hour shaking at $150 \mathrm{rpm}$. Following incubation the cells were plated onto the $\mathrm{LB}_{\mathrm{Amp} 100 \mathrm{Kan} 50}$ agar and incubated at $37^{\circ} \mathrm{C}$ overnight. Single colonies were selected and incubated into $5 \mathrm{~mL} \mathrm{LB}_{\mathrm{Amp100Kan50}}$ broth grown overnight to an 
$\mathrm{OD}_{600 \mathrm{~nm}}$ of 0.8 and $100 \mathrm{uL}$ of the culture added to $400 \mathrm{uL}$ of $80 \%$ glycerol for long term storage at ${ }^{-} 80^{\circ} \mathrm{C}$.

Because the full sequence of pUT mini-Tn5 luxCDABE was not available, preliminary restriction digests of the pUT mini-Tn5 luxCDABE plasmid were performed in order to verify the presence of some restriction enzyme sites. The restriction enzymes selected for this were Xbal, Smal, Sfil, BamHI, HindIII and a double digest of BamHI and Sfil. All restriction digests were performed according to the manufacturer's instructions (New England Biolabs) and run on a $1 \%$ agarose gel. Table 2-4 shows the bacterial strains and plasmids used in the 1080-Iux and JlacO-Iux bacterial biosensor construction.

Table 2-4: Bacterial strains and plasmids used in the construction of specific '1080-lux' bacterial biosensor and the 'JlacO-positive control' bacterial biosensor.

\begin{tabular}{|l|l|l|}
\hline Plasmids & Contains & Reference or source \\
\hline $\begin{array}{l}\text { pUT mini-Tn5 luxCDABE } \\
\text { (14.2kb) }\end{array}$ & IuxCDABE, Amp & $\begin{array}{l}\text { Aberdeen University, } \\
\text { U.K [24] }\end{array}$ \\
pAWT6 & dehl and dehll, Kan $^{r}$ & $\begin{array}{l}\text { Cardiff University, } \\
\text { U.K [86] }\end{array}$ \\
pCR2.1-TOPO vector & $\begin{array}{l}\text { Lactose promoter } \\
\text { (named JlacO) }\end{array}$ & Invitrogen \\
\hline
\end{tabular}


As a result of the preliminary restriction digests, it was determined that $\mathrm{Xbal}$ and Smal restriction enzyme sites would be used for the insertion of the promoter as it would enable insertion upstream of the lux cassette.

Initially Xbal digests of column purified pUT mini-Tn5 luxCDABE was performed in accordance with the manufacturers protocol (New England Biolabs) with minor amendments. Both 1 hour and 2 hour incubations were performed using $10 \mathrm{U}$ restriction enzyme to $1 \mathrm{ug}$ purified DNA. As there was little variation in digestion efficiency between the protocols, 1 hour incubations were subsequently carried out.
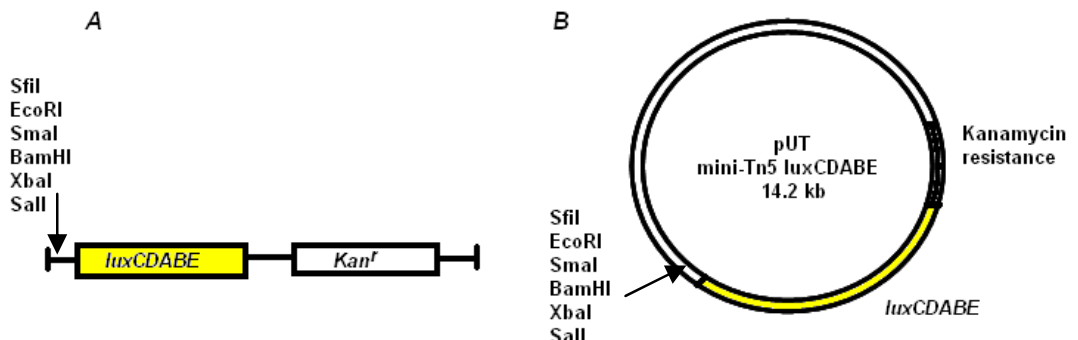

Figure 2-6: (A) IUxCDABE transposon (B) pUT mini-Tn5 IuxCDABE.

The mini-Tn5 luxCDABE transposon was cloned into pUT mini-Tn5 creating the pUT mini-Tn5 luxCDABE construct.

In all cases because further manipulations of the digested DNA were required. The digestion reactions were stopped by heat inactivation $\left(65^{\circ} \mathrm{C}\right.$ for 20 minutes, New England Biolabs) where appropriate. Figure 2-7 shows a flow chart illustrating the steps involved in constructing the specific bacterial biosensor. 


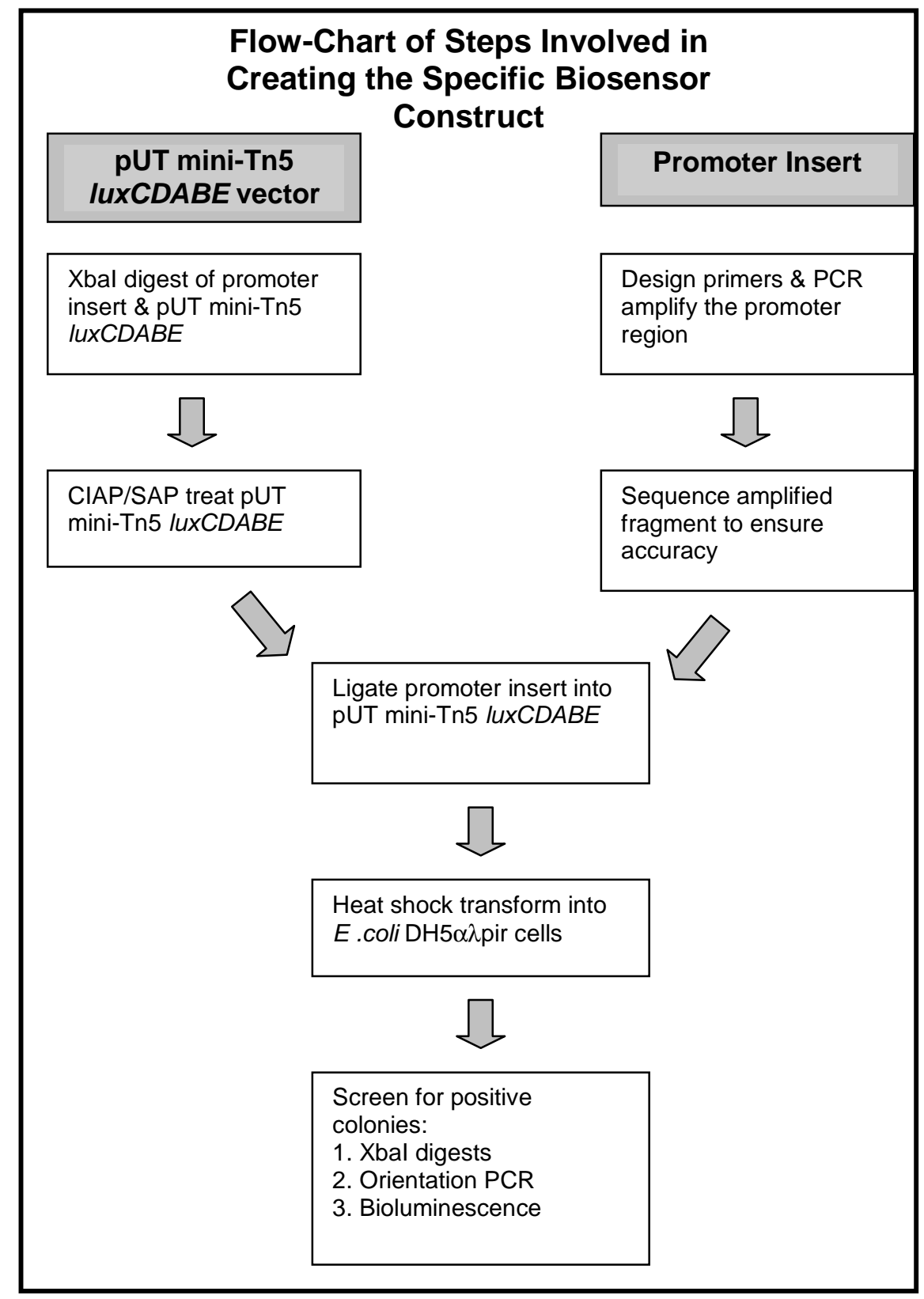

Figure 2-7: Flow chart illustrating steps involved involved in constructing the specific bacterial biosensor plasmid construct.

The digested vector was gel purified according to manufacturer's instructions, using QIAquick Gel Extraction Kit (Qiagen) to remove any residual restriction 
enzyme thereby preventing competitive inhibition of phosphatase activity in subsequent steps.

The Xbal digested mini-Tn5 luxCDABE plasmid was treated with either calf intestinal phosphatase (CIAP, New England Biolab) or shrimp alkaline phosphatase (SAP, Fermentas) according to the manufacturer's instructions and incubated at $37^{\circ} \mathrm{C}$ for 60 minutes. Dephosphorylation by CIAP or SAP, removes the 5' phosphate groups from a DNA strand. As ligases require the 5' terminal phosphoryl group, the dephosphorylation prevents self-ligation therefore decreasing the vector background in cloning. This is particularly important when only one restriction enzyme is being used. Due to difficulties with CIAP, SAP was also trialled, however there appeared to be no difference in outcome between CIAP and SAP treated vector. The dephosphorylated DNA was gel purified (QIAquick Gel Extraction Kit (Qiagen), adhering to the manufacturer's instructions) to remove residual active phosphatase that can contribute to failure in subsequent ligation and transformation experiments.

Alternatively, in an attempt to enable cloning of the promoter fragments into the pUT mini-Tn5 luxCDABE plasmid in the correct orientation, sequential Xbal-Smal (New England Biolabs) digests of the vector were undertaken according to manufacturer's instructions. 


\subsubsection{Construction of 1080-Iux and JlacO-Iux Constructs.}

The pAWT6 plasmid (Table 2-4) containing dehl gene and the dehRI promoter region was kindly provided by Professor Andrew Weightman from Cardiff University [86]. For long term storage $1 \mathrm{uL}$ of the plasmid was heat shock transformed into calcium competent $E$. coli $\mathrm{DH} 5 \alpha$ cells using standard protocols [87]. For the positive control the strong, well characterised lactose promoter of pCR2.1 TOPO cloning vector (Invitrogen) was selected. This strategy was undertaken to determine the ability of the pUT mini-Tn5 luxCDABE vector to accept the promoter insert, activate luxCDABE and induce bioluminescence on the addition of the lactose analogue IPTG.

PCR amplification of the 1080 dehalogenase promoter and the lactose promoter (positive control) was undertaken. In order to achieve cloning of the promoter inserts in the desired orientation, primers were designed incorporating two restriction enzyme sites. All primers used are listed in Table 2-5. Both Xbal and Smal restriction enzyme sites were incorporated at the $5^{\prime}$ end of the amplified fragment and Xbal only at the 3 ' end of the fragment. Both restriction enzyme sites were included at the 5 ' end of the amplified fragment in the event that directional cloning using Smal was unsuccessful. This would enable the same primers to be used for amplification of the fragment and one restriction enzyme, Xbal, to digest the fragment ends. 


\section{Table 2-5: Primers used in PCR amplification.}

Primers used for PCR amplification of promoter sequences used in this study. Also listed are primers used to determine the orientation of the promoter fragments in the plasmid constructs. Red sequence indicates Xbal cut site while blue indicates the Smal cut site.

\begin{tabular}{|c|c|}
\hline Amplified Region & Primers \\
\hline $\begin{array}{l}\text { Dehalogenase } \\
\text { promoter }\end{array}$ & $\begin{array}{l}\text { Forward(dehF3) } \\
\text { 5'-CTAGTCTAGACCCGGGGTGATCATGCTCACCATCAA-3 } \\
\text { 'Reverse(dehR1) } \\
\text { 5'-CTAGTCTAGACGGAAAGTATGCAGGGTTGGTCAT-3' }\end{array}$ \\
\hline $\begin{array}{l}\text { JlacO promoter } \\
\text { (positive control) }\end{array}$ & $\begin{array}{l}\text { Forward } \\
\text { 5'-GGGTCTAGAGCGCAACGCAATTAATGTGAG-3 } \\
\text { Reverse } \\
\text { 5'- GGGTCTAGACGTAATCATGGTCATAGCTGTTTCCTG-3' }\end{array}$ \\
\hline $\begin{array}{l}\text { 1080-lux Promoter } \\
\text { Orientation } \\
\text { Screening }\end{array}$ & $\begin{array}{l}\text { Forward (Insert Reverse Orientation) } \\
\text { 5'-ACCGCAATGGGTTGAATTAG-3 } \\
\text { Forward (Insert Correct Orientation) } \\
\text { 5'-CGATTGGTGTTGTGGAAGTG-3' } \\
\text { Reverse (Insert Reverse Orientation) } \\
\text { 5'-TCTTGACGTGCGAGTTGTTC-3 } \\
\text { Reverse Insert Correct Orientation } \\
\text { 5'-CTAGTCTAGACGGAAAGTATGCAGGGTTGGTCAT-3' }\end{array}$ \\
\hline $\begin{array}{l}\text { JlacO-lux } \\
\text { Promoter } \\
\text { Orientation } \\
\text { Screening }\end{array}$ & $\begin{array}{l}\text { Forward } \\
\text { 5'-ATGTGCTGCAAGGCGATT-3' } \\
\text { Reverse } \\
\text { 5'-TGTTCAAGATCGGCAGGTAG-3' }\end{array}$ \\
\hline
\end{tabular}

The PCR reaction consisted of a $12.5 \mu \mathrm{L}$ reaction volume. The final concentrations of reagents used for the PCR amplifications (and all subsequent PCR amplifications) used $2 \mu \mathrm{L}$ of template DNA at a concentration of $20 \mathrm{ng}$ (from mini-plasmid preparations [87]), $0.16 \mathrm{mM}$ dNTPs, $0.8 \mu \mathrm{M}$ of each primer, $2.5 \mathrm{mM}$ $\mathrm{MgCl}_{2}, 1 \times \mathrm{PCR}$ buffer $\left(-\mathrm{MgCl}_{2}\right), 0.05 \mathrm{u} / \mu \mathrm{L}$ Taq polymerase (all reagents and primers from Qiagen). Qiagen Q solution was added at a final concentration of $2.4 \%$ to optimize product formation. PCR protocols for the amplification of the 
promoter fragments are listed in Table 2-6. The PCR was performed in a Corbett Research Palmcycler (Model CG1-96). The PCR product was separated on a $1 \%$ agarose gel and gel purified using Qiaquick Gel Extraction Kit (Qiagen).

The purified PCR amplified promoter fragments were ligated into pCR2.1-TOPO vector (Invitrogen) for the blue/white selection of positive clones and subsequent sequencing of the ligated promoter insert. In a final ligation reaction volume of $50 \mu \mathrm{L}$, reagents consisted of; $0.24 \mathrm{U} / \mu \mathrm{L}$ T4 DNA ligase, $1 \mathrm{x}$ ligation buffer, $1 \mathrm{ng} / \mu \mathrm{L}$ of vector and $20 \mu \mathrm{L}$ PCR products. The ligation mixture was incubated at $4{ }^{\circ} \mathrm{C}$ overnight and heat inactivated at $65^{\circ} \mathrm{C}$ for 25 mins.

Table 2-6: PCR protocols used for the amplification of the 1080 dehalogenase promoter and the JlacO positive control promoter fragments.

\begin{tabular}{|c|c|c|c|c|c|}
\hline \multicolumn{3}{|c|}{ dehRI '1080' dehalogenase promoter } & \multicolumn{3}{|c|}{ JlacO positive control promoter } \\
\hline Process & Temp ( $\left.{ }^{\circ} \mathrm{C}\right)$ & Time & Process & Temp ( $\left.{ }^{\circ} \mathrm{C}\right)$ & Time \\
\hline 1. Denaturation & 94 & $5 \mathrm{~min}$ & 1.Denaturation & 94 & $5 \mathrm{~min}$ \\
\hline 2. Denaturation & 94 & $30 \mathrm{~s}$ & 2.Denaturation & 94 & $30 \mathrm{~s}$ \\
\hline 3. Annealing & 54 & $30 \mathrm{~s}$ & 3. Annealing & 65 & $30 \mathrm{~s}$ \\
\hline 4. Extension & 72 & $1 \mathrm{~min}$ & 4. Extension & 72 & $1 \mathrm{~min}$ \\
\hline \multicolumn{3}{|c|}{ Repeat step 2 to 4 for 30 cycles } & \multicolumn{3}{|c|}{ Repeat step 2 to 4 for 30 cycles } \\
\hline & 72 & $7 \mathrm{~min}$ & 6. Extension & 72 & $7 \mathrm{~min}$ \\
\hline
\end{tabular}

The ligated plasmid was heat shock transformed into calcium competent $E$. coli

DH5 $\alpha$ cells for the presence of inserts using manufacturer's instructions (pCR 2.1

TOPO Vector, Invitrogen). The cells were plated onto the LB Amp100IPTG100Xgal40 agar and incubated at $37^{\circ} \mathrm{C}$ overnight for blue-white colony screening. White 
colonies were selected and patched onto $L B_{A m p 100}$ plates and incubated at $37^{\circ} \mathrm{C}$ overnight. The white colonies were also inoculated into $3 \mathrm{~mL} \mathrm{LB}_{\mathrm{Amp100}}$ broth and cultured overnight at $37{ }^{\circ} \mathrm{C}$ shaking at $180 \mathrm{rpm}$ for subsequent plasmid DNA mini-preparation as per standard protocols [87]. The selected pCR2.1-TOPO sequencing plasmid with the dehRI or JlacO promoter inserts were digested with EcoRI using manufacturer's instructions (New England Biolab) to obtain the ligated insert.

The digested products were quantified using the NanoDrop ${ }^{\circledR}$ ND-1000 Spectrophotometer (Labtech International). The DNA concentrations were adjusted to $300 \mathrm{ng} / \mathrm{mL}$, in a total volume of $14 \mu \mathrm{L}$, and sent for sequencing at the Allan Wilson Centre in Palmerston North, New Zealand (www.awcmee.massey.ac.nz). The Allan Wilson Centre chromatograms were then analyzed using Invitrogen Vector NTI software (www.invitrogen.com). Sequences were edited and selected, in terms of length of identity, minimum number of mutations and clarity, for further manipulations.

Following confirmation of the correct insert sequences, the appropriate pCR2.1TOPO plasmid constructs were Xbal digested according to manufacturer's instructions (New England Biolabs), to obtain the promoter insert. On occasion Xbal-Smal sequential digests were also undertaken in an attempt to achieve the ligation of the promoter insert in the correct orientation. Sequential digests were 
prepared and incubated according to the manufacturer's instructions (New England Biolabs) and all digested fragments were gel purified using QIAquick Gel Extraction Kit (Qiagen ).

The Xbal digested product was ligated into the Xbal restriction enzyme digested pUT mini-Tn5 luxCDABE plasmid that had previously been either CIAP or SAP treated. In a final ligation reaction volume of $50 \mu \mathrm{L}$ reagents consisted of $0.24 \mathrm{U} / \mu \mathrm{L}$, T4 DNA ligase, $1 \mathrm{x}$ ligation buffer, $1 \mathrm{ng} / \mu \mathrm{L}$ of vector and $20 \mu \mathrm{L}$ PCR products. The ligation mixture was incubated at $4{ }^{\circ} \mathrm{C}$ overnight and heat inactivated at $65^{\circ} \mathrm{C}$ for 25 mins.

Alternatively the Xbal-Smal sequentially digested promoter fragment was ligated into the Xbal-Smal digested pUT mini-Tn5 luxCDABE. In this case CIAP or SAP treatment was not necessary. The ligation protocol used was the same as stated above with variations including; using estimated molar ratios of one to three vector to insert, calculating exact molar ratios of one to three vector to insert, 2 hour ligation incubation at $16{ }^{\circ} \mathrm{C}$, overnight benchtop ligation, overnight ligation at $4{ }^{\circ} \mathrm{C}, 14^{\circ} \mathrm{C}$ and $16{ }^{\circ} \mathrm{C}$ respectively. In all instances half of the ligation reaction mixture was heat inactivated and half was not heat inactivated, however there was no difference between the inactivation treatments. The resultant plasmids were named '1080-lux' and 'JlacO-lux'. 
The 1080-lux and JlacO-Iux plasmids were heat-shock transformed into E.coli DH5 $\alpha \lambda$ pir cells using standard protocols [87] on occasion amending protocols in an effort to encourage more efficient transformation. Such amendments included increasing or decreasing the amounts of plasmid added to the transformation mixture, increasing or decreasing the time spent in cold-shock, not shaking during the recovery period prior to plating onto screening agar, recovery for 180 minutes at $25{ }^{\circ} \mathrm{C}$ prior to plating on the selective $\mathrm{LB}_{\mathrm{Amp} 100 \mathrm{Kan} 50}$ agar and plate incubation at $25{ }^{\circ} \mathrm{C}$ for $18-20$ hours (rather than $37{ }^{\circ} \mathrm{C}$ for 18 to 20 hours) to overcome the possibility that the luciferase enzyme may be unstable over $30{ }^{\circ} \mathrm{C}$ [88]. On occasion cells were resuscitated in LB broth containing an extra $2 \%$ glucose.

Individual transformants were selected to screen for positive insert clones. Three screening methods were utilised. These were PCR amplification of the ligated promoter from the construct, Xbal digestion of the ligated promoter from the construct, promoter orientation PCR screening and bioluminescence screening. Plasmid mini-preparations were carried out on selected transformants using standard protocols [87].

Restriction enzyme digestion of the promoter fragments from the constructs were undertaken using Xbal. Digests were performed according to manufacturer's instructions (New England Biolabs). PCR amplification was initially performed to determine the presence of the promoter fragment using original promoter 
amplification PCR primers (Table 2-5) and protocols (Table 2-6). In addition to determining the presence or absence of the promoter inserts in the plasmid constructs, it was necessary to determine their orientation. Primers were designed to amplify a region that included part of the Tn5 IuxCDABE vector and the dehRI promoter.

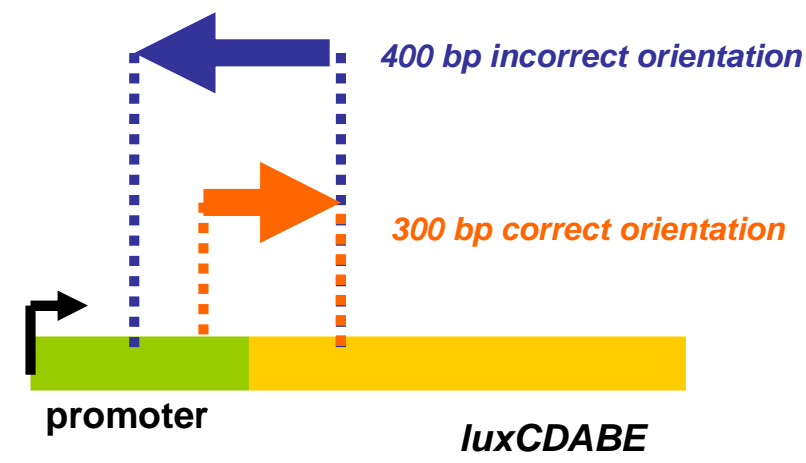

Figure 2-8: The rationale behind the design of the promoter orientation colony screening PCR.

If the promoter is ligated in the correct orientation a $300 \mathrm{bp}$ fragment will be amplified. Incorrect orientation will give a 400 bp fragment.

The multiplex PCR was designed so that the presence of a $300 \mathrm{bp}$ fragment would indicate the promoter was in the correct orientation. If a fragment of $400 \mathrm{bp}$ was present it would indicate incorrect orientation (Figure 2-8). The PCR master mixture contained a combination of all three primers (Table 2-5) to determine the orientation of the promoter insert in individual colonies, in a multiplex PCR. The final reaction volume was $12.5 \mathrm{uL}$ and the final concentrations of reagents used for multiplex PCR amplifications were $0.16 \mathrm{mM}$ dNTPs, $0.8 \mu \mathrm{M}$ of each forward primer, $1.6 \mu \mathrm{M}$ of the reverse primer, $2.5 \mathrm{mM} \mathrm{MgCl}_{2}, 1 \times \mathrm{PCR}$ buffer $\left(-\mathrm{MgCl}_{2}\right)$, 
$0.05 \mathrm{u} / \mu \mathrm{L}$ Taq polymerase and $\mathrm{Q}$ solution at a final concentration of $2.4 \%$ (all reagents from Qiagen). Template DNA was obtained directly from transformant colonies; sterile pipette tips were gently touched to the surface of the colony and mixed into the PCR mixture. The PCR protocol is listed in Table 2-7. Resulting PCR products were sequenced (Institute of Environmental and Scientific Research, Wellington). Sequences were edited using Vector NTI and were selected, in terms of length of identity, minimum number of mutations and clarity.

Table 2-7: PCR protocols used for the amplification of inserts for determination of promoter orientation in trannsformants.

\begin{tabular}{|c|c|c|c|c|c|}
\hline \multicolumn{3}{|c|}{ 1080-Iux Promoter Insert Orientation } & \multicolumn{3}{|c|}{ JlacO-Iux Promoter Insert Orientation. } \\
\hline Process & Temp ( $\left.{ }^{\circ} \mathrm{C}\right)$ & Time & Process & Temp ( $\left.{ }^{\circ} \mathrm{C}\right)$ & Time \\
\hline 1. Denaturation & 94 & 5 minutes & 1. Denaturation & 94 & 5 minutes \\
\hline 2. Denaturation & 94 & 30 seconds & 2. Denaturation & 94 & 30 seconds \\
\hline 3. Annealing & 54 & 30 seconds & 3. Annealing & 63 & 30 seconds \\
\hline 4. Extension & 72 & 1 minute & 4. Extension & 72 & 1 minute \\
\hline \multicolumn{3}{|c|}{ Repeat $2-4$ for 30 cycles } & \multicolumn{3}{|c|}{ Repeat $2-4$ for 30 cycles } \\
\hline 6. Extension & 72 & 7 minutes & 6. Extension & 72 & 7 minutes \\
\hline
\end{tabular}

The third screening method, bioluminescence screening, was undertaken by selecting single transformant colonies, inoculating them into $3 \mathrm{~mL} \mathrm{LB}_{\mathrm{Amp} 100 / \mathrm{Kan} 50}$ and incubating at $37{ }^{\circ} \mathrm{C}$ overnight. A $1 \mathrm{~mL}$ of aliquot of the overnight cell culture was inoculated into $10 \mathrm{~mL}$ fresh $\mathrm{LB}_{\mathrm{Amp} 100 / \mathrm{Kan} 50}$ broth, incubated at $25{ }^{\circ} \mathrm{C}$ and grown to $\mathrm{OD}_{600 \mathrm{~nm}}$ of 0.8 to enable sufficient cell density for bioluminescence to occur. The cells were prepared for screening by washing as described in Section 2.1.1 The inducing substance (1080 or IPTG) was added to the washed cells at 
concentrations of $1 \mathrm{mM}$ or $10 \mathrm{mM}$ to activate the promoter and induce bioluminescence. Bioluminescence was measured at 15, 30 and 60 minute intervals as well as at $3,5,6$ and 8 hours. 


\section{Chapter Three: RESULTS}

\subsection{Microbial Biosensor Bioassays.}

\subsubsection{Characterisation of Bacterial Biosensors.}

Characterisations of the luminescent bacteria V. harveyi and E. coli HB101 pUCD607, and the luminescent fungi New Zealand Mycena sp. ICMP 16534 and M. citricolor ATCC 34884, were undertaken. The isolates were evaluated in terms of growth and bioluminescence to determine the optimal growth stage to harvest the biosensors for use in subsequent toxicity bioassays. Because a high cell density is required to achieve optimal luminescence, it was necessary to determine the optimal cell harvesting time (Figure 3-1). Bioluminescence and growth $\left(\mathrm{OD}_{600}\right)$ for both E. coli HB101 pUCD607 and $V$. harveyi were measured over time.

The $E$. coli bacterium are not always confined to the intestine, and their ability to survive for brief periods outside the body makes them an ideal indicator organism to test environmental samples. In comparison, $V$. harveyi is a naturally bioluminescent species of marine bacteria with less tolerance to ecological variability, therefore to ensure optimal conditions for the $V$. harveyi biosensor, PTCs were made and bioassays carried out, in $0.1 \mathrm{M} \mathrm{NaCl}$ solutions. 

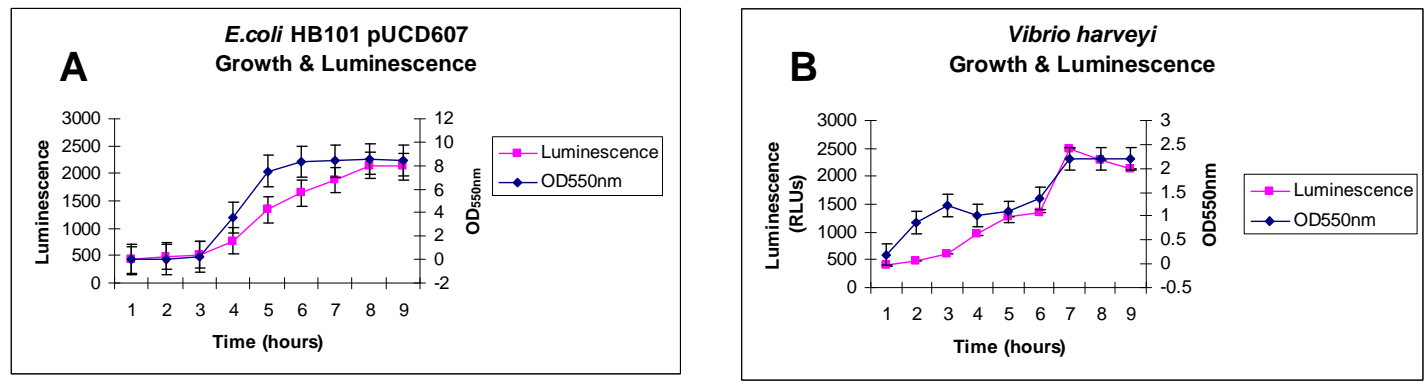

Figure 3-1: Growth and bioluminescence patterns of the two bacterial biosensors. (A) E. coli HB101 pUCD607 and (B) V. harveyi.

Growth and luminescence characterisation was undertaken to determine the optimal time for biosensor cell harvest, for subsequent use in bioassays. Growth was measured using a calliper gauge and bioluminescence was measured using relative light units (RLUs). Both experiments were undertaken using 5 replicates for each treatment. Error bars were calculated using standard error of the mean.

The shape of each graph for bioluminescence is similar with optimal bioluminescence occurring after 5 to 6 hours for $E$. coli HB101 pUCD607 and 7 hours for $V$. Harveyi (Figure 3-1). The growth curves are significantly different shapes, with E. coli HB101 pUCD607 the more traditional exponential growth curve shape compared with $V$. harveyi which demonstrates a more gradual increase in growth and a limited exponential phase. Initial bioassays with the antiseptic TCP ${ }^{\mathrm{TM}}$ were undertaken to test the biosensors reproducibility and are shown in Figure 3-2. In E. coli HB101 pUCD607 there is an exponential decrease in luminescence with increasing TCP concentration and an $\mathrm{EC}_{50}$ of approximately $0.28 \%, V$. harveyi was more sensitive to TCP with an $\mathrm{EC}_{50}$ less than $0.05 \%$. 

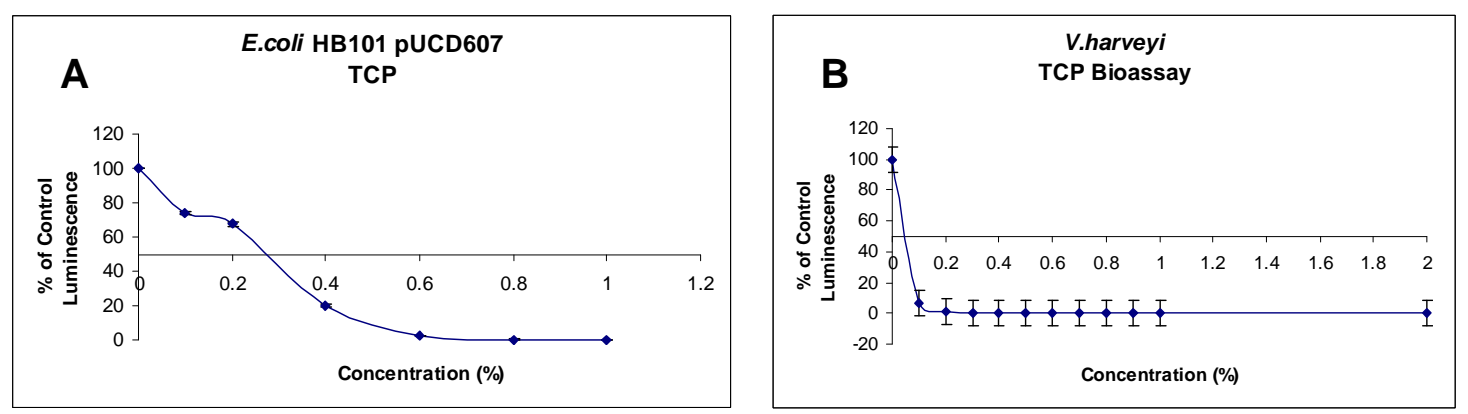

Figure 3-2: Dose-response curves of quality assurance of the bacterial biosensors, E. coli HB101 pUCD607 (A) and V. harveyi (B) using $T C P^{T M}$ as a test solution.

$T C P^{T M}$ bioassays were undertaken with both bacterial biosensors for quality assurance of the biosensor response. TCP ${ }^{T M}$ concentrations of $0 \%, 0.1 \%, 0.2 \%, 0.4 \%, 0.6 \% 0.8$ $\%$ and $1 \%$ were used. $100 \mathrm{uL}$ of prepared biosensor cells were added to $900 \mathrm{uL}$ of the prepared TCP ${ }^{T M}$ dilutions at 10 s intervals and measured following a 15 minute benchtop incubation. Luminescence was measured as RLUs. Error bars were calculated using standard error of the mean.

\subsubsection{Characterisation of Fungal Biosensors.}

Culture and growth optimisation of the basidiomycete fungi (Table 2-1) was carried out. The isolates included 10 Armillaria novae-zelandiae isolates, $1 \mathrm{New}$ Zealand fungal species ICMP 16534 (thought to be a Mycena species, [89]) and Mycena citricolor ATCC 34884. The fungal specimen deposited into Landcare Research by a private collector, Mycena sp. ICMP 16534 is known to have a bioluminescent fruiting body and is the first known bioluminescent Mycena species to be deposited in the Landcare Collection, New Zealand [89]. 
None of the ten New Zealand Armillaria isolates are known to be bioluminescent however, it is possible that under optimised growth and luminescence conditions these Armillaria may produce bioluminescent globular mycelium that are able to be used in a bioassay to detect the presence of PTCs.

Table 3-1 shows bioluminescence screening of the ten $A$. novae-zelandiae cultures, Mycena sp. ICMP 16534 and M. citricolor ATCC 34884 on three different nutrient agars, and in three different nutrient broths. The $A$. novaezelandiae isolates did not exhibit the required growth efficiency, formation of globular mycelium in broth or luminescence in broth.

Table 3-1: Luminescence of sourced potential fungal biosensors on three different agars and in three different broths, screened for desired growth and luminescence patterns.

\begin{tabular}{|c|c|c|c|c|c|c|c|}
\hline \multirow{3}{*}{$\begin{array}{l}\text { Isolate name and } \\
\text { identification }\end{array}$} & \multirow{3}{*}{$\begin{array}{l}\text { Formation of } \\
\text { Globular } \\
\text { Mycelium }\end{array}$} & \multicolumn{6}{|c|}{ Luminescence } \\
\hline & & \multicolumn{2}{|c|}{$\begin{array}{c}\text { Potato } \\
\text { Dextrose }\end{array}$} & \multicolumn{2}{|c|}{ Breadcrumb } & \multicolumn{2}{|c|}{ Malt Extract } \\
\hline & & Agar & Broth & Agar & Broth & Agar & Broth \\
\hline $\begin{array}{l}\text { A. novae-zelandiae } \\
\text { LU872, LU874, LU878, LU881, } \\
\text { LU887, LU904, LU906, LU911, } \\
\text { LU916, LU917 }\end{array}$ & No & No & No & No & No & No & No \\
\hline Mycena sp. ICMP 16534 & Yes & No & Yes & No & Yes & No & Yes \\
\hline M. citricolor ATCC 34884 & Yes & Yes & Yes & Yes & Yes & Yes & Yes \\
\hline
\end{tabular}

Figure 3-3 shows growth and bioluminescence of New Zealand Mycena sp. ICMP 16534 on three different nutrient agars and broths over time. Optimal 
bioluminescence was achieved using PD broth and maximum bioluminescence occurred after 25 to 30 days. Growth of Mycena sp. ICMP 16534 was slow even on the optimal ME agar.

A

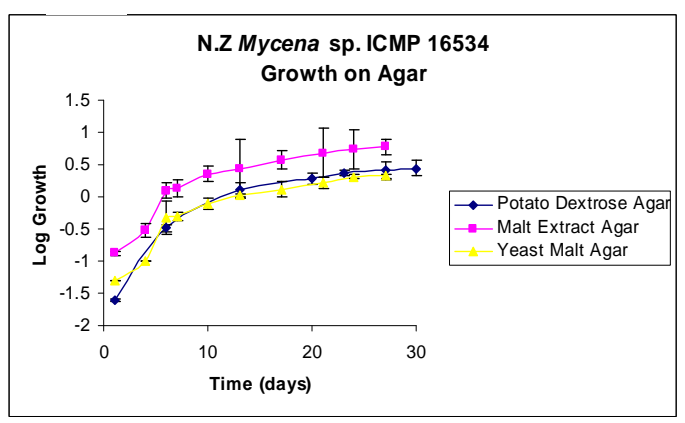

B

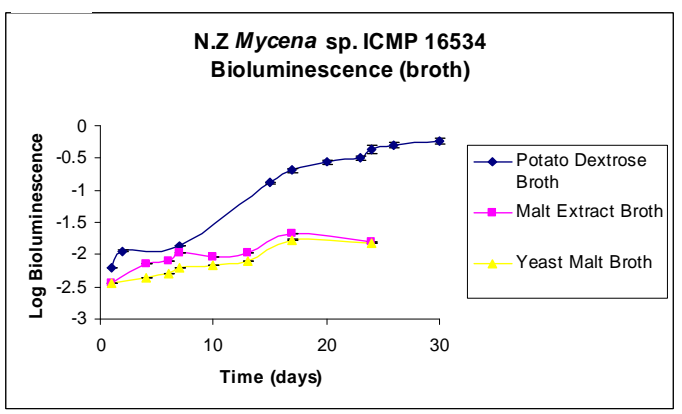

Figure 3-3: Characterisation experiments of Mycena sp. ICMP 16534

Growth and bioluminescence levels achieved in different medias. Growth on agar (A) was measured using calliper gauges and growth in broth using optical density. Bioluminescence in broth (B) was measured using RLUs. 5 replicates were used for each treatment. Of the media used the best bioluminescence was achieved on PD broth and optimal growth on ME agar. Error bars were calculated using standard error.

Despite Mycena sp. ICMP 16534 ability to luminesce in broth it was not considered for utilisation in bioassays because of its slow growth compared to M. citricolor ATCC 34884 (Figure 3-4). Therefore only M. citricolor ATCC 34884 was used in subsequent bioassays. 


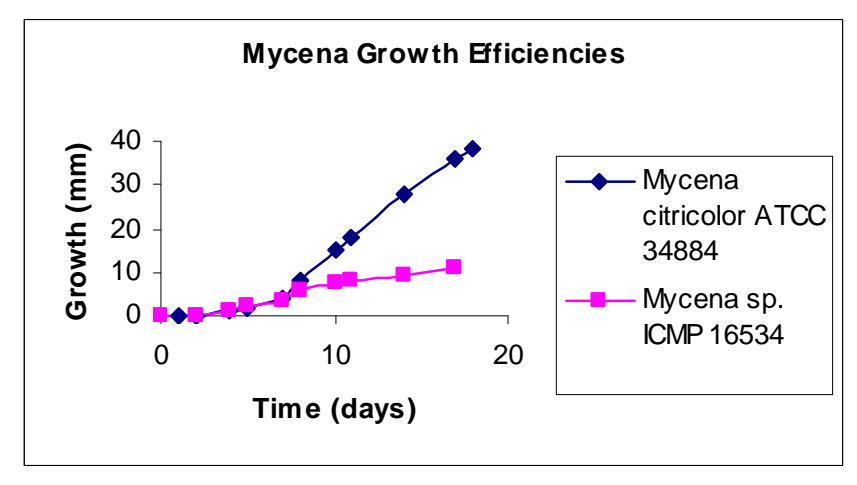

Figure 3-4: Graph depicting differing growth efficiencies of the U.K sourced M. citricolor ATCC 34884 and the New Zealand Mycena sp. ICMP 16534. M. citricolor ATCC 34884 has a faster growth habit translating to increased value as a biosensor. Error bars were calculated using standard error of the mean.

Figure 3-5 (A) illustrates the response of the $M$. citricolor ATCC 34884 fungal biosensor to copper at 15,30, 60 and 90 minute exposure. This graph demonstrates that bioluminescence decreases with increasing concentrations of copper. It also illustrates that there is no difference over the time periods. Figure 3-5 (B) shows the response of $M$. citricolor ATCC 34884 fungal biosensor to copper in a study carried out by Weitz [43]. Weitz observed differences in the biosensor response over time, nonetheless both bioassays showed similar $\mathrm{EC}_{50}$ values. 
A

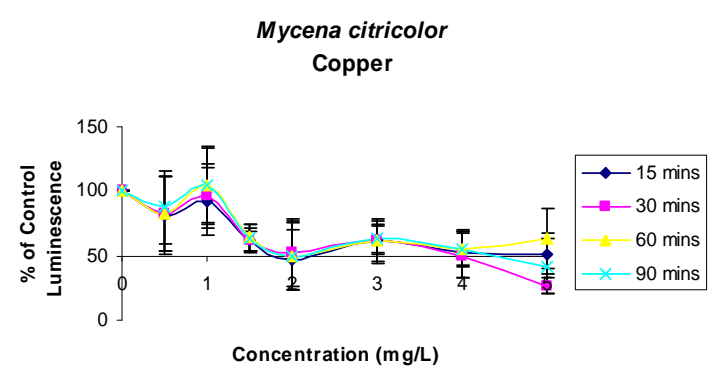

B

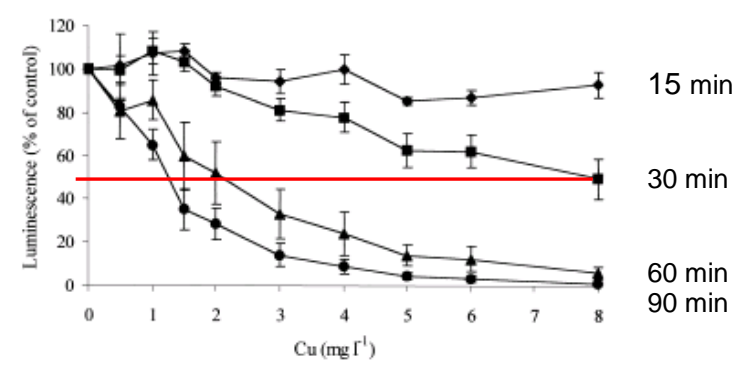

Figure 3-5: Comparisons of the effect of copper on Mycena citricolor.

$(A)$; shows the effect of copper in the bioassay undertaken in this investigation. (B); shows the results of the bioassay carried out by Weitz (2002),(reproduced with permission). The red line indicates $E C_{50}$ values. Both studies show similar $E C_{50}$ values. Three replicates were used in each treatment. Luminescence was measured in RLUs. Error bars were calculated using standard error of the mean.

\subsection{Initial PTC Water Bioassays.}

Bioassays to investigate the sensitivity of the biosensors to a range of PTCs (Table 2-2) were carried out. Potentially toxic compounds were diluted in SDW for E. coli HB101 pUCD607 bioassay. However, because $V$. harveyi is a marine species $0.1 \mathrm{M} \mathrm{NaCl}$ was used as a diluent for all $V$. harveyi bioassays [14]. This sodium chloride solution is isotonic to the $V$. harveyi bacterium therefore it was considered that it would not increase the availability of the PTC to the cell via osmosis thereby making the biosensor more sensitive to the PTC.

Table 3-2 shows $\mathrm{EC}_{50}$ values for the three microbial biosensors used in initial water bioassays after exposure to ten PTCs. The E. coli HB101 pUCD607 water bioassays showed similar results to bioassays previously described [16],[14], [15]. For some of the compounds data variability prevented calculation of an $\mathrm{EC}_{50}$ 
using the CSIRO dose-response model. These bioassays included the E. coli HB101 pUCD607 with acephate (Figure 3-6) and M. citricolor ATCC 34884 with acephate, arsenate, copper, cyanide and zinc (Figure 3-7).

Dose-response curves for the bioassays that did not fit the CSIRO data analysis model were plotted and the $\mathrm{EC}_{50}$ extrapolated. An $\mathrm{EC}_{50}$ value for acephate was extrapolated around $5000 \mathrm{mg} / \mathrm{L}$. Difenacoum did not elicit a response from the biosensor up to a level of $10,000 \mathrm{mg} / \mathrm{L}$ thus no further investigation was carried out using this PTC (Table 3-2).
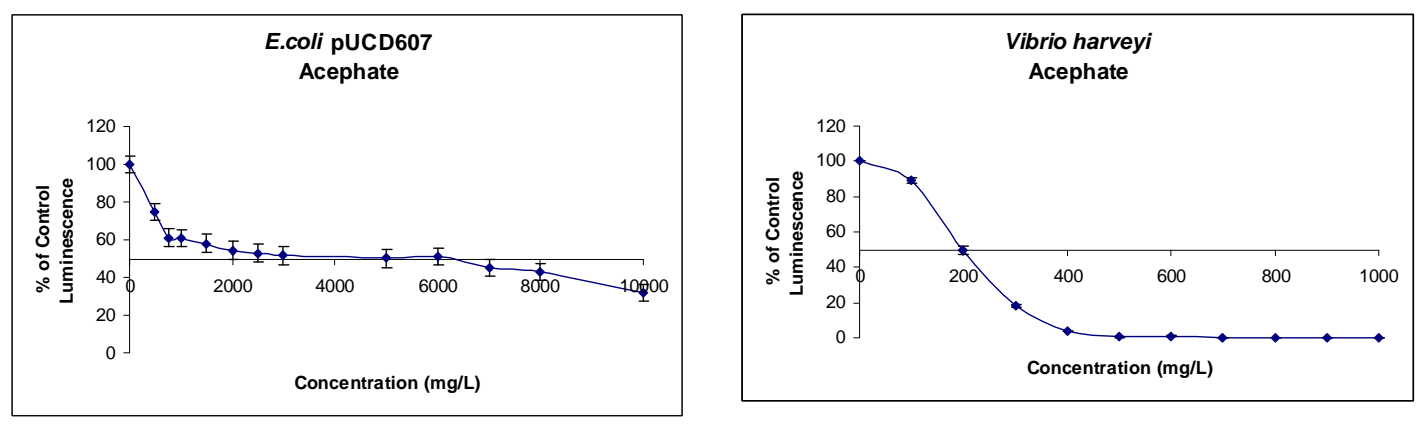

Figure 3-6: Initial acephate bioassays of E. coli HB101 pUCD607 and $V$. harveyi biosensors.

The dose-response curve for E. coli HB101 pUCD607 and V. harveyi acephate bioassays demonstrates $E C_{50}$ values of $200 \mathrm{mg} / \mathrm{L}$ and approximately $5000 \mathrm{mg} / \mathrm{L}$ respectively. Three replicates were used in each treatment. Error bars were calculated using standard error of the mean.

V. harveyi was considerably more sensitive to acephate than E. coli HB101 pUCD607, with an $\mathrm{EC}_{50}$ of $200 \pm 14 \mathrm{mg} / \mathrm{L}$ compared to $5000 \mathrm{mg} / \mathrm{L}$ (Figure 3-6). V. harveyi also showed lower $\mathrm{EC}_{50}$ values for several other PTCs than the more 
widely exploited, genetically modified E. coli HB101 pUCD607 biosensor. The bioassays using carbaryl, copper, cyanide and PCP demonstrate this. 
Table 3-2: Initial bioassays of PTCs in water using the three microbial biosensors; E. coli HB101 pUCD607, V. harveyi and Mycena citricolor. Shaded boxes indicate the microbial biosensor with the greatest sensitivity to the given PTC.

\begin{tabular}{|c|c|c|c|c|c|c|c|c|c|}
\hline \multirow{3}{*}{ PTCs in water } & \multicolumn{9}{|c|}{$\mathrm{EC}_{50}(\mathrm{mg} / \mathrm{L})$} \\
\hline & \multicolumn{3}{|c|}{ E. coli pUCD607 HB101 } & \multicolumn{3}{|c|}{ V. harveyi } & \multicolumn{3}{|c|}{ M. citricolor ATCC 34884} \\
\hline & Value & $95 \% \mathrm{CL}^{\mathrm{a}}$ & $\mathbf{R}^{2}$ & Value & $95 \% \mathrm{CL}^{\mathrm{a}}$ & $\mathbf{R}^{2}$ & Value & $95 \% C^{a}$ & $\mathbf{R}^{2}$ \\
\hline Acephate & \multicolumn{3}{|c|}{$5000 \mathrm{mg} / \mathrm{L}^{\mathrm{c}}$} & 200 & $186-214$ & .997 & \multicolumn{3}{|c|}{$8000 \mathrm{mg} / \mathrm{L}^{\mathrm{c}}$} \\
\hline Arsenate & 2.55 & $1.3-5.1$ & .985 & 50.1 & 21.9-114.9 & .973 & \multicolumn{3}{|c|}{$9640 \mathrm{mg} / \mathrm{L}^{\mathrm{c}}$} \\
\hline Arsenite & 61.7 & $54-70.4$ & .994 & 150 & $145-155.2$ & .987 & $N D^{b}$ & - & - \\
\hline Carbaryl & 100 & $78-128$ & .992 & 67 & $38-118.7$ & .990 & $N D^{b}$ & - & - \\
\hline Copper & 3.05 & $2.4-3.9$ & .991 & 0.79 & $0.73-0.56$ & .998 & \multicolumn{3}{|c|}{$2 \mathrm{mg} / \mathrm{L}^{\mathrm{c}}$} \\
\hline Cyanide & 20 & $15.4-26.0$ & .973 & 9.66 & $9.4-9.8$ & .982 & \multicolumn{3}{|c|}{$170 \mathrm{mg} / \mathrm{L}^{\mathrm{c}}$} \\
\hline Difenacoum & $N D^{b}$ & - & - & - & - & - & $N D^{b}$ & - & - \\
\hline PCP & 3.44 & $6.1-8.0$ & .995 & 0.25 & $0.24-0.26$ & .963 & 0.591 & $2.8-4.7$ & .992 \\
\hline Zinc & 0.48 & $0.41-0.56$ & 0.993 & 7.9 & $6.9-8.9$ & .993 & \multicolumn{3}{|c|}{$280 \mathrm{mg} / \mathrm{L}^{\mathrm{c}}$} \\
\hline 1080 & \multicolumn{3}{|c|}{$N D^{c}$} & \multicolumn{3}{|c|}{$N D^{c}$} & \multicolumn{3}{|c|}{$1000 \mathrm{mg} / \mathrm{L}^{\mathrm{c}}$} \\
\hline
\end{tabular}

95\% Confidence level

${ }^{\mathrm{b}}$ Not Detected

${ }^{c} \mathrm{EC}_{50}$ estimated from data points on luminescence graphs 
Variability in the data of the $V$. harveyi 1080 bioassay prevented the $\mathrm{EC}_{50}$ being calculated using CSIRO dose-response model. From the plotted data points the $\mathrm{EC}_{50}$ was extrapolated as approximately $6650 \mathrm{mg} / \mathrm{L}$.
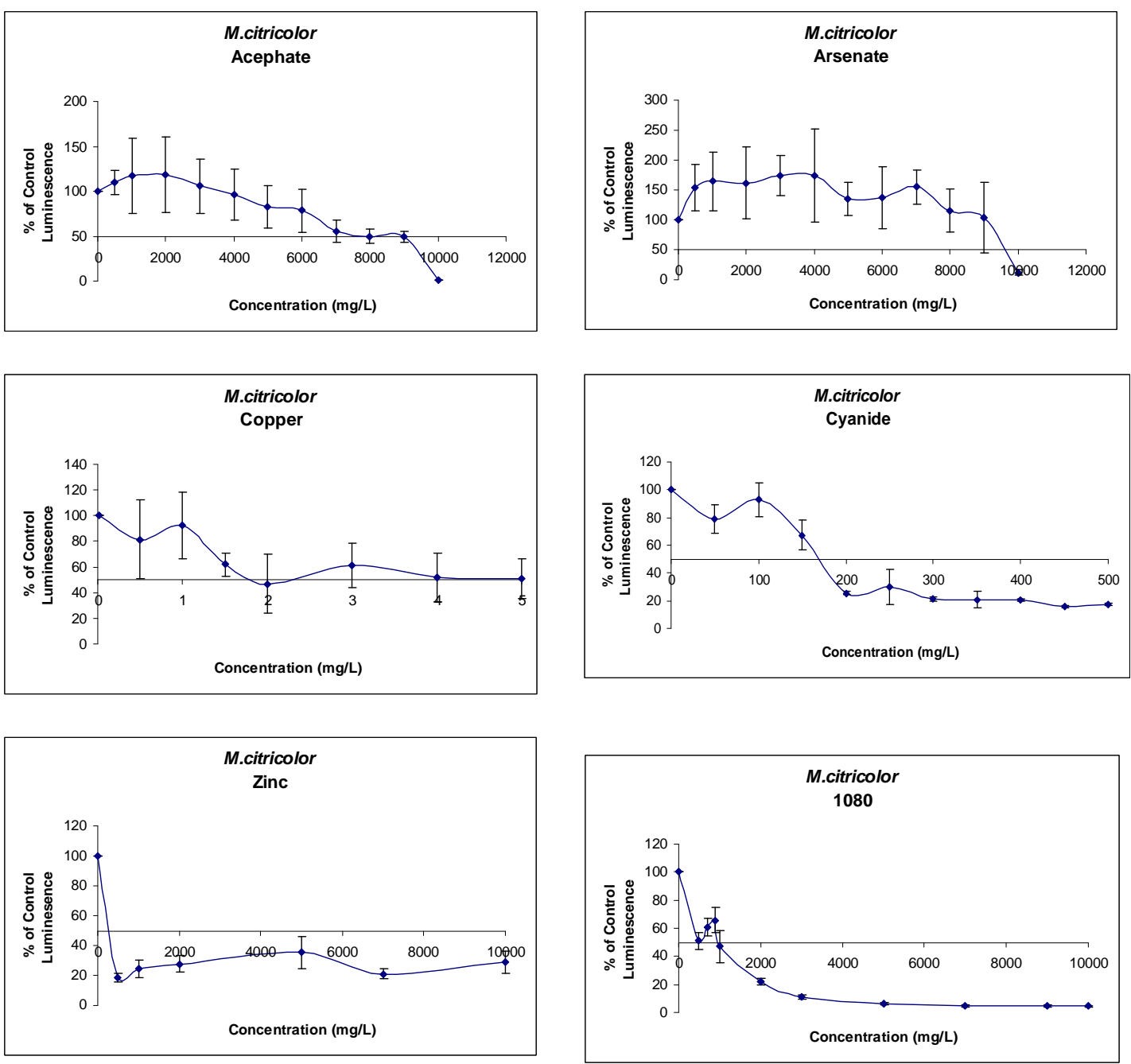

Figure 3-7: M. citricolor ATCC 34884 bioassay dose response curves for acephate, arsenate, copper, cyanide, zinc and 1080.

These graphs were plotted in Microsoft Excel and indicate the variability of the $M$. citricolor ATCC 34884 response to the PTCs. Luminescence was measured in RLUs and three replicates were used for each treatment. Error bars were calculated using standard error of the mean. 
The fungal bioassays were undertaken using the same PTCs as were used in the bacterial biosensor bioassays. Figure 3-7 shows the response of the fungal biosensor to acephate, arsenate, copper, cyanide, zinc and 1080. Approximate $\mathrm{EC}_{50}$ values were determined from the graphs (Figure 3-7) and are presented in Table 3-2. The M. citricolor ATCC 34884 fungal biosensor, appears to be less sensitive to all PTCs tested when compared to the sensitivity of both E. coli HB101 pUCD607 and $V$. harveyi. The exception to this is $M$. citricolor ATCC 34884 greater sensitivity to PCP.
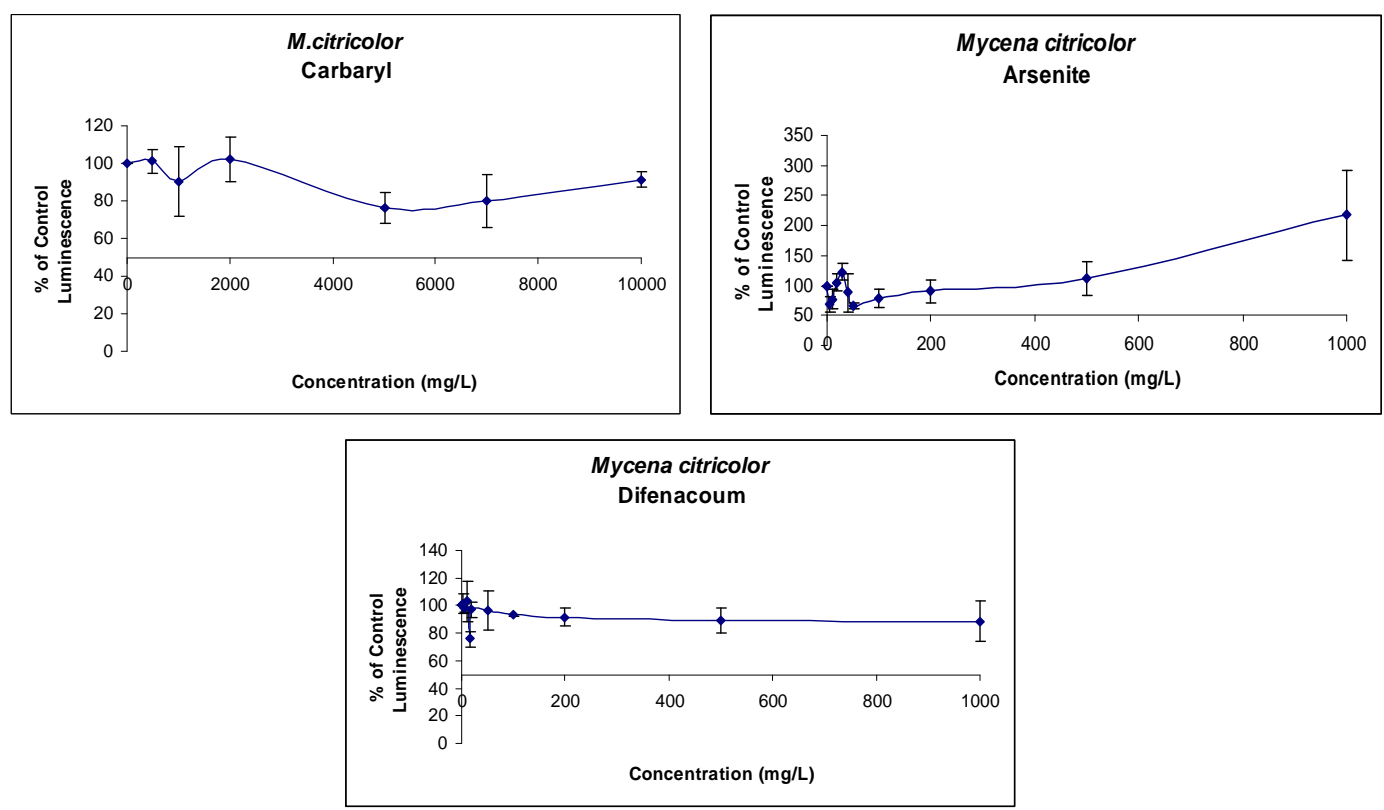

Figure 3-8: M. citricolor ATCC34884 dose response curves indicating the biosensors inability to detect carbaryl, arsenite and difenacoum. Bioluminescence was measured as RLUs and three replicates were used in each treatment. Error bars were calculated using standard error of the mean. 
M. citricolor ATCC 34884 was unable to detect the presence of carbaryl, arsenite and difenacoum (up to $10,000 \mathrm{mg} / \mathrm{L}$ ), in initial water bioassays as demonstrated in Figure 3-8, where no $\mathrm{EC}_{50}$ values can be extrapolated.

\subsection{PTC Spiked White Powder Bioassays.}

Results from initial water bioassays (Table 3-2) demonstrate that for some PTCs, E. coli HB101 pUCD607 was the most sensitive of the biosensors to arsenate, arsenite and zinc with $\mathrm{EC}_{50}$ values of $2.55 \mathrm{mg} / \mathrm{L}, 61.7 \mathrm{mg} / \mathrm{L}, 0.48 \mathrm{mg} / \mathrm{L}$ respectively. However $V$. harveyi was more sensitive to acephate, copper and PCP giving $\mathrm{EC}_{50}$ values of $200 \mathrm{mg} / \mathrm{L}, 0.79 \mathrm{mg} / \mathrm{L}$ and $0.25 \mathrm{mg} / \mathrm{L}$ respectively. For these last three compounds both bacterial biosensors were used in subsequent white powder bioassays. V. harveyi was also more sensitive to carbaryl $(67 \mathrm{mg} / \mathrm{L})$ and cyanide $(9.66 \mathrm{mg} / \mathrm{L})$ however in the interest of environmental responsibility these toxins were not selected for further bioassays. Table 3-3 shows the $\mathrm{EC}_{50}$ values for $E$. coli $\mathrm{HB} 101$ pUCD607 and $V$. harveyi for white powders spiked with PTCs.

Because the data points did not match those of the CSIRO EC $\mathrm{E}_{50}$ analysis model no $\mathrm{EC}_{50}$ values could be calculated for the $V$. harveyi white powder bioassays. $E C_{50}$ values were therefore read from plotted data points(Figure 3-9). These $E_{50}$ values were determined to be $190 \mathrm{mg} / \mathrm{L}$ for copper spiked in analytical talc and $400 \mathrm{mg} / \mathrm{L}$ in flour. For PCP spiked white powders talc gave an $\mathrm{EC}_{50}$ of $2.8 \mathrm{mg} / \mathrm{L}$ 
while flour was $265 \mathrm{mg} / \mathrm{L}$ (Table 3-3). The $V$. harveyi biosensor was not able to detect acephate at all when spiked in either of the white powders.
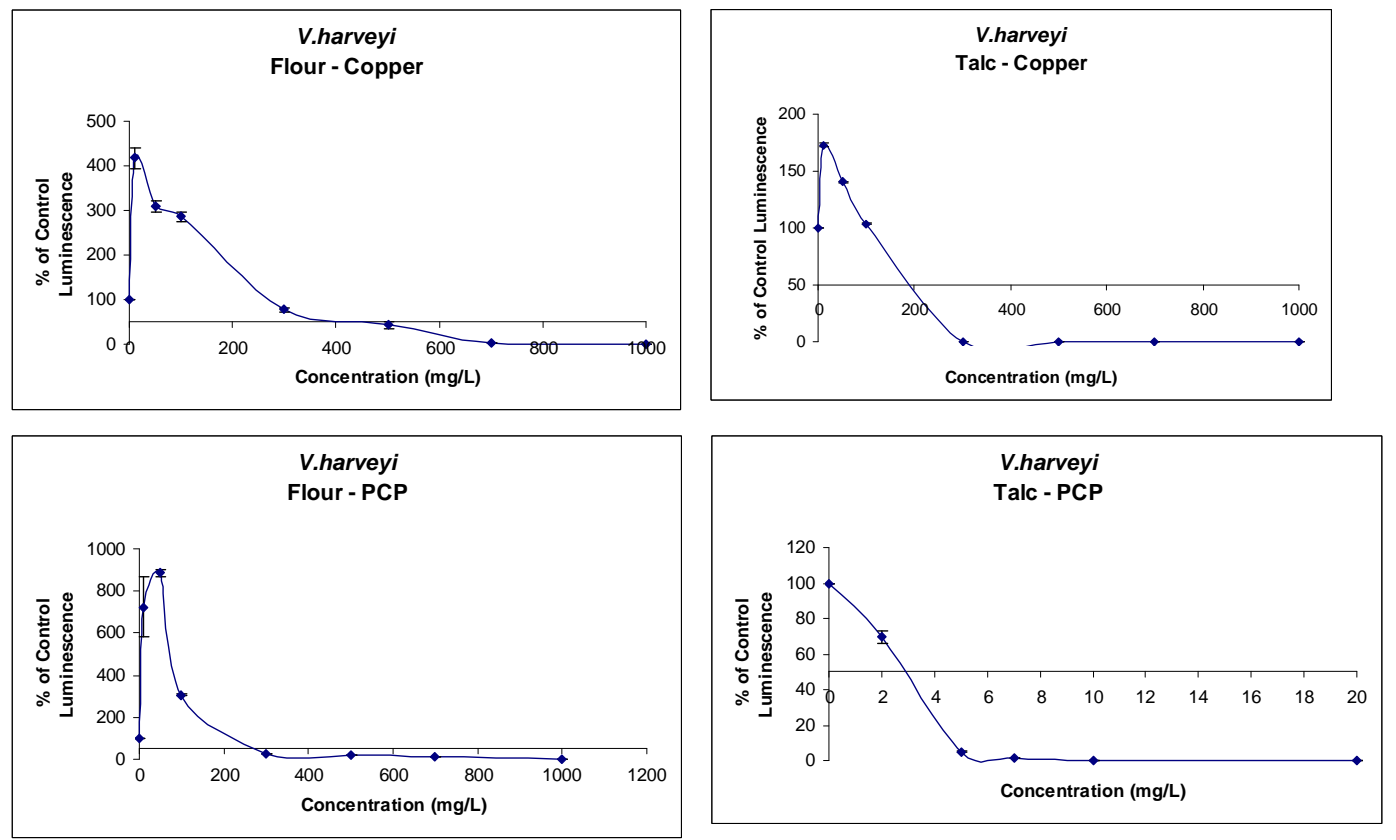

Figure 3-9: V. harveyi white powder dose-response curves

$E C_{50}$ values for copper and PCP spiked talc and flour. V.harveyi was sensitive to PCP and copper when spiked in talc and flour however the biosensor response is clearer in spiked talc. Acephate was not detected at all when spiked in either white powder. Three replicates were used in each treatment. Error bars were calculated using standard error of the mean.

The E. coli HB101 pUCD607 biosensor was less sensitive to all PTCs when spiked in talc and flour compared to the initial water bioassays. Comparison between PTC spiked analytical talc and PTC spiked flour shows the flour bioassays gave lower $\mathrm{EC}_{50}$ values (Table 3-3). 
Table 3-3: Bioassays of PTC spiked flour and talc using the two bacterial biosensors; E. coli HB101 pUCD607 and $V$. harveyi.

\begin{tabular}{|c|c|c|c|c|c|c|c|c|c|c|c|c|}
\hline \multirow{4}{*}{$\begin{array}{l}\text { PTCs in } \\
\text { white } \\
\text { powders }\end{array}$} & \multicolumn{12}{|c|}{$\mathrm{EC}_{50}(\mathrm{mg} / \mathrm{L})$} \\
\hline & \multicolumn{6}{|c|}{ E. coli pUCD607 HB101 } & \multicolumn{6}{|c|}{ V. harveyi } \\
\hline & \multicolumn{3}{|c|}{ Talc } & \multicolumn{3}{|c|}{ Flour } & \multicolumn{3}{|c|}{ Talc } & \multicolumn{3}{|c|}{ Flour } \\
\hline & Value & $\begin{array}{c}95 \% \\
C^{a}{ }^{a}\end{array}$ & $\mathbf{R}^{2}$ & Value & $95 \% C^{a}$ & $\mathbf{R}^{2}$ & Value & $\begin{array}{l}95 \% \\
C^{a}\end{array}$ & $\mathbf{R}^{2}$ & Value & $\begin{array}{c}95 \% \\
C L^{a}\end{array}$ & $\mathbf{R}^{2}$ \\
\hline Acephate & $N D^{b}$ & - & - & $N D^{b}$ & - & - & $N D^{b}$ & - & - & $N D^{b}$ & - & - \\
\hline Arsenate & 25 & $\begin{array}{c}13.5- \\
46.4\end{array}$ & .995 & 2300 & $\begin{array}{l}1832- \\
2889\end{array}$ & .997 & - & - & - & - & - & - \\
\hline Arsenite & 210 & $\begin{array}{l}120- \\
367\end{array}$ & .998 & 250 & $210-297$ & .999 & - & - & - & - & - & - \\
\hline Carbaryl & 219 & $\begin{array}{l}136- \\
352\end{array}$ & .990 & 400 & $131-1220$ & .988 & - & - & - & - & - & - \\
\hline Copper & 36 & $\begin{array}{c}30.8- \\
42.0\end{array}$ & .992 & 468 & $371-588$ & .999 & & $\mathrm{mg} / \mathrm{L}^{\mathrm{c}}$ & & & $\mathrm{mg} / \mathrm{L}^{\mathrm{c}}$ & \\
\hline Cyanide & 589 & $\begin{array}{l}512- \\
678\end{array}$ & .982 & 700 & 616-794 & .911 & - & - & - & - & - & - \\
\hline PCP & 6 & $4.5-9.3$ & .969 & 849 & 616-1170 & .930 & & $\mathrm{mg} / \mathrm{L}^{\mathrm{c}}$ & & & $\mathrm{mg} / \mathrm{L}^{\mathrm{c}}$ & \\
\hline Zinc & 34 & $\begin{array}{c}28.5- \\
40.4\end{array}$ & .998 & 700 & $611-800$ & .910 & - & - & - & - & - & - \\
\hline
\end{tabular}

a5\% Confidence level

${ }^{\mathrm{b}}$ Not Detected

${ }^{c} \mathrm{EC}_{50}$ calculated from Excel plots 
It is appropriate here to discuss the shape of the dose-response curves from the bioassays. The relationship illustrated by this curve depicts the change in effect, on an organism, caused by differing concentrations to a stressor (chemical) [78].
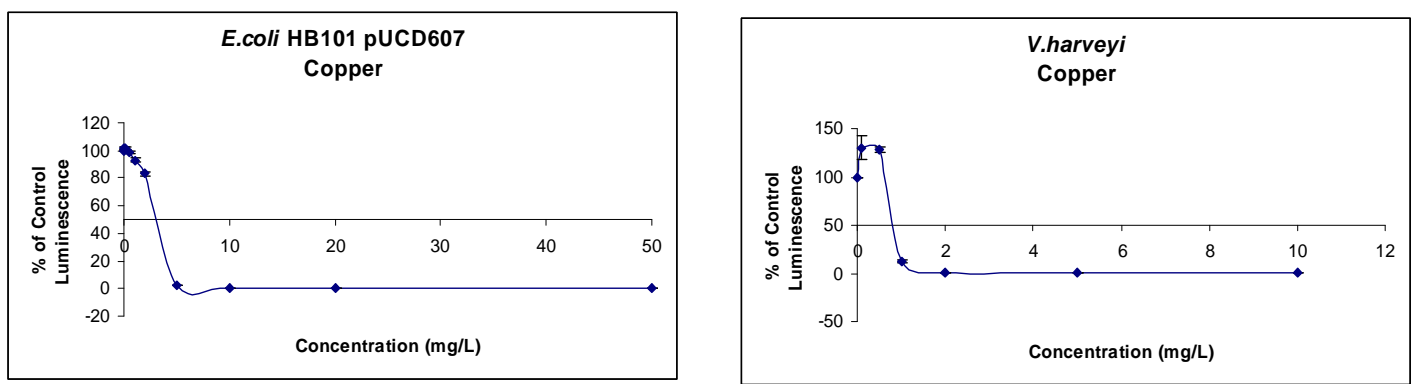

Figure 3-10: Comparison of the E. coli HB101 pUCD607 and V. harveyi biosensor dose-response curve shapes.

The slight initial increase in luminescence relative to the control in some dose-response curves is dependent on the biosensor. Error bars were calculated using standard error of the mean.

In several of the bioassays in this study, there is an initial increase in luminescence before the PTC concentration increases to a level that becomes toxic to the biosensor and luminescence decreases. It is possible that this trend is the result of the biosensors initially using some PTCs as a food source, resistance factors may be applicable or the cellular stress response may be inducing luminescence.

In Figure 3-10, this trend appears to be dependent on the biosensor. The initial water bioassay with copper shows the dose-response curve initial increase in luminescence with $V$. harveyi biosensor that it is not evident with the $E$. coli HB101 pUCD607 biosensor. Miranda and Rojas [90] investigated the 
accumulation of copper by bacteria and determined that bacterial copper accumulation could be very active in marine environments. Resistance to copper differs from resistances to other inorganic ions because copper is an essential nutrient cation at low levels but toxic at high levels [91]. This illustrates the bacterial cells need to determine at which level the cation becomes toxic and respond accordingly. Miranda and Rojas [90] results indicate that the Vibrio sp. studied appears to be very efficient in accumulating copper in the cell wall as well as internally [90]. $V$. harveyi may therefore respond to low concentrations of copper by increasing luminescence.

It is also apparent that the initial increase in luminescence is dependent on the matrix that the PTC is spiked into. Using the same biosensor (E. coli HB101 pUCD607), the PCP bioassays show the initial increase trend in spiked flour but not in the spiked talc bioassays (Figure 3-11). 

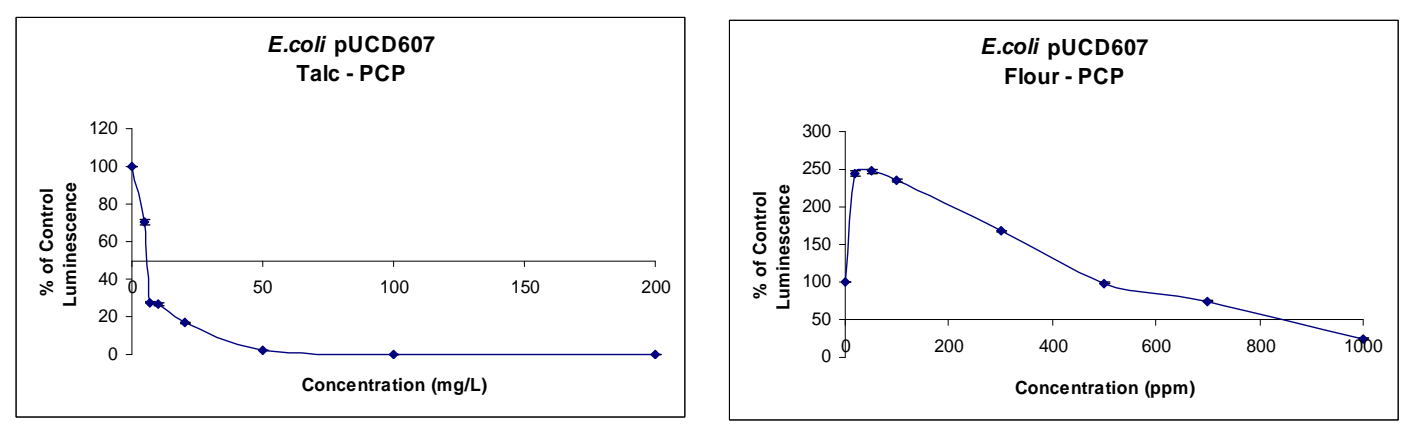

Figure 3-11: Comparison of the E. coli HB101 pUCD607 biosensor dose-response curve shapes.

The initial increase in luminescence relative to the control in some dose-response curves is dependent on the matrix into which the PTC is spiked. Talc spiked with PCP does not show the initial increase in luminescence, while flour spiked with PCP does. Error bars were calculated using standard error of the mean.

Finally, perhaps unsurprisingly, the initial increase in luminescence depends on the toxin. As can be seen in E. coli HB101 pUCD607 water bioassays (Figure 3-12) the tendency is evident in the cyanide, zinc and arsenite bioassays however not in the carbaryl, PCP and acephate bioassays. It should be noted that if the PTC spiking concentrations are too high it is likely that the initial increase trend will not be seen. 

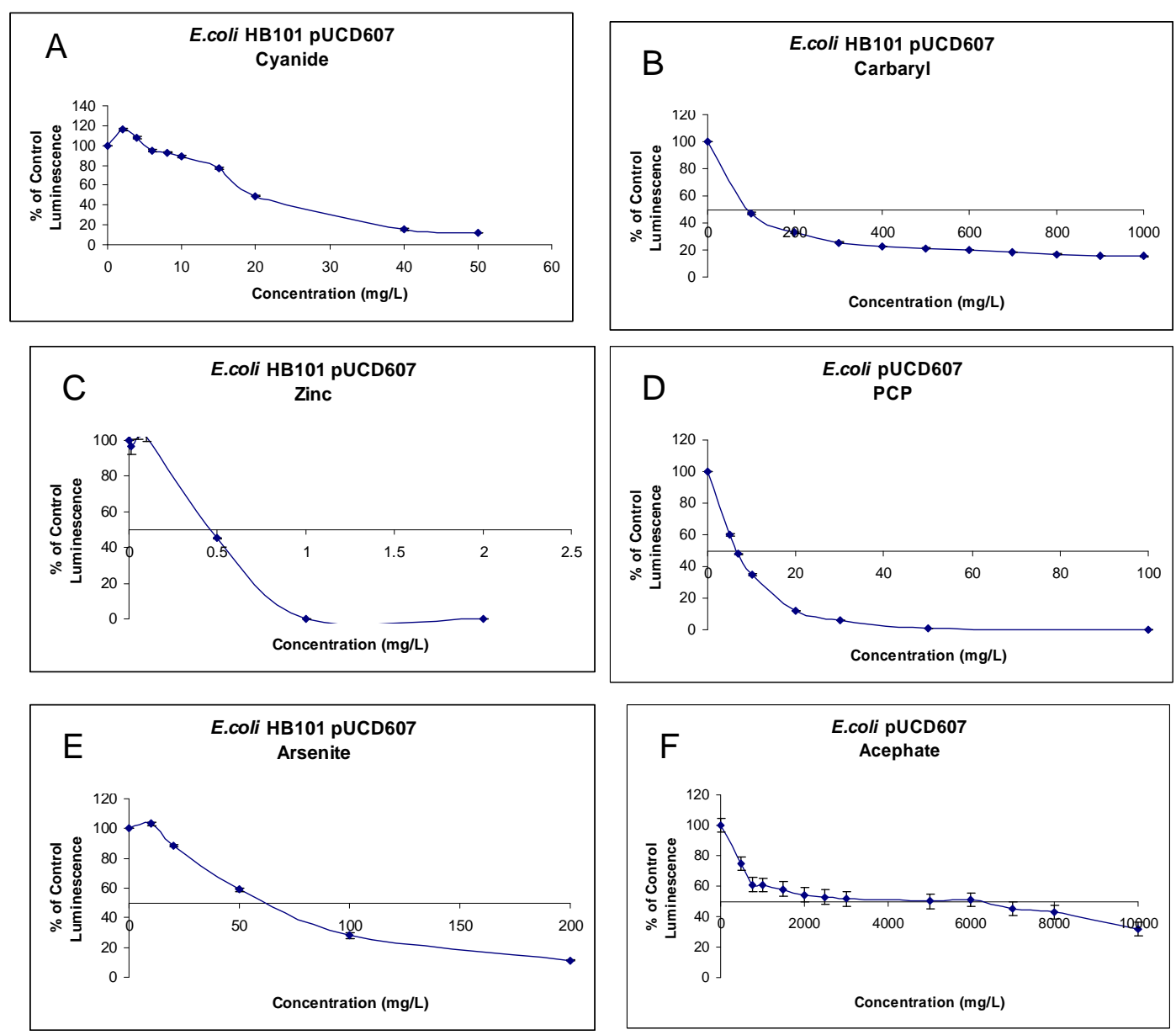

\section{Figure 3-12: Comparison of dose-response curve shapes with different PTCs used.}

The slight initial increase in luminescence relative to the control in some dose-response curves is dependent on the PTC. Graphs cyanide $(A)$, zinc $(C)$ and arsenite $(E)$ show the slight increase while graphs carbaryl $(B), P C P(D)$ and acephate $(F)$ do not. Error bars were calculated using standard error of the mean.

\subsubsection{PTC Methanol Extraction.}

As stated in Section 2.1.3.1, Redshaw et al. [16] showed that for some PTCs, biosensor sensitivity can be increased by extracting the PTC from the carrier with methanol. Preliminary control bioassays to measure the impact of methanol exposure on the biosensor were undertaken and it was determined that methanol 
only inhibits biosensor activity at levels above $2 \%$ total volume. Therefore it was considered that once methanol was removed during the extraction process any residual methanol would be well below this level. It was not thought that methanol would alter the toxicity of either carbaryl or acephate [34].

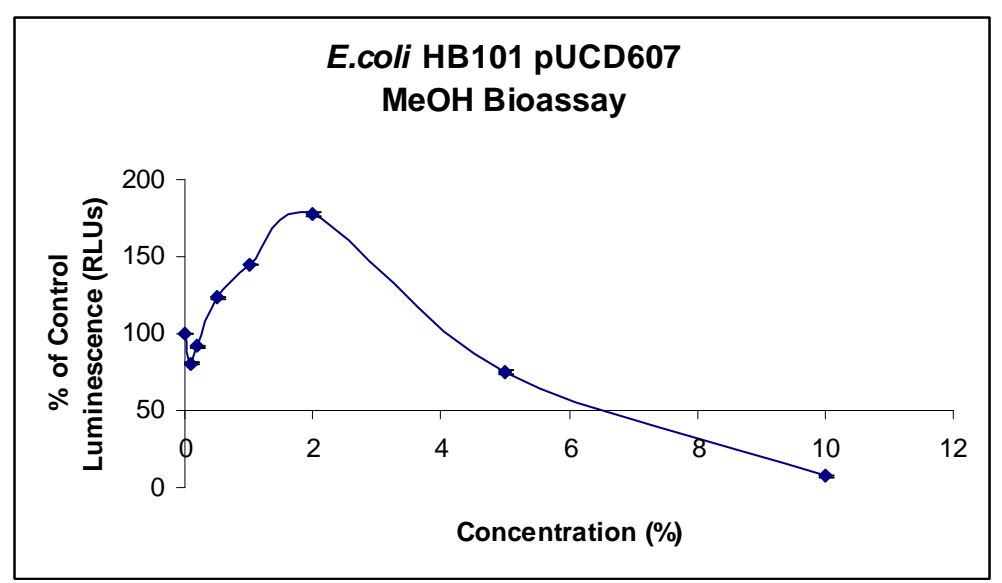

Figure 3-13: Preliminary methanol bioassay results to determined that above $2 \%$ the presence of methanol will inhibit biosensor activity potentially giving false positive results. Error bars were calculated using standard error of the mean.

The E. coli HB101 pUCD607 biosensor was unable to detect acephate spiked in either analytical talc or flour (Table 3-3). Following methanol extraction E. coli HB101 pUCD607 remained unable to detect acephate in either spiked white powder (Figure 3-14). Initial PTC spiked white powder bioassays determined that E. coli HB101 pUCD607 detected carbaryl at $219 \mathrm{mg} / \mathrm{L}$ and $400 \mathrm{mg} / \mathrm{L}$ in talc and flour respectively (Table 3-3). After methanol extraction the biosensor was unable to detect carbaryl in spiked flour but was able to detect carbaryl spiked analytical talc at a concentration of approximately $430 \mathrm{mg} / \mathrm{L}$ (Figure 3-14). 

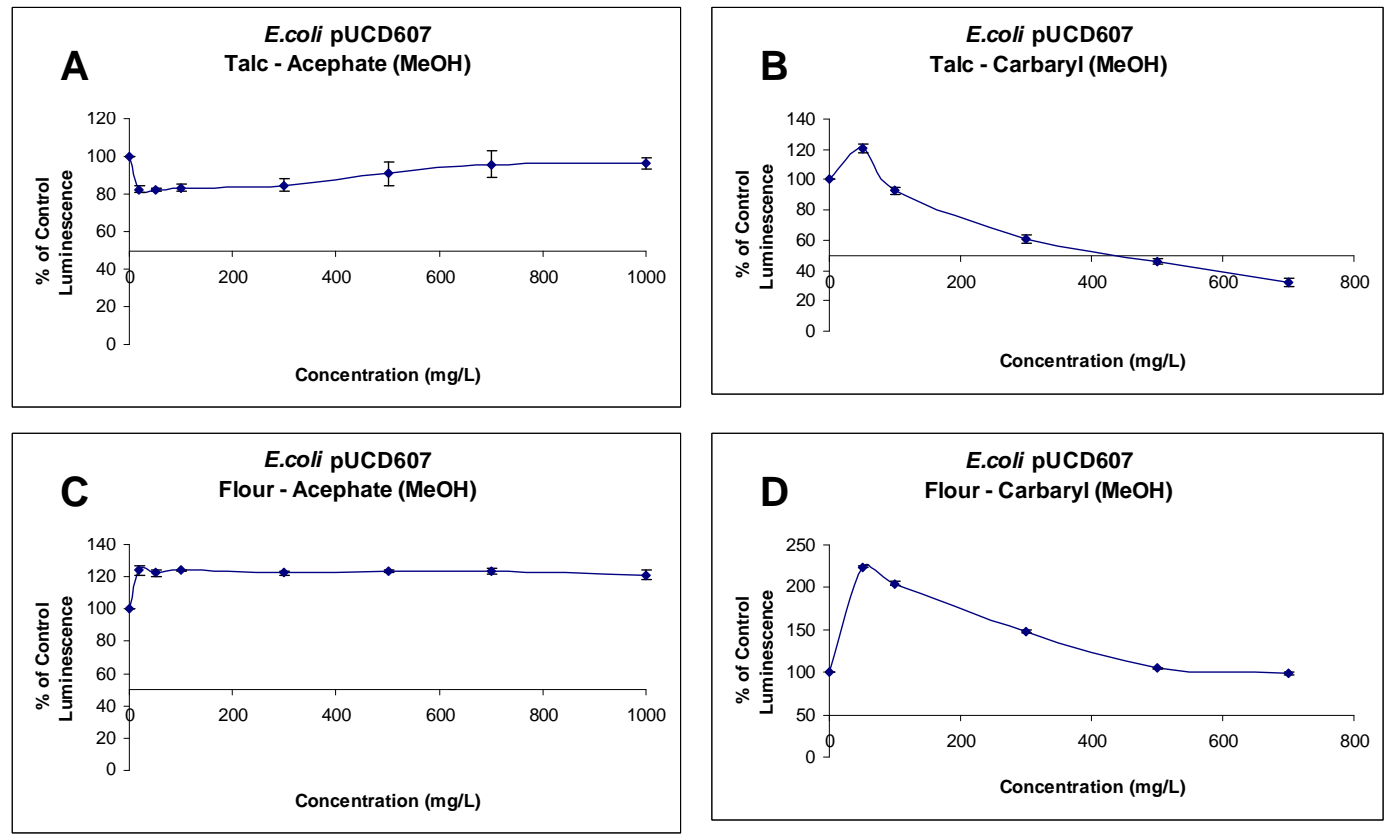

Figure 3-14: Dose-response curves showing the E. coli HB101 pUCD607 response to the organic pesticides acephate and carbaryl following methanol extraction.

(A) acephate spiked talc. (B) carbaryl spiked talc. (C) acephate spiked flour. (D) carbaryl spiked flour. Error bars were calculated using standard error of the mean.

\subsubsection{Case Study: Vomit Bioassay.}

The vomit bioassays were undertaken to determine the biosensor reaction to vomit and the toxins in conjunction with the vomit. Previous studies have been undertaken using stomach contents [16], however forensic toxicologists are frequently required to determine the presence or absence of PTCs in vomit samples. Due to the unavailability of human vomit, dog vomit was sourced.

The three vomit bioassays were carried out by spiking vomit with three different PTCs; arsenate, arsenite and carbaryl. Preliminary investigation showed the 
vomit was not in itself toxic to the E. coli HB101 pUCD607 biosensor, in fact there was an increase in luminescence (RLUs) in the unspiked dog vomit (Figure 3-15). Due to the organic nature of the vomit matrix some chemical binding of the toxin was expected, thus the vomit was spiked with relatively high concentrations of the PTCs $(200 \mathrm{mg} / \mathrm{L}, 500 \mathrm{mg} / \mathrm{L} 1000 \mathrm{mg} / \mathrm{L}$ and $2000 \mathrm{mg} / \mathrm{L})$.

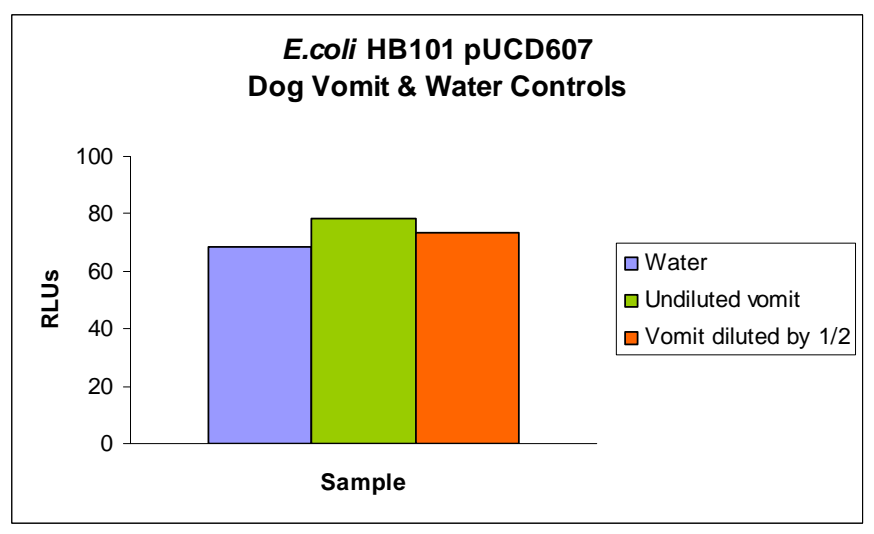

Figure 3-15: Vomit and water controls.

This control bioassay was performed using undiluted vomit and vomit diluted by half. The average results of three undiluted vomit bioassays results are shown here. The dog vomit shows no toxicity to the E. coli HB101 pUCD607 biosensor. Dilutions were undertaken to minimise any increase in bioluminescence likely to occur due to the presence of organic compounds and potential food sources in the vomit.

The response of the E. coli HB101 pUCD607 biosensor to vomit, spiked with arsenate, arsenite and carbaryl can be seen in Figure 3-16. The vomit bioassay values increased from the initial water bioassays to $90 \mathrm{mg} / \mathrm{L}, 90 \mathrm{mg} / \mathrm{L}$ and $220 \mathrm{mg} / \mathrm{L}$ for arsenate, arsenite and carbaryl respectively as shown in Table 3-4. This data suggests that a lower concentration of PTCs for spiking may have been 
more appropriate, particularly with arsenate and arsenite. Because there are no data points above the $50 \%$ luminescence level it is not possible to calculate $\mathrm{EC}_{50}$ values.

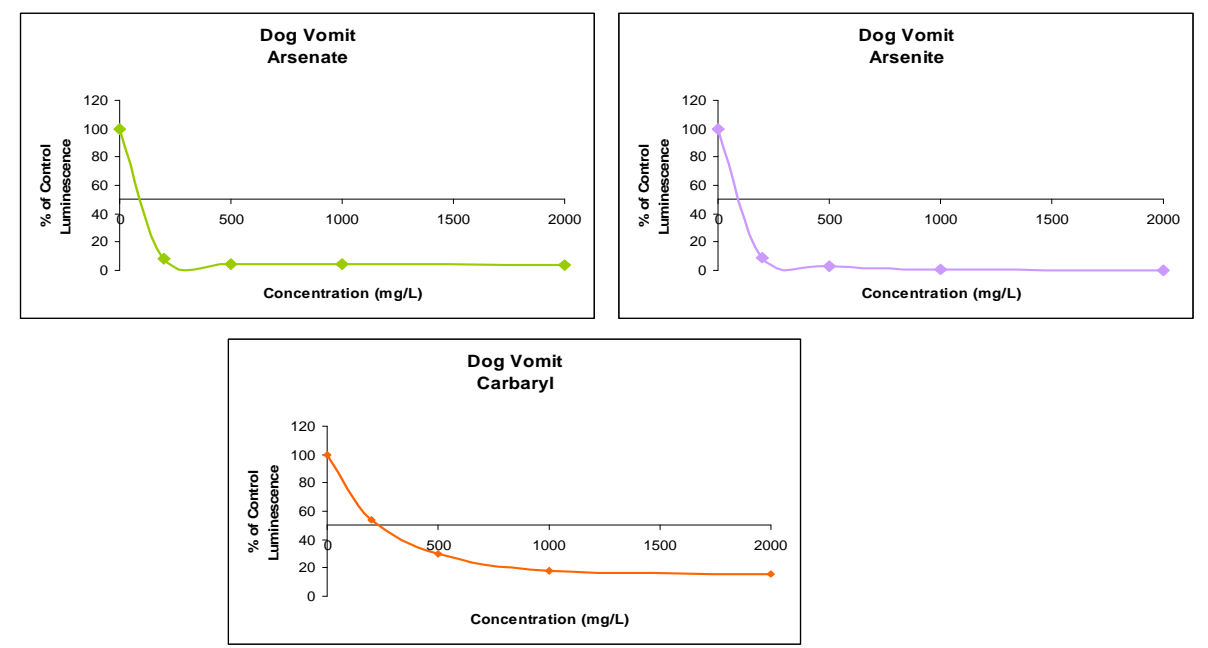

Figure 3-16: Spiked dog vomit bioassays using three PTCs; (A) arsenate, (B) arsenite and (C) carbaryl.

$E C_{50}$ values are not able to be calculated because of the lack of data points above the $50 \%$ bioluminescence level suggesting spiking with lower concentrations of PTCs would be more appropriate. Three replicates were performed for each treatment and bioluminescence was measured in RLUs.

Table 3-4 illustrates the comparisons between $\mathrm{EC}_{50}$ values and subsequent PTC toxicity, using different matrices. With the exception of carbaryl, because there are no data points above $50 \%$ luminescence level it is difficult to make reliable comparisons between matrices and their effects on toxicity and biosensor sensitivity. 
Table 3-4: E. coli HB101 pUCD607 biosensor sensitivity to three PTCs in different spiked matrices.

$E C_{50}$ values demonstrate the trend that with increasing organic matter there is decreased biosensor sensitivity.

\begin{tabular}{|c|c|c|c|c|}
\hline \multirow{2}{*}{ PTC } & \multicolumn{4}{|c|}{ EC $_{50}$ values } \\
& Water & Dog Vomit & Talc & Flour \\
\hline Arsenate & 61.7 & 90 & 210 & 250 \\
Arsenite & 2.55 & 90 & 25 & 2300 \\
Carbaryl & 100 & 220 & 219 & 400 \\
\hline
\end{tabular}

\subsection{Solid-Phase Extraction Bioluminescence Bioassays.}

The development of an additional protocol enabling the investigation of a PTC in solid complex matrices such as soils, foodstuffs and white powders will further reduce the need for the current protracted sample preparation and provide relevance to soil toxicity and forensic chemical analysis applications. Although invaluable, traditional methods can be time consuming and less sensitive to those PTCs with limited water solubility, for example pentachlorophenol (PCP). In these preliminary bioassays the efficiency of a solid-phase extraction method of sample preparation was investigated, using two soils and two white powders. Solid-phase extraction could offer a more rapid and sensitive alternative to extracting PTCs using classical centrifugation or filtration sample preparation methods. In order to compare the novel solid-phase bioluminescence bioassay sample preparation method, both filtration and centrifugation extraction methods were used with a sub-sample of the same spiked samples. The bacterial biosensor E. coli HB101 pUCD607 was used in this investigation. 

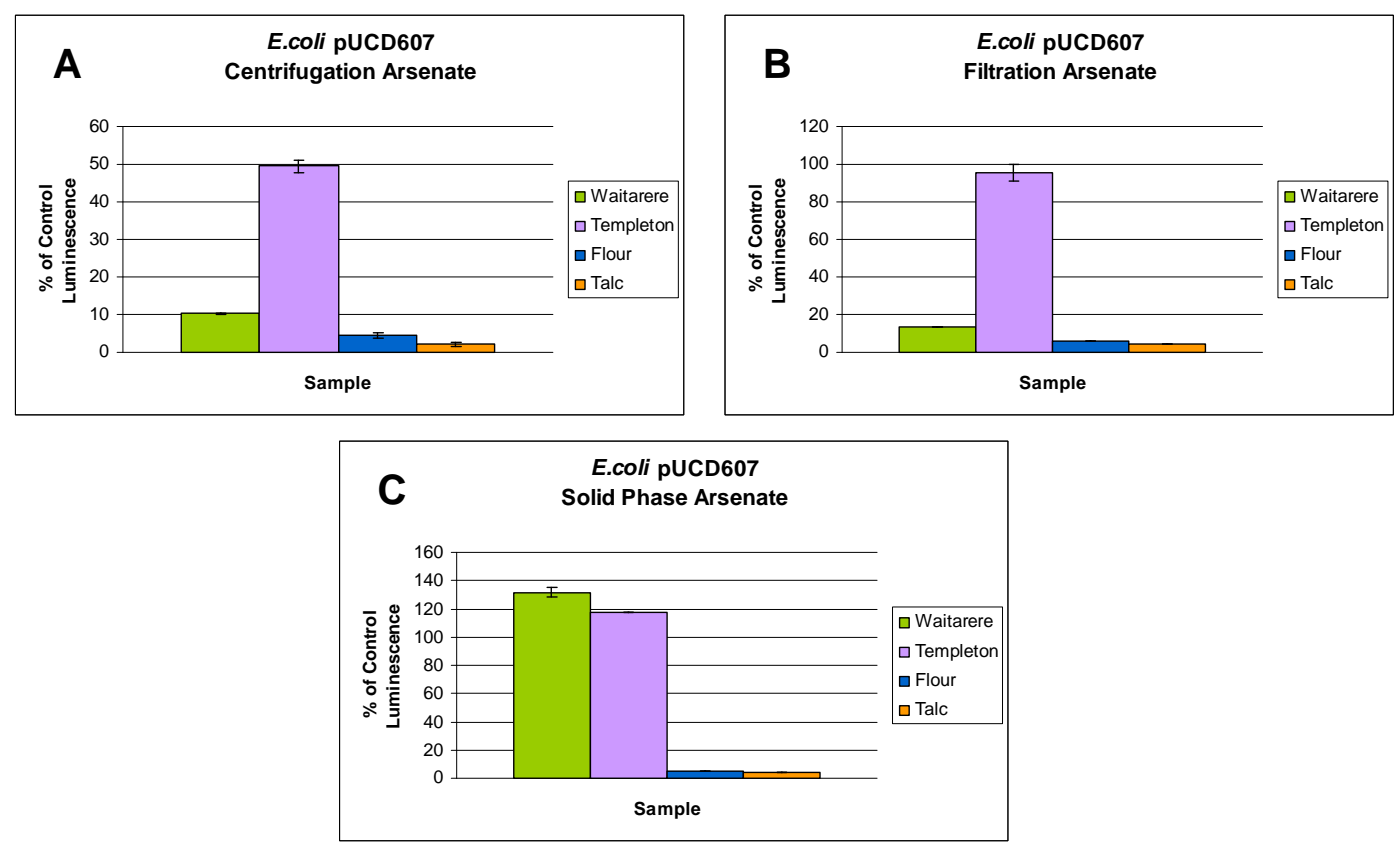

Figure 3-17: E. coli HB101 pUCD607 arsenate bioassays.

Comparison of sample preparation methods (A) Centrifugation, (B) Filtration and (C) Solid-Phase Bioluminescence Bioassay. Error bars were calculated using standard error of the mean.

The biosensor detected $1000 \mathrm{mg} / \mathrm{L}$ of arsenate using centrifugation and filtration sample preparation methods in Waitarere soil, flour and talc (Figure 3-17). An almost $50 \%$ reduction in bioluminescence was seen for Templeton spiked soils using centrifugation as a sample preparation method and virtually no decrease in luminescence when using filtration or solid-phase. Solid-phase sample preparation of arsenate spiked soils showed an increase in luminescence, although this method saw a significant decrease in luminescence with the spiked white powders. 

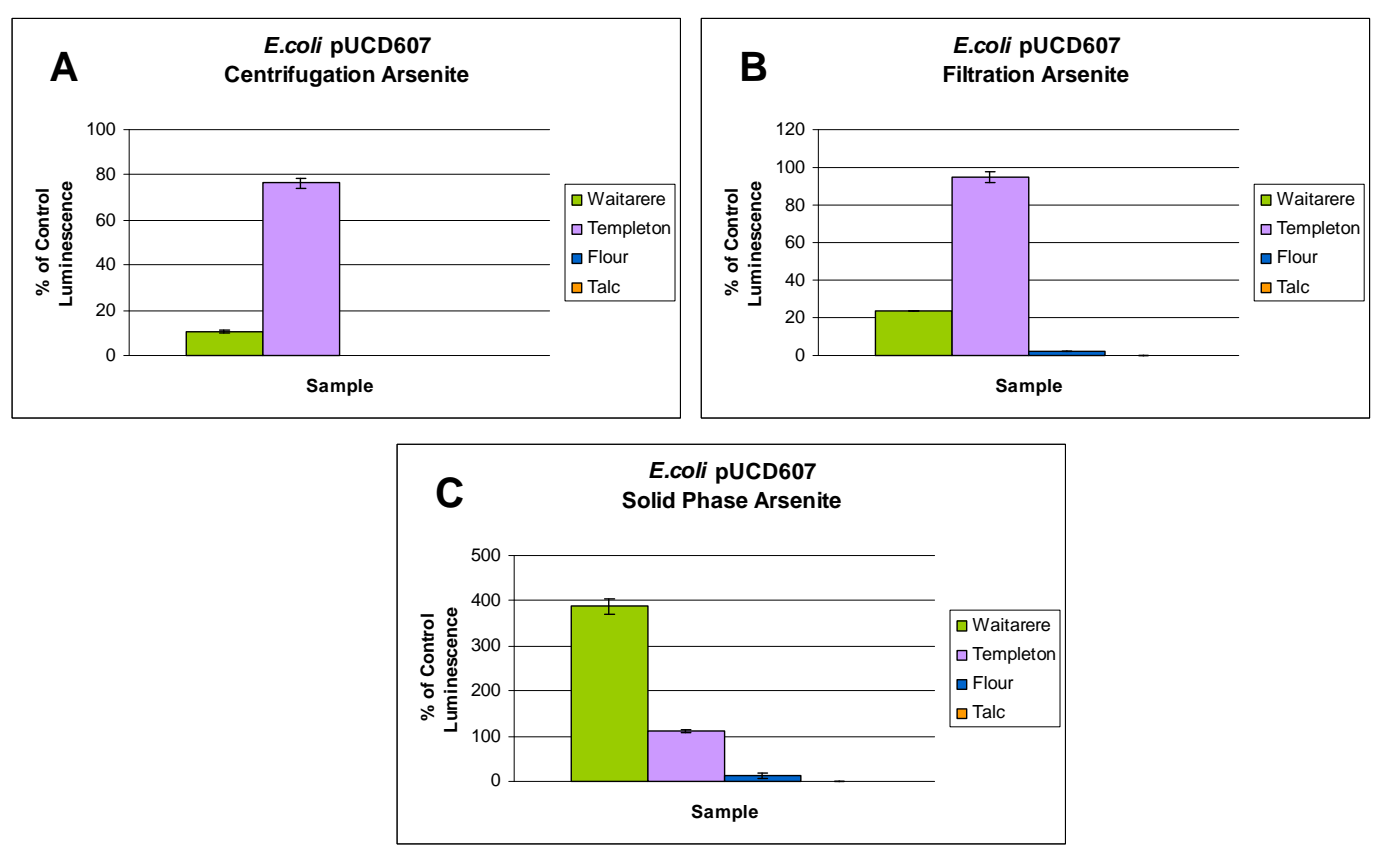

Figure 3-18: E. coli HB101 pUCD607 bioassays with arsenite.

Comparison of sample preparation methods (A) Centrifugation, (B) Filtration and (C) Solid-Phase Bioluminescence Bioassays. Error bars were calculated using standard error of the mean.

Arsenite results (Figure 3-18) were similar to arsenate but more pronounced particularly with the spiked Waitarere soil sample. The biosensor clearly indicated the presence of a toxin in both white powders with all preparation methods. Spiked Templeton soil bioassays indicate the biosensor was not sensitive to the toxin in any of the sample preparation methods used in this soil. The biosensor indicated toxicity in both centrifugation and filtration sample preparation methods in arsenite spiked Waitarere soil, but not in the solid-phase extraction method.

The bioassays of soils and white powders spiked with cyanide Figure 3-19 suggest that biosensor sensitivity appears to be dependent on the sample 
preparation method. Filtration showed little or no toxicity in either spiked soils or white powders. However both centrifugation and solid-phase methods exhibited significant toxicity in spiked white powders but minimal or no toxicity in either soil types (Figure 3-19).

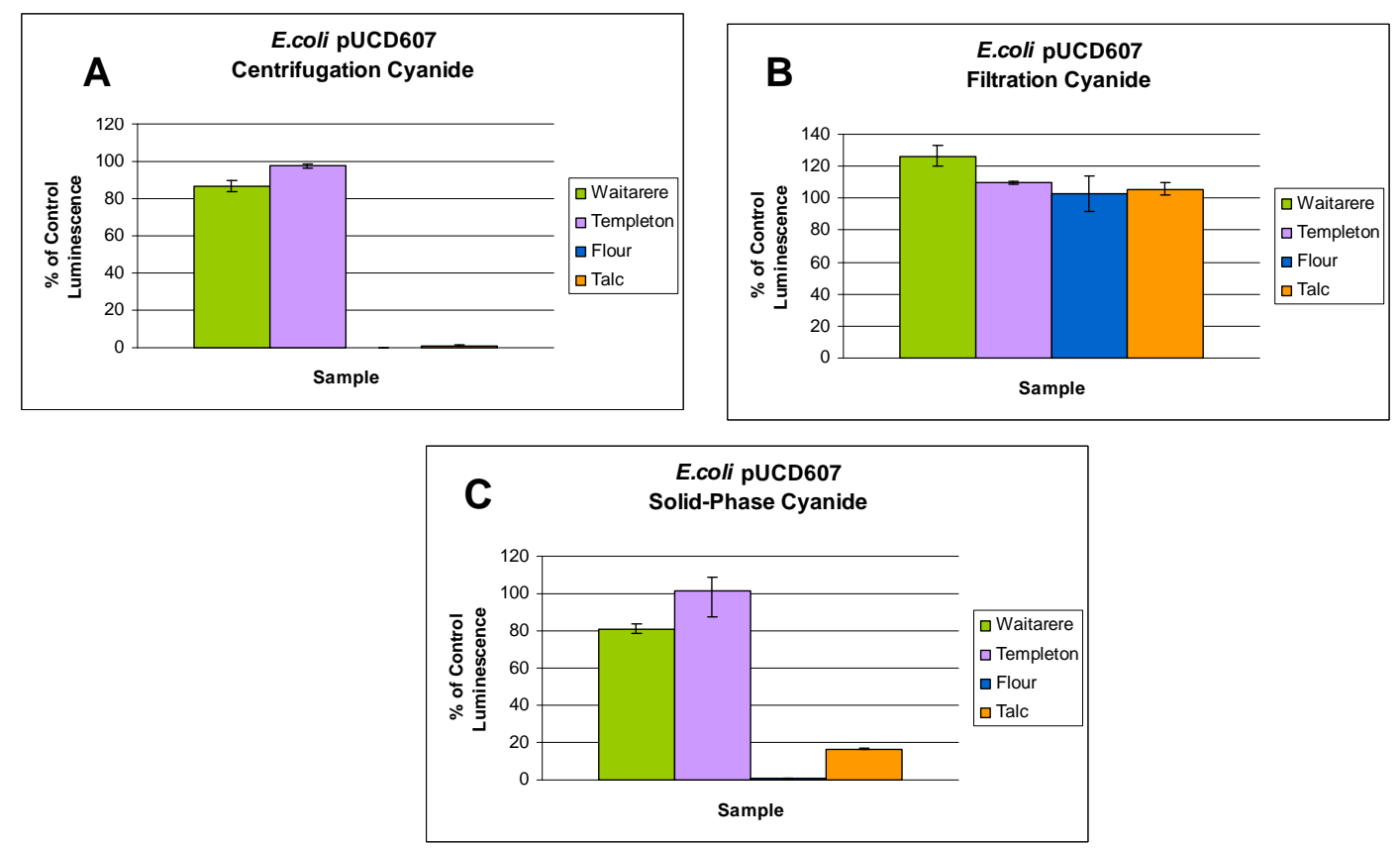

Figure 3-19: E. coli HB101 pUCD607 bioassays with cyanide.

Comparison of sample preparation methods $(A)$ Centrifugation, (B) Filtration and $(C)$ Solid-Phase Bioluminescence Bioassays. Error bars were calculated using standard error of the mean.

Copper bioassays show similar results to those of cyanide. Both centrifugation and solid-phase sample preparation methods show the biosensors sensitivity to copper in white powders. The filtration method demonstrated sensitivity to copper spiked talc but not spiked flour. Regardless of which method was used for the soil the biosensor indicated no sensitivity to copper (Figure 3-20). 

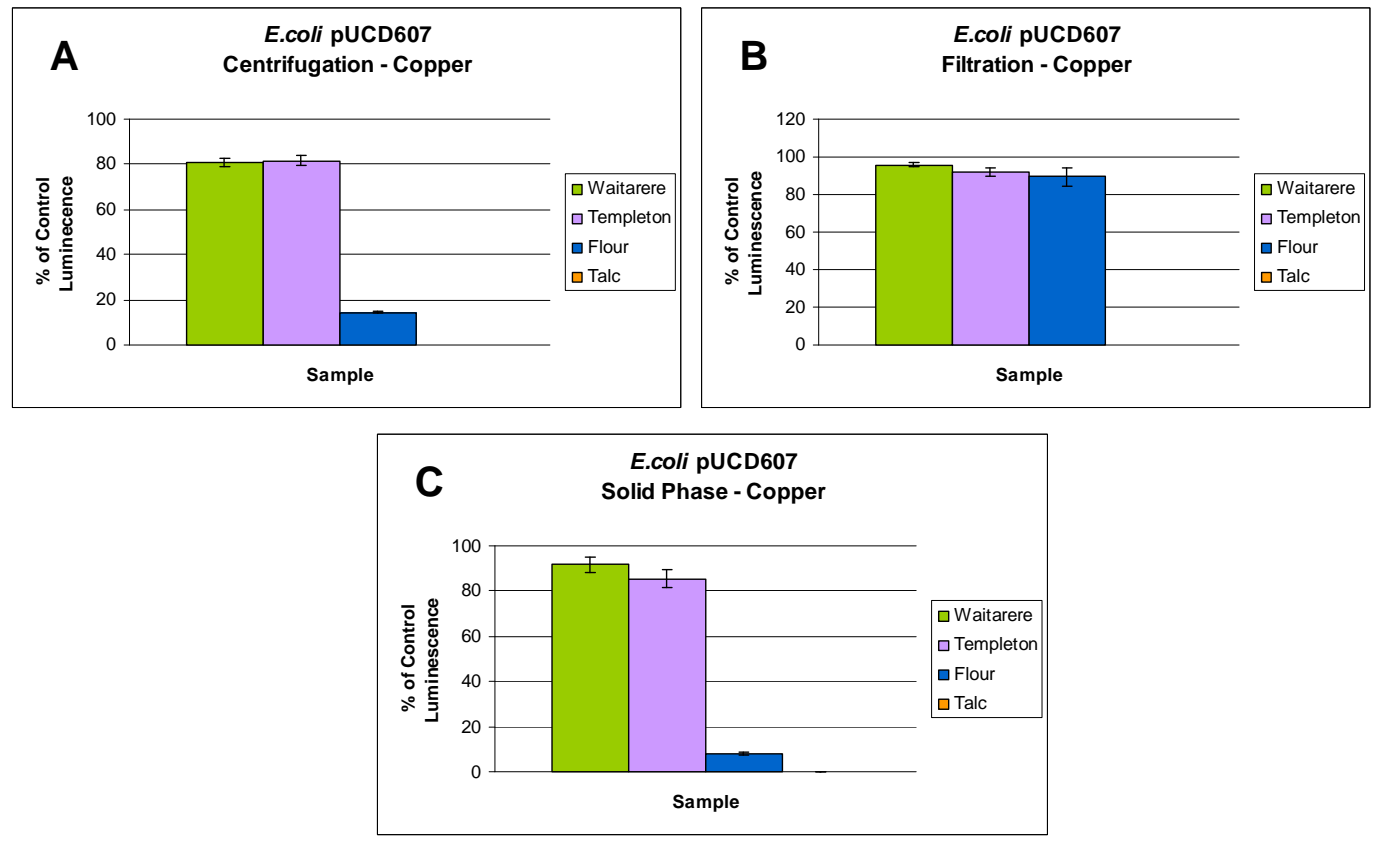

Figure 3-20: E. coli HB101 pUCD607 bioassays with copper.

Comparisons of sample preparation methods $(A)$ Centrifugation, (B) Filtration and $(C)$ Solid-Phase Bioluminescence Bioassays. Error bars were calculated using standard error of the mean.

The biosensor was most sensitive to PCP in the white powders as opposed to the spiked soils. The sample preparation method appeared to be of minimal importance with regard to the white powders. The PCP spiked Waitarere soil gave the same result as Templeton spiked soil, regardless of the sample preparation method used. The spiked Templeton soil was dependant on sample preparation methods. When either the centrifugation or solid-phase sample preparation method was used biosensor indicated the presence of the toxin. When filtration was used as a sample preparation method no biosensor sensitivity was indicated (Figure 3-21). 

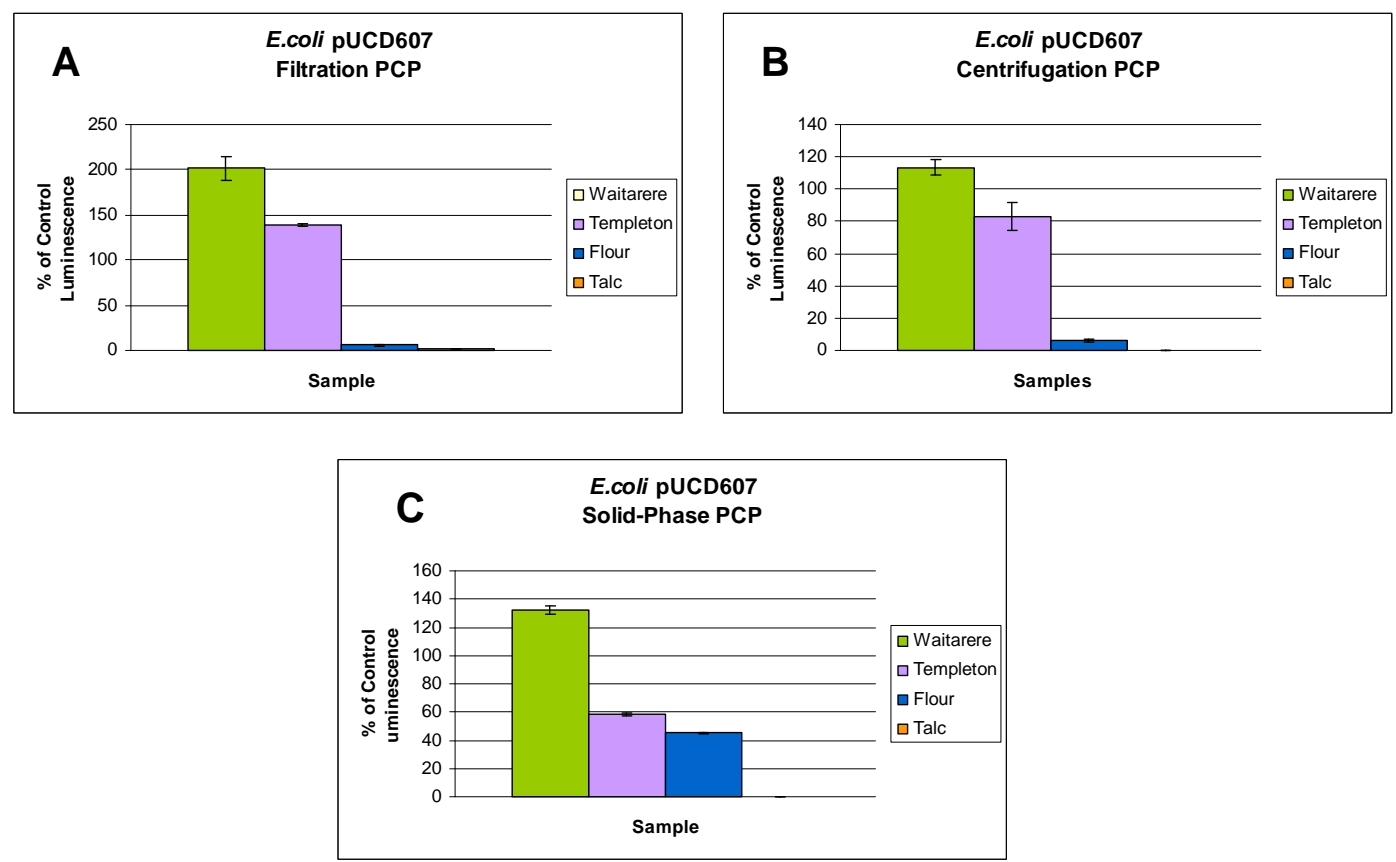

Figure 3-21: E. coli HB101 pUCD607 bioassays with PCP.

Comparisons of sample preparation methods $(A)$ Centrifugation (B) Filtration and $(C)$ Solid-Phase Bioluminescence Bioassays. Error bars were calculated using standard error of the mean.

\subsection{Development of Specific Bacterial Biosensors.}

The Tn5 derived mini-transposon integrates into the chromosome of the host bacteria minimising the concern of genetic instability [92] and Vollmer et al. [93], reported some loss of sensitivity when using plasmids instead of chromosomal inserts [93]. Plasmid deoxy-ribose nucleic acid (DNA) containing a dehalogenase promoter regulatory region (dehRl) was amplified by PCR using primers designed to include restriction enzyme sites. The resulting 1080-responsive bacterial promoter sequence was digested by the restriction enzyme and ligated into a promoter-less mini Tn-5 luxCDABE luciferase plasmid. Heat shock transformation of the plasmid into E. coli DH5 $2 \lambda$ pir cells enabled efficient 
replication of the constructs and determination of the constructed plasmids ability to detect 1080. Restriction enzyme digestion, PCR amplification of promoter inserts and bioluminescence screening was carried out for this purpose. The same rationale was applied for the construction of a positive control plasmid constructs using a strong, well characterised inducible lac promoter.

As discussed in Section 1.3.2, the dehalogenase gene, designated dehl, preferentially degrades fluorine substrates and its regulatory region is termed dehRI [68]. At the onset of this research project, only the pAWT6 plasmid (containing dehl) was able to be sourced. This dehl gene and its regulatory sequence, dehRI, originated from Pseudomonas putida strain PP3 [86]. No published data was available to confirm this specific dehalogenase genes regulation as being either constitutive or inducible. Expression of dehl has been shown to be dependent on the presence of a functional $\sigma^{54}$ transcription factor [94]. Figure 3-24 indicates the presence of the $\sigma^{54}$ dependant activator DehR/ in the amplified fragment sequenced. Most $\sigma$-factors belong to the $\sigma^{70}$ family involved in expression of the majority of house-keeping genes during exponential growth [95]. In comparison $\sigma^{54}$ are present in a wide range of bacteria implying it represents a response mechanism, rather than a house-keeping mechanism, that has been conserved in evolution [95]. The functions carried out by the multiple products of $\sigma^{54}$ dependent transcriptions have no obvious theme nor are they necessary for growth [96]. These functions include the utilisation of carbon 
and nitrogen sources [97], energy metabolism [98], RNA modification [99], flagellation [100], sporulation [101] and electro transport [102]. These divergent functions suggest the dehRI promoter is likely to be inducible. The primary involvement of dehalogenases in dehalogenation [70], along with the fact that they are usually regulated [69], suggests that this dehalogenase promoter may be inducible indicating its potential for use as a promoter in a biosensor construction.

The convenience of using luxCDABE as a reporter construct, as discussed in Section 1.3.1.1, lies with its ability to luminesce without the need for the addition of secondary substrates or the need for an external light source. It was for this reason that luxCDABE was chosen as the reporter construct for this study. The advantages of using the Tn5 derived mini-transposon combined with the advantages of using the lux operon as a reporter construct (as stated in Chapter 2) dictated the selection of plasmids sourced for the construction of a 1080specific bacterial biosensor and a positive control (Table 2-4). Figure 3-22 shows the approximate $14.2 \mathrm{~kb}$ band in lane 3 corresponding to the size of the pUT mini-Tn5 luxCDABE plasmid. 


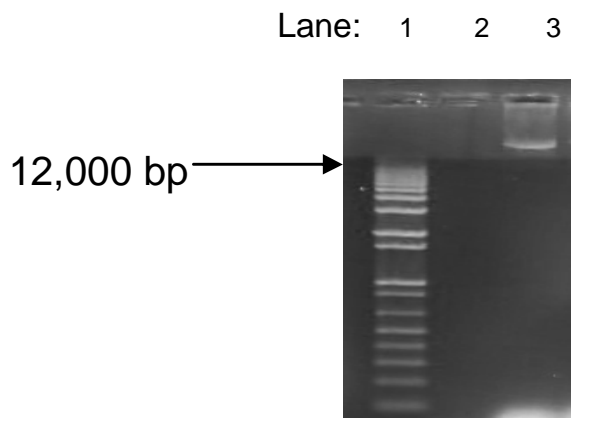

$14.2 \mathrm{~kb}$

Figure 3-22: 1\% agarose gel electrophoresis showing a $14.2 \mathrm{~kb}$ band corresponding to pUT mini-Tn5 IuxCDABE plasmid.

Invitrogen $1 \mathrm{~kb}$ plus molecular marker is shown in lane 1.

\subsubsection{Construction of 1080-Iux.}

Figure 3-23 illustrates, in lanes 8 and 9 , the $550 \mathrm{bp}$ region of the dehRI promoter

PCR amplified from pAWT6 plasmid. The promoter region was confirmed using NCBIs Basic Local Alignment Search Tool (BLAST) (Figure 3-24).

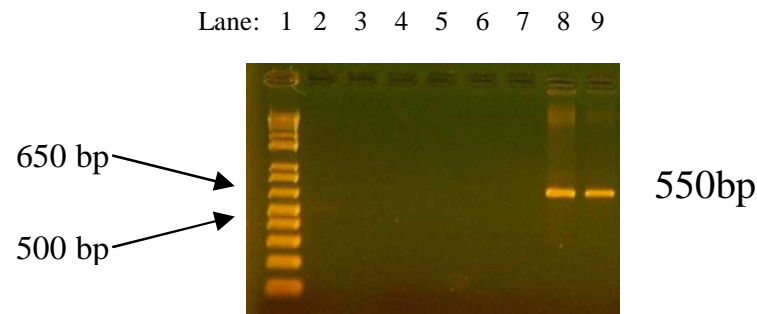

Figure 3-23: 1\% agarose gel showing the 550 bp PCR amplified region of dehRI promoter. Invitrogen 100bp marker can be seen in lane 1. 
The confirmed dehalogenase promoter region was then ligated into the dephosphorylated pUT mini-Tn5 luxCDABE plasmid and heat shock transformed into E. coli $\mathrm{DH} 5 \alpha \lambda$ pir cells.

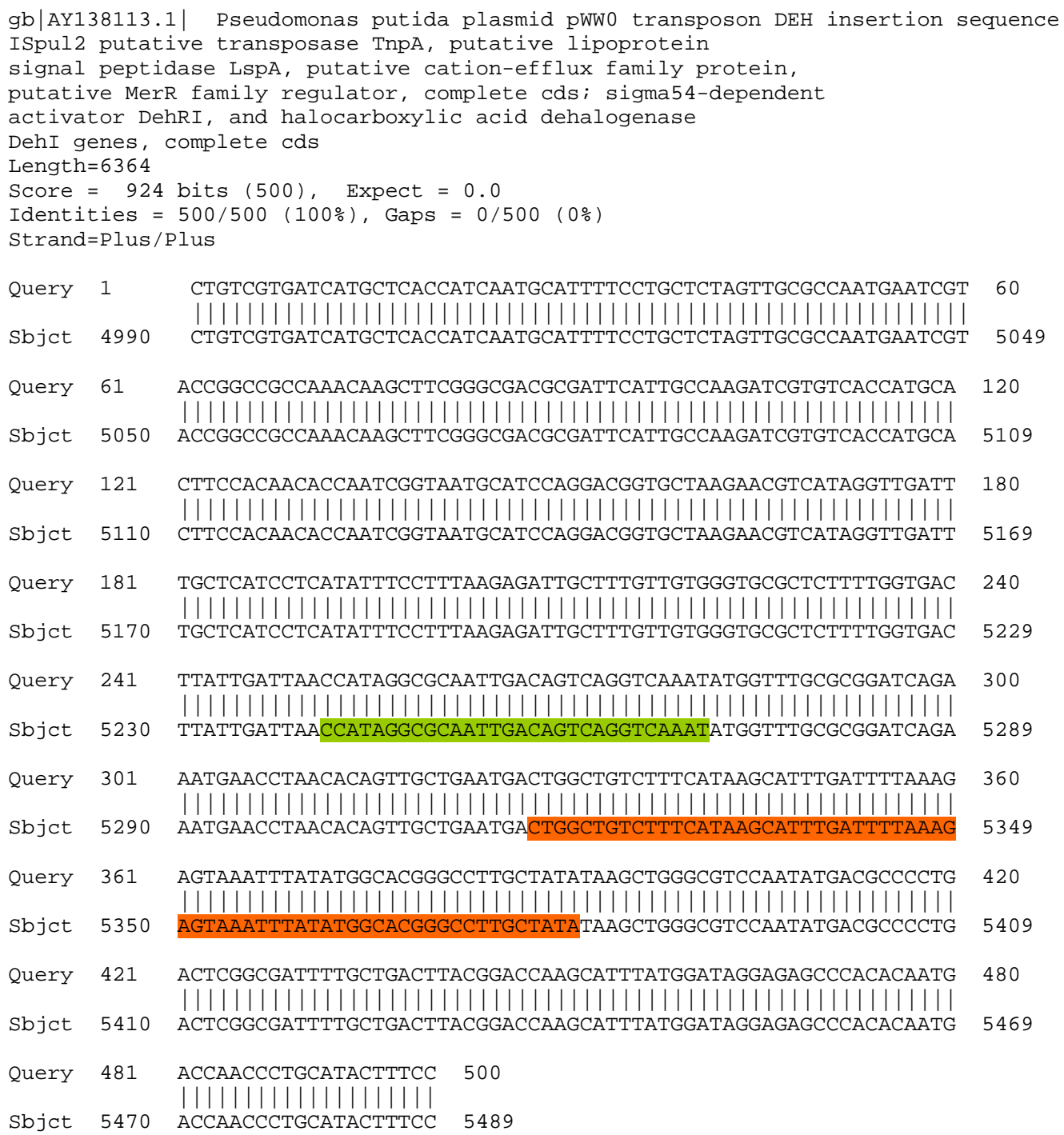

Figure 3-24: Fragment analysis using BLAST for the PCR amplified dehRI promoter region. The green highlighted region indicates dehRI. The orange highlighted region indicates the $\sigma^{54}$ transcription factor. 


\subsubsection{Screening for Positive Insert Clones.}

Thorough screening for the presence of the promoter, orientation of the promoter and bioluminescence in the presence of 1080 was undertaken on a total 144 transformants selected on many separate occasions before the strategy was abandoned despite continued persistence. An Xbal restriction enzyme digest confirmed the presence of the promoter sequence in the pUT mini-Tn 5 luxCDABE plasmid. Figure 3-25 shows in (A) the ability to PCR amplify the 1080 promoter insert fragment from the ligated plasmid using the original PCR primers and in Figure 3-25 (B) the Xbal digests of 1080-lux construct. The Xbal digest releases the promoter insert sequence indicating the promoter had been successfully ligated into the plasmid construct. Lanes $1,3,5,7,9,11$ demonstrate Xbal digestions and Lanes 2, 4, 6, 8, 10 and 12 are the uncut controls.

A

B

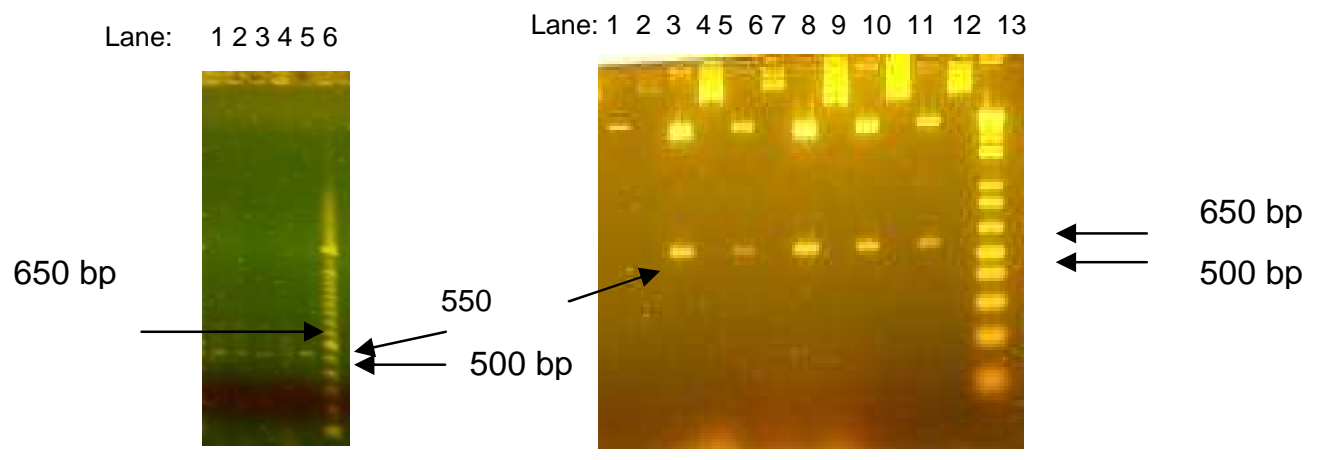

Figure 3-25: The successful ligation of the 550bp dehRI promoter segment into the mini-Tn5 luxCDABE.

(A) PCR amplification the 1080 promoter fragment from the plasmid construct (B) Xbal digestion of 1080-lux construct 
The gel also indicates that colony 1 (Lane 1 cut and Lane 2 uncut) does not have the dehRI promoter region digested from the plasmid.

It is essential that the promoter insert is orientated correctly to activate the luxCDABE cassette and induce luminescence in the presence of 1080 . Restriction enzyme maps constructed in this study for pUT mini-Tn5 luxCDABE and documented cut sites were inconsistent; therefore PCR amplification of a region of the construct allowing determination of the insert orientation was carried out. Results of 1080-lux orientation PCR screening (Figure 3-26) are typical of the 144 colonies with the promoter insert after Xbal digestion. A 300 bp fragment indicated the promoter had ligated in the correct orientation and a $400 \mathrm{bp}$ fragment indicated that the promoter was in the incorrect orientation.

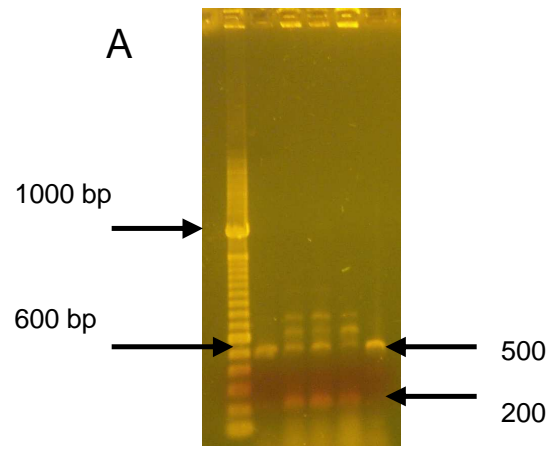

B

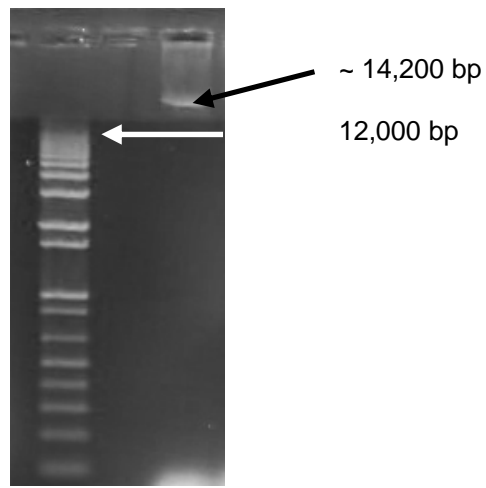

Figure 3-26: 1080-Iux orientation screening.

(A) PCR amplification of transformant 1080-lux DNA gave band sizes of 200 bp and 500 bp. 100 bp DNA molecular marker is in lane 1. (B) Purified pUC 607 luxCDABE plasmid for comparison purposes indicating the bands in $(A)$ are not template DNA. 
The fragments amplified appeared closer to 200 bp and 500 bp (than the expected $300 \mathrm{bp}$ and $400 \mathrm{bp}$ expected sizes). These fragments were sequenced to determine if they did contain the promoter. The 200 bp band (Figure 3-27) does show some sequence similarity to the Pseudomonas putida plasmid pWW0 transposon DEHRI sequence suggesting the promoter insert has ligated into the vector. Neither the site of insertion nor orientation of the ligated promoter fragment was able to be determined. Because PCR amplification provided inconclusive evidence regarding the orientation of the promoter sequence, bioluminescence screening was carried out. Table 3-5 shows results of bioluminescence screening in 12 1080-lux colonies. In all cases luminescence was at background levels. The sequenced 500 bp band indicates no sequence similarity to either known sequences of the pUT mini-Tn5 luxCDABE vector or the dehRI promoter insert (Figure 3-28). 


\section{Sequences producing significant alignments:}

\begin{tabular}{clcccc} 
Accession & \multicolumn{1}{c}{ Description } & $\begin{array}{c}\text { Max } \\
\text { score }\end{array}$ & $\begin{array}{c}\text { Total } \\
\text { score }\end{array}$ & $\begin{array}{c}\text { Query } \\
\text { coverage value ident }\end{array}$ & $\begin{array}{c}\text { Max } \\
\text { Pseudomonas putida plasmid pWW0 transposon }\end{array}$ \\
$\begin{array}{l}\text { DEH insertion sequence ISpul2 putative } \\
\text { transposase TnpA, putative lipoprotein signal } \\
\text { peptidase LspA, putative cation-efflux family } \\
\text { protein, putative MerR family regulator, complete } \\
\text { cds; sigma54-dependent activator DehRI, and } \\
\text { halocarboxylic acid dehalogenase DehI genes, } \\
\text { complete cds }\end{array}$ & 204 & 204 & $72 \%$ & $1 \mathrm{e}-4996 \%$ & $\mathbf{G}$
\end{tabular}

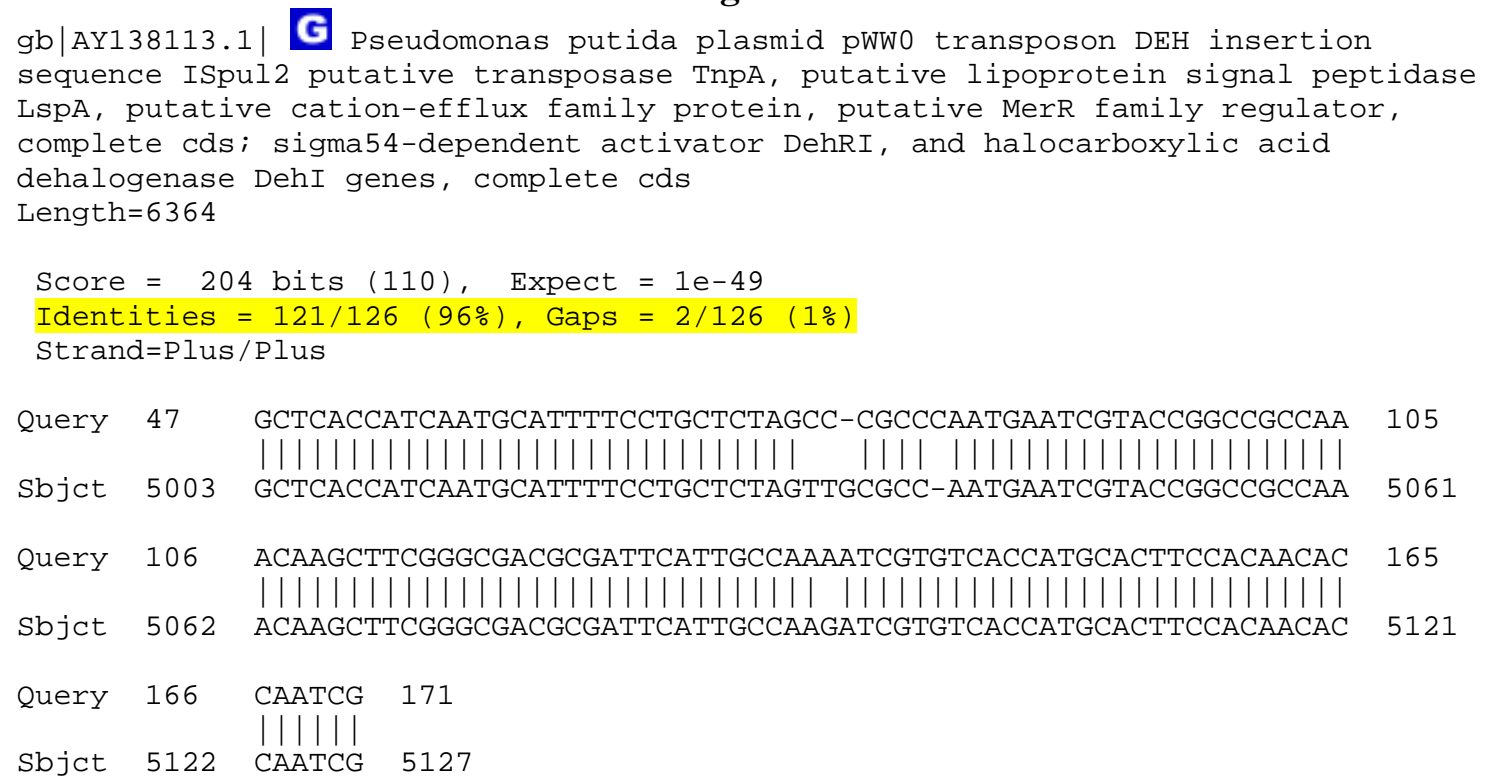

Figure 3-27: The 200 bp band shows some sequence similarity to the dehaolgenase promoter sequence. 


\begin{tabular}{|c|c|c|c|c|c|c|c|}
\hline \multicolumn{8}{|c|}{ Sequences producing significant alignments: } \\
\hline Accession & Description & $\begin{array}{l}\text { Max } \\
\text { score }\end{array}$ & $\begin{array}{l}\text { Total } \\
\text { score }\end{array}$ & $\begin{array}{l}\text { Query } \\
\text { coverage }\end{array}$ & & $\begin{array}{l}\mathbf{E} \\
\text { alue }\end{array}$ & $\begin{array}{l}\text { Max } \\
\text { ident }\end{array}$ \\
\hline $\mathrm{CP} 000800.1$ & $\begin{array}{l}\text { ischerichia coli E24377A, } \\
\text { omplete genome }\end{array}$ & 654 & 654 & $76 \%$ & $0 .($ & & $95 \%$ \\
\hline \multicolumn{2}{|c|}{$\begin{array}{l}\text { AP009048.1 Escherichia coli W3110 } \\
\text { DNA, complete genome }\end{array}$} & 654 & 654 & $76 \%$ & $0 .($ & & $95 \%$ \\
\hline U00096.2 & $\begin{array}{l}\text { ischerichia coli K12 } \\
\text { AG1655, complete genome }\end{array}$ & 654 & 654 & $76 \%$ & 0.0 & & $95 \%$ \\
\hline \multicolumn{8}{|c|}{$\begin{array}{l}\text { gb } \mid \text { CP000800.1| D Escherichia coli E24377A, complete genome } \\
\text { Length }=4979619\end{array}$} \\
\hline \multicolumn{8}{|c|}{$\begin{array}{l}\text { Features in this part of subject sequence: } \\
\text { penicillin-binding protein } 7\end{array}$} \\
\hline \multicolumn{8}{|c|}{$\begin{array}{l}\text { Score }=654 \text { bits }(354), \quad \text { Expect }=0.0 \\
\text { Identities }=393 / 411 \quad(95 \%), \text { Gaps }=5 / 411 \quad(1 \%) \\
\text { Strand=Plus/Plus }\end{array}$} \\
\hline Query 124 & \multicolumn{7}{|c|}{ AATAGACCCCTTTC-TCTCCGGCGTCTGGCTGA-AT-CTGTTTTAATTTTTCATCCAGCG 180} \\
\hline Sbjet 2406985 & \multicolumn{5}{|c|}{5 AATAGACCCCTTTCATCTCCGGCGTCTGGCTGATATCCACTTTTAGTTTTCATCCAGCG } & \multicolumn{2}{|c|}{2407044} \\
\hline Query 181 & \multirow{2}{*}{\multicolumn{5}{|c|}{ 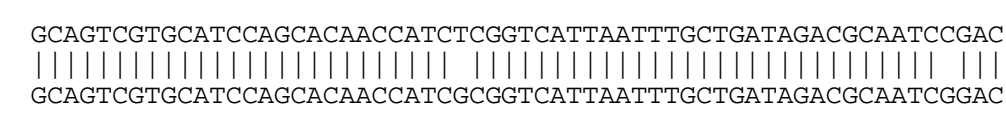 }} & \multicolumn{2}{|l|}{240} \\
\hline 2407045 & & & & & & \multicolumn{2}{|c|}{2407104} \\
\hline Query & \multirow{2}{*}{\multicolumn{5}{|c|}{ 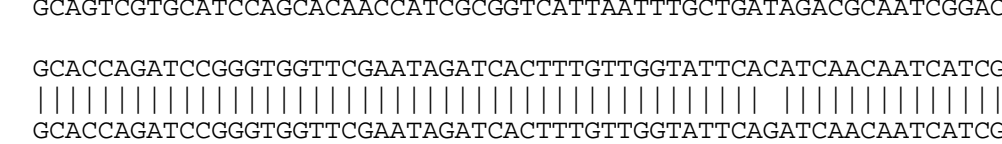 }} & 300 & \\
\hline Sbjet 2407105 & & & & & & \multicolumn{2}{|c|}{2407164} \\
\hline Query 301 & \multirow{2}{*}{\multicolumn{5}{|c|}{ 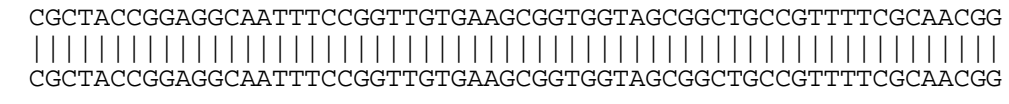 }} & \multicolumn{2}{|l|}{360} \\
\hline 2407165 & & & & & & \multicolumn{2}{|c|}{2407224} \\
\hline \multirow{2}{*}{$\begin{array}{ll}\text { Query } & 361 \\
\text { Sbjct } & 2407225\end{array}$} & \multirow{2}{*}{\multicolumn{5}{|c|}{ 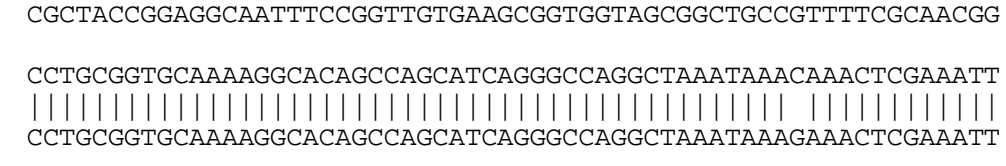 }} & 420 & \\
\hline & & & & & & 2407 & 7284 \\
\hline Query 421 & \multirow{2}{*}{\multicolumn{5}{|c|}{ 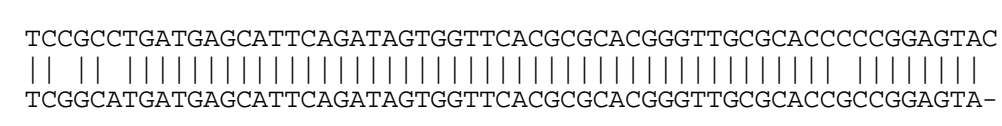 }} & \multicolumn{2}{|l|}{480} \\
\hline 2407285 & & & & & & \multirow{3}{*}{\multicolumn{2}{|c|}{2407343}} \\
\hline Query 481 & \multirow{2}{*}{\multicolumn{4}{|c|}{ 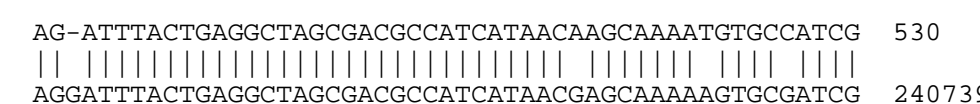 }} & & & \\
\hline Sbjet 2407344 & & & & & & & \\
\hline
\end{tabular}

Figure 3-28: The sequenced 500 bp band

The sequence indicates no sequence similarity to either the pUT mini-Tn5 IuxCDABE vector or the dehRI promoter insert 
Table 3-5: Bioluminescence measurement of positive 1080-lux colonies. Measurements are the averages of three readings for each colony.

\begin{tabular}{|c|c|c|c|c|c|c|c|c|c|}
\hline Colony & $\begin{array}{l}15 \\
\text { mins }\end{array}$ & $\begin{array}{l}30 \\
\text { mins }\end{array}$ & $\begin{array}{l}60 \\
\text { mins }\end{array}$ & $\begin{array}{l}120 \\
\text { mins }\end{array}$ & $\begin{array}{l}180 \\
\text { mins }\end{array}$ & $\begin{array}{l}240 \\
\text { mins }\end{array}$ & $\begin{array}{l}300 \\
\text { mins }\end{array}$ & $\begin{array}{l}360 \\
\text { mins }\end{array}$ & $\begin{array}{l}420 \\
\text { mins }\end{array}$ \\
\hline 1 & 0.015 & 0.013 & 0.014 & 0.015 & 0.014 & 0.013 & 0.010 & 0.009 & 0.004 \\
\hline 2 & 0.013 & 0.015 & 0.014 & 0.013 & 0.012 & 0.014 & 0.011 & 0.008 & 0.005 \\
\hline 3 & 0.014 & 0.014 & 0.013 & 0.011 & 0.012 & 0.010 & 0.011 & 0.009 & 0.006 \\
\hline 4 & 0.014 & 0.013 & 0.014 & 0.014 & 0.014 & 0.010 & 0.008 & 0.008 & 0.007 \\
\hline 5 & 0.013 & 0.013 & 0.014 & 0.014 & 0.013 & 0.011 & 0.008 & 0.007 & 0.006 \\
\hline 6 & 0.015 & 0.015 & 0.015 & 0.015 & 0.014 & 0.013 & 0.009 & 0.007 & 0.007 \\
\hline 7 & 0.012 & 0.013 & 0.014 & 0.012 & 0.012 & 0.013 & 0.010 & 0.011 & 0.012 \\
\hline 8 & 0.009 & 0.011 & 0.012 & 0.013 & 0.013 & 0.012 & 0.022 & 0.009 & 0.008 \\
\hline 9 & 0.013 & 0.013 & 0.012 & 0.014 & 0.012 & 0.011 & 0.013 & 0.010 & 0.009 \\
\hline 10 & 0.014 & 0.013 & 0.013 & 0.013 & 0.011 & 0.012 & 0.010 & 0.009 & 0.008 \\
\hline 11 & 0.014 & 0.014 & 0.012 & 0.011 & 0.012 & 0.011 & 0.009 & 0.004 & 0.005 \\
\hline 12 & 0.013 & 0.013 & 0.012 & 0.011 & 0.010 & 0.009 & 0.008 & 0.006 & 0.003 \\
\hline Blank & 0.008 & 0.010 & 0.007 & 0.005 & 0.011 & 0.009 & 0.004 & 0.010 & 0.006 \\
\hline
\end{tabular}

\subsubsection{Construction of Positive Control JlacO luxCDABE Constructs.}

Figure 3-29 shows the $137 \mathrm{bp}$ JlacO promoter insert PCR product amplified from pCR2.1 -TOPO cloning vector (Invitrogen). 


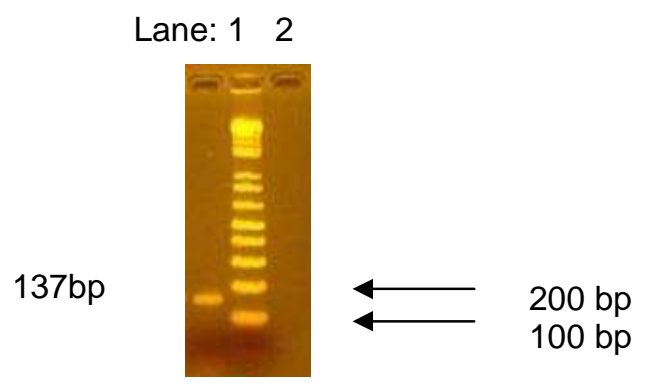

Figure 3-29: 1\% agarose gel shows the 147 bp JlacO promoter insert.

The JlacO promoter insert was digested with $\mathrm{Xbal}$ and ligated into the multiple cloning site of pCR2.1-TOPO cloning vector (Invitrogen) to allow sequencing. The promoter fragment was sequenced (Institute of Environmental Science and Research, Wellington) and BLAST analysis confirmed the JlacO promoter sequence.

\subsubsection{Screening for JlacO Promoter Positive Insert Clones.}

Resultant colonies were screened for the presence of the JlacO promoter insert by PCR colony screening and Xbal digestion. Figure 3-30 shows typical results for Xbal digestion (A) and PCR promoter fragment (B) presence in colonies. 
A

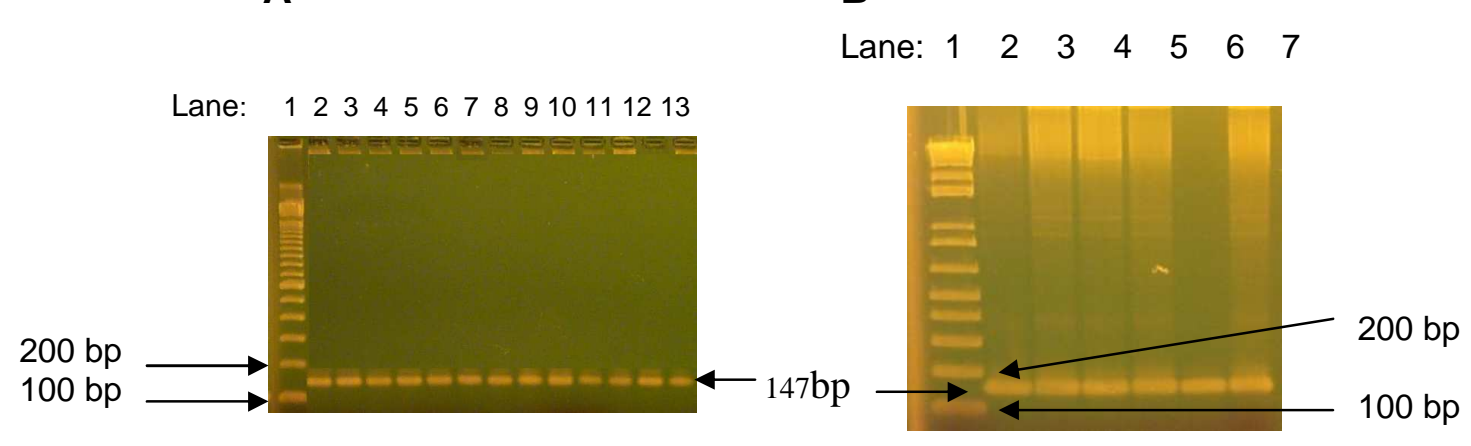

Figure 3-30: The confirmed presence of the JlacO promoter ligated into pUT mini-Tn5 luxCDABE. (A) Xbal digests and (B) PCR amplification. Both have been run on a $1 \%$ agarose gel. Lane 1 of both gels shows the molecular markers. 100 bp molecular markers are in lane 1 of both gels.

Primers were designed to amplify a segment of the JlacO-lux construct to determine if the insert was in the correct orientation and therefore able to activate the luxCDABE cassette. No inserts were seen in any of the 96 colonies screened; typical results can be seen in Figure 3-31.

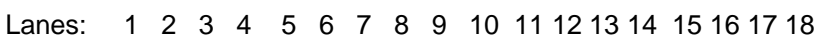

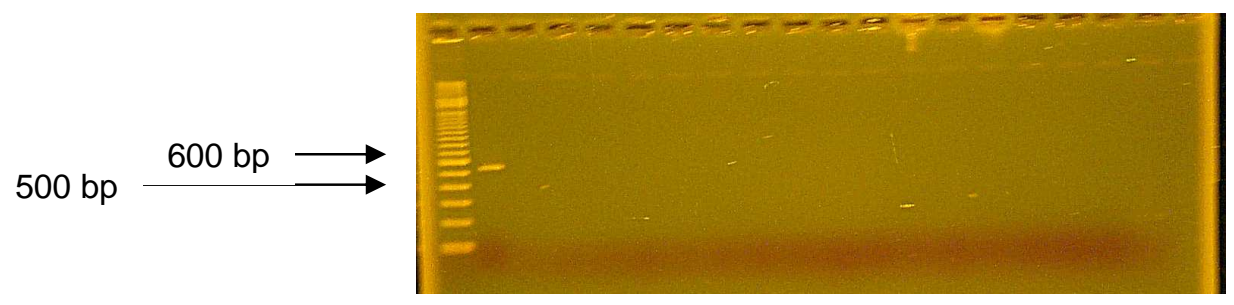

Figure 3-31: Insert orientation screening of JlacO promoter in pUT mini-Tn5 luxCDABE vector.

100 bp molecular marker in Lane 1 and PCR positive control in Lane 2. 
Despite inconclusive evidence of the orientation of the promoter sequence by PCR amplification, bioluminescence screening in the presence of IPTG, a lactose analogue was carried out. Table 3-6 shows that no luminescence above background levels was induced in the presence of IPTG.

Table 3-6: Bioluminescence screening of JlacO-lux construct

\begin{tabular}{|c|c|c|c|c|c|c|c|c|c|}
\hline Colony & $\begin{array}{l}15 \\
\text { mins }\end{array}$ & $\begin{array}{l}30 \\
\text { mins }\end{array}$ & $\begin{array}{l}60 \\
\text { mins }\end{array}$ & $\begin{array}{l}120 \\
\text { mins }\end{array}$ & $\begin{array}{l}180 \\
\text { mins }\end{array}$ & $\begin{array}{l}240 \\
\text { mins }\end{array}$ & $\begin{array}{l}300 \\
\text { mins }\end{array}$ & $\begin{array}{l}660 \\
\text { mins }\end{array}$ & $\begin{array}{l}420 \\
\text { mins }\end{array}$ \\
\hline 1 & 0.012 & 0.013 & 0.015 & 0.014 & 0.013 & 0.016 & 0.010 & 0.010 & 0.009 \\
\hline 2 & 0.016 & 0.014 & 0.014 & 0.013 & 0.012 & 0.014 & 0.013 & 0.012 & 0.008 \\
\hline 3 & 0.015 & 0.013 & 0.014 & 0.015 & 0.016 & 0.014 & 0.013 & 0.011 & 0.009 \\
\hline 4 & 0.014 & 0.014 & 0.013 & 0.014 & 0.015 & 0.013 & 0.012 & 0.010 & 0.009 \\
\hline 5 & 0.019 & 0.017 & 0.018 & 0.017 & 0.016 & 0.016 & 0.014 & 0.012 & 0.010 \\
\hline 6 & 0.014 & 0.013 & 0.013 & 0.014 & 0.012 & 0.014 & 0.013 & 0.011 & 0.008 \\
\hline 7 & 0.013 & 0.014 & 0.015 & 0.020 & 0.017 & 0.015 & 0.014 & 0.013 & 0.013 \\
\hline 8 & 0.017 & 0.016 & 0.016 & 0.018 & 0.019 & 0.016 & 0.014 & 0.013 & 0.010 \\
\hline 9 & 0.017 & 0.015 & 0.016 & 0.017 & 0.016 & 0.014 & 0.013 & 0.011 & 0.011 \\
\hline 10 & 0.018 & 0.016 & 0.017 & 0.017 & 0.016 & 0.014 & 0.013 & 0.013 & 0.011 \\
\hline 11 & 0.020 & 0.018 & 0.019 & 0.017 & 0.017 & 0.015 & 0.014 & 0.013 & 0.010 \\
\hline 12 & 0.019 & 0.017 & 0.018 & 0.018 & 0.016 & 0.013 & 0.015 & 0.012 & 0.011 \\
\hline Blank & 0.010 & 0.011 & 0.008 & 0.006 & 0.013 & 0.011 & 0.010 & 0.007 & 0.009 \\
\hline
\end{tabular}




\section{Chapter Four: DISCUSSION}

\subsection{Microbial Biosensor Bioassays.}

\subsubsection{Bacterial Biosensors.}

This current research has demonstrated that bacterial biosensors have the potential to rapidly (in less than 15 minutes) detect a range of PTCs in a variety of different matrices; including water, flour, analytical talc, two soil types and vomit. Initial water bioassays using bacterial biosensors, E. coli HB101 pUCD607 and $V$. harveyi, illustrated that sensitivity is dependent on the biosensor used and the PTC tested. It was determined that E. coli HB101 pUCD607 biosensor was most sensitive to arsenate $(2.55 \mathrm{mg} / \mathrm{L})$, arsenite $(61.7 \mathrm{mg} / \mathrm{L})$ and zinc $(0.48$ $\mathrm{mg} / \mathrm{L})$. V. harveyi was conversely more sensitive to acephate (200 mg/L), carbaryl (67 mg/L) copper (0.79 mg/L), cyanide $(9.66 \mathrm{mg} / \mathrm{L})$ and PCP $(0.25 \mathrm{mg} / \mathrm{L})$ (Table 3-2). Although $V$. harveyi was more sensitive to some PTCs than the genetically modified E. coli HB101 pUCD607, $V$. harveyi is a marine organism and required the adjustment of test solutions to saline conditions. As previously noted by Bhattacharyya et al. [10], saline conditions may alter the chemical properties and subsequently the toxicity of the toxins; a significant limitation to the assay [103].

Variation in biosensor species response is probably due to different species ecological appropriateness [16]. For example, the stomach contents environment may not be optimal for a marine species such as V.harveyi or the intestinal 
species E. coli. Redshaw et al. [16], investigated the use of two bacterial biosensors, E. coli HB101 pUCD607 and Salmonella typhimurium pUCD607, and demonstrated different subsequent $\mathrm{EC}_{50}$ values when exposed to the same toxins [16]. Ecological appropriateness was also demonstrated in this study, in the white powder bioassays. Results from these current bioassays have demonstrated that the genetically modified E. coli HB101 pUCD607, provided superior results in the complex matrices of talc and flour compared to $V$. harveyi (Table 3-3). Although biosensor sensitivity had decreased, in comparison to the initial water bioassays, $\mathrm{EC}_{50}$ values were able to be determined using $E$. coli HB101 pUCD607, but not with the $V$. harveyi biosensor. Matrix complexities of the white powders may have been too ecologically inappropriate for $V$. harveyis narrow ecological preferences, in comparison to $E$. coli species. These environmental limitations of $V$. harveyi which include a limited optimal $\mathrm{pH}$ range, the necessity for $\mathrm{NaCl}$ and limited tolerance to complex matrices, like talc and flour, limiting its use as a biosensor in this naturally occurring form.

This current study has demonstrated the significance of ecological appropriateness in the selection of a suitable microbial biosensor, particularly when utilising them in complex matrices. Selecting the best option biosensor ensures optimal biosensor efficacy. Conversely, selecting an unsuitable microbial biosensor, may give subsequent false negative or false positive results or alter the biosensor sensitivity. 
Direct interactions of PTCs with soils, such as the binding of organic soil particulate matter, may decrease the $\mathrm{EC}_{50}$ value of the biosensor to the PTC lowering the sensitivity of the biosensor. These interactions and consequent reductions in sensitivity have been previously demonstrated in environmental testing [35], [14], [24]. In the current study, the trend is illustrated by the PTC spiked flour and talc bioassays. For example, the E. coli HB101 pUCD607 biosensor has an $\mathrm{EC}_{50}$ value of $20 \mathrm{mg} / \mathrm{L}$ for the cyanide water bioassay. In talc, the $\mathrm{EC}_{50}$ value increased to $589 \mathrm{mg} / \mathrm{L}$ and in flour the $\mathrm{EC}_{50}$ increased further to $700 \mathrm{mg} / \mathrm{L}$. With biosensor sensitivity decreasing in white powders, detection levels are subsequently at higher concentrations. The same trend occurred with all the PTCs tested. It is the presence of organic compounds in flour that are likely to bind organic PTCs [104] making them less bioavailable to the biosensor and therefore the assay less sensitive. This feature must be considered when determining concentrations of PTCs in matrices with organic content. Increased organic matter in the matrix increases the possibility of getting a false negative PTC detection result.

This decreased sensitivity in complex matrices may be of little consequence, as any aberrant spiking with PTCs would likely occur at concentrations above these levels. For example, the $589 \mathrm{mg} / \mathrm{L}$ of cyanide detected in talc by the $E$. coli HB101 pUCD607 biosensor (Table 4-1) would loosely equate to half a gram of sugar in one kilogram of flour. The spiking of white powders or soils for terrorism purposes would occur at higher concentrations than detected here. 
Table 4-1: Microbial bioassay results showing published rodent $L_{50}$ in comparison to the E. coli HB101 pUCD607 biosensor response in PTC spiked water, vomit, talc and flour.

\begin{tabular}{|c|c|c|c|c|c|c|}
\hline \multirow{2}{*}{ PTC } & \multirow{2}{*}{$\begin{array}{l}\text { Stomach contents } \\
\text { concentration in fatal } \\
\text { poisonings } \\
(\mathrm{mg} / \mathrm{L})\end{array}$} & \multirow{2}{*}{$\begin{array}{l}\mathrm{LD}_{50} \\
\mathrm{mg} / \mathrm{kg} \\
\text { (Oral, } \\
\text { rats) }\end{array}$} & \multicolumn{4}{|c|}{$\begin{array}{c}\text { E. coli HB101 pUCD607 } \\
\mathrm{EC}_{50} \mathrm{~s}(\mathrm{mg} / \mathrm{L})\end{array}$} \\
\hline & & & In water & In vomit & In talc & In flour \\
\hline Acephate & $N A^{c}$ & $\begin{array}{l}700 \\
{[78]}\end{array}$ & 5000 & - & $N D^{b}$ & $N D^{b}$ \\
\hline Arsenate & $>\underset{[105]}{70(\text { minimum })^{a}}$ & $\begin{array}{c}8 \\
{[29]}\end{array}$ & 2.55 & 90 & 25 & 2300 \\
\hline Arsenite & $\begin{array}{c}70(\operatorname{minimum}) \\
{[105]}\end{array}$ & $\begin{array}{c}14-18 \\
{[29]}\end{array}$ & 61.7 & 90 & 210 & 250 \\
\hline Carbaryl & $\begin{array}{l}1200 \\
{[106]}\end{array}$ & $\begin{array}{l}500-600 \\
{[29]}\end{array}$ & 100 & 200 & 219 & 400 \\
\hline Copper & - & - & 3.05 & - & 36 & 468 \\
\hline Cyanide & $\begin{array}{c}100(\text { minimum }) \\
{[29]}\end{array}$ & $\begin{array}{c}5.2-7 \\
{[107]}\end{array}$ & 20 & - & 589 & 700 \\
\hline PCP & $\begin{array}{c}2000 \text { average } \\
{[29]}\end{array}$ & $\begin{array}{c}146-210 \\
{[29]}\end{array}$ & 3.44 & - & 6 & 849 \\
\hline Zinc & - & - & 0.48 & - & 34 & 700 \\
\hline
\end{tabular}

${ }^{a}$ Pentavalent (arsenate) is less toxic than trivalent (arsenite)

${ }^{b}$ Not Detected

${ }^{c}$ Not Available

Previous studies have shown that methanol extraction of PTCs from organic matrices can improve biosensor sensitivity [16]. For this reason it was investigated whether methanol extractions from talc and flour would improve the sensitivity of the biosensor to the organic pesticides carbaryl and acephate. However methanol extraction did not increase the E. coli HB101 pUCD607 biosensor sensitivity to acephate spiked flour, carbaryl spiked flour, acephate spiked talc or carbaryl spiked talc (Figure 3-14), even at concentrations of 10,000 $\mathrm{mg} / \mathrm{L}$ and no $\mathrm{EC}_{50}$ values could be determined. In fact carbaryl spiked talc appeared to decrease biosensor sensitivity which increased from an $\mathrm{EC}_{50}$ value 
of approximately $219 \mathrm{mg} / \mathrm{L}$ to an $\mathrm{EC}_{50}$ value of $470 \mathrm{mg} / \mathrm{L}$. These trends of decreased sensitivity have been noted in previous studies [16].

Despite these results, methanol extraction of PTCs from complex matrices such as soils and organic white powders should not necessarily be dismissed. The value of methanol extraction as a means of increasing biosensor sensitivity to PTCs, may be seen in PTCs that have not been investigated in this study. It can nonetheless be considered a useful means of determining if a PTC is organic [16]. It should be considered that as a PTC extraction method, methanol extraction is considerably more time consuming, therefore it may be considered less useful when a rapid indication of the presence of a toxin is required.

\subsubsection{Case Study: Vomit Bioassay.}

After altering the $\mathrm{pH}$ of the vomit to be within the optimal range for the biosensor, the vomit matrix itself had no detrimental effect on the biosensor. Initial water $E$. coli HB101 pUCD607 bioassays indicated $\mathrm{EC}_{50}$ values of $2.55 \mathrm{mg} / \mathrm{L}, 61.7 \mathrm{mg} / \mathrm{L}$ and $100 \mathrm{mg} / \mathrm{L}$ for arsenate, arsenite and carbaryl respectively. The E. coli HB101 pUCD607 bacterial biosensor demonstrated sensitivity to all PTC spiked vomit bioassays. An $\mathrm{EC}_{50}$ value of $200 \mathrm{mg} / \mathrm{L}$ for carbaryl was achieved however no conclusions could be drawn for either arsenate or arsenite due to the lack of data points above the $50 \%$ bioluminescence cut-off line. The corresponding concentrations in fatal poisonings have been documented at $70 \mathrm{mg} / \mathrm{L}, 70 \mathrm{mg} / \mathrm{L}$ and $1200 \mathrm{mg} / \mathrm{L}$ for arsenate, arsenite and carbaryl respectively [29]. The $\mathrm{EC}_{50}$ 
values indicate the biosensor showed sensitivity in the range likely to be found in samples submitted for toxicological analysis (Table 4-1). Decreased biosensor sensitivity in vomit indicates that although some toxin binding has occurred in the vomit matrix, the biosensor still shows acceptable sensitivity. The results of the vomit bioassay, although preliminary, indicate the ability of a bacterial biosensor to quickly determine the presence of a toxin without interference from the vomit matrix $\mathrm{EC}_{50}$ (Table 4-1).

Despite reductions in sensitivity of the E. coli HB101 pUCD607 biosensor to PTCs spiked in talc, flour and vomit, the biosensor detected the presence of commonly encountered agricultural and ecological toxins within the range of those encountered in published fatal poisoning case studies (Table 4-1). The E. coli HB101 pUCD607 biosensor can therefore complement analytical methods for initial detection of these toxins and pollutants, prior to undertaking rigorous, expensive analytical testing, in environmental samples or in cases of suspicious death or illness.

\subsubsection{Fungal Biosensors.}

Although $\mathrm{EC}_{50}$ values for the initial copper bioassay were analogous to Weitz's [43] fungal copper bioassay for the 15 minute exposure time, Weitz demonstrated a change in $\mathrm{EC}_{50}$ values of the biosensor over extended time periods (30 minutes, 60 minutes and 90 minutes) [43]. This current study did not see any difference in $\mathrm{EC}_{50}$ values over time. The reason for these differences in 
biosensor responses is unknown, as the $M$. citricolor ATCC 34884 used in this study was obtained from the Weitz laboratory. The differences in biosensor response could be related to differences in water, media or reagent differences or differences in the microclimates.

Because the data points did not fit the CSIRO data analysis model for most of the fungal bioassays, $E_{50}$ values were determined from graphs by reading determining at what concentration (x-axis) $50 \%$ bioluminescence occurred $(y-$ axis). Because the CSIRO data analysis model failed to explain the fungal bioassay data, it is inappropriate to use this model to derive an $\mathrm{EC}_{50}$ value. The failure of the CSIRO data analysis model is likely to be due to the variable nature of the preparation and protocol of the fungal bioassay. Fungal bioassays indicated that Mycena citricolor ATCC 34884 was not sensitive to arsenite, carbaryl and difenacoum even at concentrations above $10,000 \mathrm{mg} / \mathrm{L}$ thus this biosensor could not be used to detect these compounds (Figure 3-8).

Naturally bioluminescent fungi were investigated in this project with a view to complement the range of bacterial biosensors currently available. The effect of some toxins may be quite different in prokaryote cells than in eukaryote cells [41] thus a eukaryotic biosensor potentially provides more toxicological relevance for eukaryotes, including humans [108]. To develop a fungal bioassay to be carried out in the field would be both valuable and relevant to New Zealand, due to the constraints of using genetically modified organisms, such as E. coli HB101 
pUCD607, only in a controlled laboratory environment as discussed in Section 1.3.1.4. Ten New Zealand $A$. novae-zelandiae isolates and one New Zealand Mycena (sp. ICMP16534) were investigated and screened for bioluminescence and preferred growth characteristics. None of the ten $A$. novae-zelandiae isolates showed bioluminescence either on agar or in broth. Mycena sp. ICMP 16534 was slow to grow on agar taking greater than 30 days to reach the edges of the plate on ME agar and showed no bioluminescence. Whilst Mycena sp. ICMP 16534 did not bioluminesce on agar, it did show luminescence following growth in PD broth after around 30 days growth. Currently the extended time taken for the New Zealand Mycena species ICMP 16534 to reach maximum bioluminescence in broth, suggests its use as a biosensor is limited at this stage.

Due to these limitations of slow growth of New Zealand Mycena species ICMP 16534 determined in this study in, only M. citricolor ATCC 34884 was used to investigate the eukaryotic biosensor response to the chosen PTCs. The M. citricolor ATCC 34884 fungal biosensor response was notably more variable than those of bacterial biosensors due, in part, to the unavoidable variability of the bioassay protocol itself. As the process of inoculating the trimmed and quartered agar plugs into broth (for development of mycelial growth and bioluminescence) is manual, variability is unavoidable. In addition the development of fungal mycelium is dependent on optimal conditions. Variation in freshness of the culture (prior to sub-culturing into broth) and natural differences in individual isolates also contribute to overall variation. Anecdotal evidence 
suggests better luminescence from globular mycelium occurs from fresh agar cultures [109].

Despite inherent variability of the fungal bioassay, $\mathrm{EC}_{50}$ values were able to be extrapolated. M. citricolor ATCC $34884 \mathrm{EC}_{50}$ values for PCP, copper and zinc bioassays in this project demonstrated similar $\mathrm{EC}_{50}$ values to those determined by Weitz [43] in her investigation. The results of $M$. citricolor ATCC 34884 bioassays in this research demonstrate that the biosensor is significantly less sensitive to acephate, arsenate, arsenite, carbaryl, copper cyanide, PCP and zinc, when compared to the response of the two bacterial biosensors (Table 3-2).

Variation between the bacterial and fungal biosensor response is likely to result from multicellular eukaryotic organisms possessing more complex detoxification mechanisms, enabling them to minimise the effects of PTCs in their environment [110]. Resilience may contribute to decreased sensitivity of the basidiomycete biosensor, M. citricolor ATCC 34884 to some PTCs, compared to the bacterial biosensors in the bioassays carried out in this study. Chiu et al. [111] suggest that water-insoluble polysaccharides observed in cultures of basidiomycete species may form a PCP diffusion barrier and binding matrix making these species less sensitive to toxins [111]. Despite this finding, the fungal biosensor used in this study, M. citricolor ATCC 34884 (also a basidiomycete), was sensitive to PCP at a low concentration $(0.591 \mathrm{mg} / \mathrm{L})$. The differences in bacterial 
and fungal responses to PTCs highlight the importance of using both prokaryotic and eukaryotic cells in toxicity testing.

\subsection{Solid-Phase Extraction Bioassays.}

The current study has demonstrated that the bioavailability of toxins influences biosensor sensitivity in PTC spiked white powders and soils. The solid-phase sample preparation method has been demonstrated here as a potential technique for determining the toxicity of PTCs with limited water solubility. The solid-phase extraction bioassays indicated the biosensor was more sensitive to the PTCs spiked in white powders than those spiked in soils.

Both centrifugation and filtration sample preparation methods are commonly used for sample preparation in soil toxicity experiments. Although there are currently few alternatives, the concern with using filtration, and to a lesser extent centrifugation, is that these sample preparation methods impact on the final concentration of toxin in the solution used for the bioassay. At each step of sample preparation it is possible that some PTC is either lost or becomes unavailable. Therefore bioassay solutions prepared using the solid-phase centrifugation method are liable to have a higher toxin concentration than solutions prepared by filtration method.

In sample preparation by filtration, the sample is first centrifuged and the supernatant subsequently filtered to remove fine particles. With this extra 
filtration sample preparation step it is possible that some PTC may be bound to the filter, thereby decreasing the amount of PTC available to the biosensor. Results from this research have demonstrated that the solid-phase extraction efficiency was dependant on the matrix and PTC tested. The extent to which the PTCs bind in soil system or complex matrix depends on the organic content of the soil as well as the PTC itself [104], [112], [113], [114].

One apparent anomaly in this current research was that the biosensor did exhibit sensitivity to one PTC (PCP) spiked in the more organic Templeton soil. As mentioned previously (Section 2.1.3.1), PCP is less water soluble than other PTCs tested. The solid-phase sample preparation method compensates for this characteristic where the other methods utilised, centrifugation and filtration, do not.

On the basis of these preliminary results I would recommend using the solidphase extraction sample preparation method, particularly for use with white powders, soils with lower contents of organic material and toxins with low solubility. Further validation and optimisation of this method would be valuable for soil ecotoxicity analysis and forensic purposes. 
Table 4-2: Summary table comparing the biosensor ability to detect PTCs spiked into different matrices using different sample preparation methods.

\begin{tabular}{|c|c|c|c|c|c|c|}
\hline \multirow{3}{*}{ PTC } & \multicolumn{6}{|c|}{ PTC Detection } \\
\hline & \multicolumn{2}{|c|}{ Centrifugation } & \multicolumn{2}{|c|}{ Filtration } & \multicolumn{2}{|c|}{ Solid-Phase } \\
\hline & Yes & No & Yes & No & Yes & No \\
\hline Arsenate & $\begin{array}{c}\text { Talc } \\
\text { Flour } \\
\text { Waitarere }\end{array}$ & Templeton & $\begin{array}{c}\text { Talc } \\
\text { Flour } \\
\text { Waitarere }\end{array}$ & Templeton & $\begin{array}{l}\text { Talc } \\
\text { Flour }\end{array}$ & $\begin{array}{l}\text { Templeton } \\
\text { Waitarere }\end{array}$ \\
\hline Arsenite & $\begin{array}{c}\text { Talc } \\
\text { Flour } \\
\text { Waitarere }\end{array}$ & Templeton & $\begin{array}{c}\text { Talc } \\
\text { Flour } \\
\text { Waitarere }\end{array}$ & Templeton & $\begin{array}{l}\text { Talc } \\
\text { Flour }\end{array}$ & $\begin{array}{l}\text { Templeton } \\
\text { Waitarere }\end{array}$ \\
\hline Copper & $\begin{array}{l}\text { Talc } \\
\text { Flour }\end{array}$ & $\begin{array}{l}\text { Templeton } \\
\text { Waitarere }\end{array}$ & Talc & $\begin{array}{c}\text { Flour } \\
\text { Templeton } \\
\text { Waitarere }\end{array}$ & $\begin{array}{l}\text { Talc } \\
\text { Flour }\end{array}$ & $\begin{array}{l}\text { Templeton } \\
\text { Waitarere }\end{array}$ \\
\hline Cyanide & $\begin{array}{l}\text { Talc } \\
\text { Flour }\end{array}$ & $\begin{array}{l}\text { Templeton } \\
\text { Waitarere }\end{array}$ & - & $\begin{array}{c}\text { Talc } \\
\text { Flour } \\
\text { Templeton } \\
\text { Waitarere }\end{array}$ & $\begin{array}{l}\text { Talc } \\
\text { Flour }\end{array}$ & $\begin{array}{l}\text { Templeton } \\
\text { Waitarere }\end{array}$ \\
\hline PCP & $\begin{array}{l}\text { Talc } \\
\text { Flour }\end{array}$ & $\begin{array}{l}\text { Templeton } \\
\text { Waitarere }\end{array}$ & $\begin{array}{l}\text { Talc } \\
\text { Flour }\end{array}$ & $\begin{array}{l}\text { Templeton } \\
\text { Waitarere }\end{array}$ & $\begin{array}{c}\text { Templeton } \\
\text { Flour } \\
\text { Talc }\end{array}$ & Waitarere \\
\hline
\end{tabular}

An overall summary of the sample preparation methods and matrices the biosensor showed the most sensitivity with is shown in Table 4-2. In most sample preparation methods the biosensors were sensitive to the spiked analytical talc and flours. The exceptions to this are the filtration method with cyanide and copper spiked flour and cyanide spiked talc. The biosensors were not generally sensitive in the PTC spiked soils with the exception of Waitarere, the more sandy soil. Therefore solid-phase, the quickest method, is recommended. 


\subsection{Development of Specific Bacterial Biosensor.}

The development of a suite of specific bacterial biosensors that indicate the presence or absence of a PTC, for example 1080, in complex matrices would be beneficial. Biosensors have often been a challenge for molecular biologists to construct [60]. In this project advances have been made towards developing a specific 1080-biosensor. The dehalogenase promoter region has been successfully targeted, amplified, ligated into the vector and transformed into E. coli DH5 $\alpha \lambda$ pir cells. None of the resultant colonies induced luminescence in the presence of 1080 although, sequencing suggested the promoter was inserted in the correct orientation.

The difficulties encountered in constructing an effective 1080-specific bacterial biosensor can be attributed to three factors. First, the major limiting factor was the unavailability of the complete pUT mini-Tn5 luxCDABE sequence. Consequently it was difficult to conclusively determine if the promoter was ligated in the correct location or orientation.

It is desirable that the required restriction enzyme sites are upstream of the luxCDABE cassette. This could be achieved by designing primers to PCRamplify the entire luxCDABE region incorporating new restriction sites. This construct could the be ligated into a new plasmid and the desired promoter inserted in front of this. Unfortunately due to time and financial constraints neither of these strategies were attempted. 
The JlacO-lux positive control was constructed using a well characterised lactose promoter amplified from a cloning vector (PCR2.1 TOPO, Invitrogen). This strong promoter should have induced luminescence in the presence of lactose or the lactose analogue, IPTG. However the JlacO-lux positive control produced similar results and had the same issues as the 1080-lux construct. As the positive control, with a known strong promoter failed also to luminesce in the presence of the inducing substance, it suggests the vector is either unreliable or unsuitable for this purpose.

\subsection{Conclusion.}

Sophisticated analytical procedures may be able to quantify and identify lower concentrations of PTCs although, they cannot distinguish bioavailability. Biosensors are able to determine bioavailability, report total biological toxicity and assess environment risk. While not a substitute for rigorous analytical chemistry, biosensors complement this data and offer a rapid and environmentally focused assessment of toxicity. Where metabolic biosensors show overall toxicity, specific biosensors indicate causes of toxicity and are more sensitive, making them preferable. Using more than one biosensor will always provide the best interpretation of toxic samples [16], [43] , [1]. Nonetheless, it should be noted that biosensor performance is dependent on more than one single factor [60].

This project has demonstrated that a suite of microbial biosensors (E. coli HB101 pUCD607, V. harveyi and M. citricolor ATCC 34884) can, and should, be used to 
detect a wide range of PTCs in a variety of matrices. The PTCs used in this study are likely to be encountered in a forensic investigation in matrices including water, vomit, talc, flour and soils. The current research demonstrates the microbial biosensors used here have the potential to rapidly screen suspicious white powders and soils contaminated with high concentrations of PTCs. They are also sensitive enough to detect low concentrations of PTCs that are present in environmental samples such as soil and water. In addition this project has demonstrated that sample manipulation, including $\mathrm{pH}$ alteration, methanol extraction or variation in the sample preparation methods can increase the sensitivity of a biosensor.

Using fungi as a biosensor expands the range of organisms that can be used for bioluminescence-based toxicity testing and complements existing biosensors [43]. The fungal bioassay results obtained from this study complement investigations undertaken by Weitz [43]. The value of having a naturally bioluminescent fungi sourced from within New Zealand is its potential for use 'out-in-the-field' eliminating the need to prepare and transport samples to a laboratory. The results in this thesis support previous work that biosensor analysis should include more than one test organism [16], [43] used simultaneously to achieve reliable and robust results. 
This work has made considerable advances in the development of general biosensor systems. With a more reliable plasmid vector and known inducible 1080-promoter the 1080-specific biosensor would be achievable.

\subsection{Future Directions.}

\subsubsection{Metabolic Biosensor Bioassays.}

Further investigation of biosensors that have been used to date will enhance and expand current knowledge of the sensitivities and limitations of these biosensors and their potential in environmental and forensic applications. Expanding the use and analysis of current bacterial biosensors to determine their response to additional chemicals and PTC groups is desirable, particularly in complex matrices of white powders and soils. The bioassays undertaken in this study have also highlighted some PTCs, for example 1080, that remain difficult to detect using broad spectrum metabolic biosensors. For these PTCs it is preferable to construct a suite of specific microbial biosensors, providing increased sensitivity.

At this stage growth and bioluminescence induction of the New Zealand Mycena sp. ICMP 16534 is slow. The key to maximising bioluminescence is optimising growth conditions, including investigating diurnal periodicity and the impact of circadian rhythms. Further investigation may also elicit a quicker response by using a different nutrient media. It is possible that to further decrease the time required for the preparation of fungi for a bioassay, the fungi may be grown to the 
bioluminescence induction stage and processed for storage enabling it to be ready for immediate use, as is the case with the freeze-dried E. coli HB101 pUCD607 bacterial biosensor. The use of $M$. citricolor ATCC34884 as a biosensor highlighted the need for a standardised protocol, as much as is possible with multicellular biological tools.

\subsubsection{Solid-Phase Sample Preparation.}

This project has highlighted the potential of the solid-phase technique and the need for optimisation and validation. This could include investigations of PTCs with limited water solubility and to undertake chemical analysis of spiked soils and white powders. Chemical analysis would determine the PTC concentration in the water extract used in the bioassay solutions and would enable comparisons to be made between spiked PTC concentration and PTC available to the biosensor. Investigation of optimal quantities of biosensor cells, and the minimal quantity of water able to be added to the spiked matrix, would be valuable undertakings towards optimising this method. For PTCs with limited or no water solubility the addition of water, to obtain a soil or white powder extract for use in a bioassay, potentially compromises the bioassay. Once fully validated and optimised, the solid-phase biosensor sample preparation method would be beneficial in reducing the time-consuming sample preparation required. 


\subsubsection{Specific 1080-Iux Biosensor.}

Specific bacterial biosensors are more sensitive than their non-specific counterparts and as such they have the ability to detect PTCs at levels that other biosensors cannot. On completion of the successful construction of one specific catabolic biosensor a suite of biosensors specific to a range of PTCs would be possible. The ability to construct a specific 1080-lux biosensor is dependent on the sourcing and utilisation of a known inducible promoter [63] or using a different more reliable reporting system [115]. The acquisition of a characterised inducible fluoroacetate dehalogenase promoter would greatly enhance the ability to produce a specific 1080-lux biosensor. 


\section{References}

1. Dennison, M.J., Turner, P.F., Biosensors for environmental monitoring. Biotechnological Advances., 1995. 13: p. 1-12.

2. Marty, J.L., Mionetto, N., Noguer, T., Ortega, F., Roux, C., Enzyme sensors for the detection of pesticides. Biosensors and Bioelectronics, 1993. 8(6): p. 273-280.

3. Flynn, H., McMahon, V., Diaz, G.C., Demergasso, C.S., Corbister, P., Meharg, A.A., Paton, G.I.,, Assessment of bioavailable arsenic and copper in soils and sediments from the Antofagasta region in Northern Chile. The Science of the Total Environment, 2002. 286: p. 51-59.

4. Selifonova, O., Burlage, R., Barkay, T., Bioluminescent sensors for detection of bioavailable $\mathrm{Hg}(\mathrm{II})$ in the environment. Applied Environmental Microbiology, 1993. 59(9).

5. Ivask, A., Francois, M., Kahru, A., Dubourguier, H.C., Virta, M., Douay, F.,, Recombinant luminescent bacterial sensors for the measurement of bioavalability of cadmium and lead in soils polluted by metal smelters. Chemosphere, 2004. 55: p. 147-156.

6. Rasmussen, L.D., Sorenson, S.J., Turner, R.R., Barkay, T. Application of a mer-lux biosensor for estimating bioavailable mercury in soil. Soil Biology and Biochemistry, 2000. 32: p. 639-646.

7. Miertus, S., Katrlik, J., Pizzarielo, A., Stred'ansky, M., Svital, J., Svorc, J. Amperometric biosensors based on solid binding matrices applied in food quality monitoring. Biosensors and Bioelectronics, 1998. 13(7-8): p. 911-923.

8. Verma, N., Singh, M.,, A disposable microbial based biosensor for quality control in milk. Biosensors and Bioelectronics, 2003. 18(10): p. 1219-1224.

9. Amine, A., Mohammaddi, H., Bourais, I., Palleschi, G. Enzyme inhibition based biosensors for food safety and environmental monitoring. Biosensors and Bioelectronics, 2005. 21(8): p. 1405-1423.

10. Bhattacharyya, J., Read, D., Amos, S., Dooley, S., Killham, K., Paton, G. I., Biosensorbased diagnostics of contaminated groundwater: assessment and remediation strategy. Environmental Pollution, 2005. 134(3): p. 485-492.

11. Paton, G.I., Campbell, C.D., Glover, L.A., Killham, K., Assessment of bioavailability of heavy metals using lux-modified constructs of Pseudomonas fluorescens. Letters in Applied Microbiology, 1995. 20: p. 52-56.

12. Keane, A., Phoenix, P., Ghoshal, S., Lau, P.C.K., Exposing culprit organic pollutants: $A$ review. Journal of Microbiological Methods, 2002. 49(2): p. 103-119.

13. Dickson, S.J., Meinhold, R.H., Beer, I.D., Koelmeyer, T.D., Rapid determination of glyphosate in post-mortem specimens using ${ }^{13} P$ NMR. Journal of Analytical Toxicology, 1988. 12: p. 284-286.

14. Paton, G.I., Rattray, E.A.S., Campbell, C.D., Cresser, M.S., Glover, L.A., Meeussen, J.C L., Killham, K., Use of genetically modified microbial biosensors for soil ecotoxicity testing. Biological Indicators of Soil Health and Sustainable Productivity, 1997: p. 397418. 
15. Horswell, J., Dickson, S.J., Use of biosensors to screen urine samples for potentially toxic chemicals. Journal of Analytical Toxicology, 2003. 27(6): p. 372-376.

16. Redshaw, N., Dickson, S. J., Ambrose, V., Horswell, J., A preliminary investigation into the use of biosensors to screen stomach contents for selected poisons and drugs. Forensic Science International, 2007. 172(2-3): p. 106-11.

17. Ramanathan, S., Ensor, M., Daunert, S., Bacterial biosensors for monitoring toxic materials. Tibtech, 1997. 15: p. 500-506.

18. van der Meer, J.R., Tropel, D., Jaspers, M., Illuminating the detection chain of bacterial bioreporters. Environmental Microbiology, 2004. 6(10): p. 1005-1020.

19. Winson, M.K., Swift, S., Hill, P.J., Sims, C.M., Griesmayr, G., Bycroft, B.W., Williams, P., Stewart, G.S., Engineering the luxCDABE genes from Photorhabdus luminescens to provide a bioluminescent reporter for constitutive and promoter probe plasmids and miniTn5 constructs. Federation of European Microbiological Societies (FEMS) Microbiology Letters., 1998. 163(2): p. 193-202.

20. Hansen, L.H., Sorensen S.J., Versatile biosensor vectors for detection and quantification of mercury. Federation of European Microbiological Societies (FEMS) Microbiology Letters., 2000. 193: p. 123-127.

21. Shaw, J.J., Kado, C.I., Development of a Vibrio Bioluminescence Gene-Set to Monitor Phytopathogenic Bacteria During the Ongoing Disease Process in a Non-Disruptive Manner. Nature Biotechnology, 1986. 4(6): p. 560-564.

22. Winson, M.K., Swifta, S., Fisha, S.,Throupa S.P., Jørgensena, F., Chhabrab, S.R., Bycroftb, B.W., Williamsb, P., Stewart, G.S.A.B., Construction and analysis of luxCDABEbased plasmid sensors for investigating $\mathrm{N}$-acyl homoserine lactone-mediated quorum sensing. Federation of European Microbiological Societies (FEMS) Microbiology Letters., 1998. 163(2): p. 185-192.

23. Paton, G.I., Palmer, G., Burton, M., Rattray, E.A.S., McGrath, S.P., Glover, L.A., Killham, K. , Development of an acute and chronic ecotoxicity assay using lux-marked Rhizobium leguminosarum biovar trifolii. Letters in Applied Microbiology, 1997. 24(4): p. 296-300.

24. Weitz, H.J., Ritchie, J.M., Bailey, D.A., Horsburgh, A.M., Killham, K., Glover, L. A., Construction of a modified mini-Tn5 luxCDABE transposon for the development of bacterial biosensors for ecotoxicity testing. Federation of European Microbiological Sciences (FEMS) Microbiology Letters, 2001. 197(2): p. 159-165.

25. Meighen, E.A., Bacterial bioluminescence: organization, regulation, and application of the lux genes. . Journal of Federation of American Societies for Experimental Biology 1993. 7: p. 1016-1022.

26. Meighen, E.A., Molecular biology of bacterial bioluminescence. Microbiological Reviews, 1991. 51(1): p. 123-142.

27. Ellenhorn, M.J., Ellenhorn's medical toxicology: diagnosis and treatment of human poisoning. 2nd edition ed, ed. M.J. Ellenhorn, Schonwald, S., Ordog, G., Wasserberger, J. pp. 1267-1304. 1997, Baltimore.: Williams \& Wilkins Baltimore. 
28. Dyer, W.C., Byers, K.L., Martin, J.V., Application of a convenient extraction procedure to analyse gamma hydroxybutyrate in fatalities involving gamma-hydroxybutyric acid, gamma-butyrolacetone and 1,4-butanediol. Journal of Analytical Toxicology, 2001. 25: p. 576-582.

29. Baselt, R., Disposition of toxic drugs and chemicals in man. Fifth ed, ed. p. 360. 2000, Forster City, C.A: Chemical Toxicology Institute.

30. Reid, B.J., Semple, K.T., Macleod, C.J., Weitz, H.J., Paton, G.I., Feasibility of using prokaryote biosensors to assess acute toxicity of polycyclic aromatic hydrocarbons. Federation of European Microbiological Sciences (FEMS) Microbiology Letters., 1998. 169: p. 227-233.

31. Peijnenburg, W.J.G.M., Posthuma, L., Zweers, P.G.P.C., Baerselman, R., de Groot, A.C., Van Veen, R.P.M., Jager, T., Prediction of metal bioavailability in dutch feild soils for the Oligochaete enchytraeus crypticus. Ecotoxicology and Environmental Safety., 1999. 43(2): p. 170-186.

32. Ernst, W.H.O., Bioavailability of heavey metals and decontamination of soils by plants. Applied Geochemistry., 1996. 11(1-2): p. 163-167.

33. Welp, G., Brummer, G.W., Microbial toxicity of $\mathrm{Cd}$ and $\mathrm{Hg}$ in different soils related to total and water-soluble contents. Ecotoxicology and Environmental Safety., 1997. 38(3): p. 200-204.

34. Dickson, S.J., Personal Communication. 2007: Wellington.

35. Bundy, J.G., Wardell, J.L., Campbell, C.D., Killham, K., Paton, G.I., Application of bioluminescence-based microbial biosensors to the ecotoxicity assessment of organotins. Letters in Applied Microbiology, 1997. 25(5): p. 353-358.

36. Kwon-Chung, K.J., Bennet J.E., Medical Mycology. 1992, London, U. K.: Lea \& Febiger.

37. Weitz, H.J., Campbell, C.D., Killham, K., The effects of culture conditions on mycelial growth and luminescence of naturally bioluminescent fungi. Federation of European Microbiological Sciences (FEMS) Microbiology Letters, 2001. 202.

38. Herring, P.J., Luminous fungi. Mycologist, 1994. 8: p. 181-183.

39. Parry, J.M., The use of short and medium term tests for carcinogens and data on genetic effects in carcinogenic hazard evaluation. IARC Scientific Publications, 1999. 146: $p$. 471-485.

40. Hollis, R.P., Killham, K., Glover, L.A., Design and application of a biosensor for monitoring toxicity of compounds to eukaryotes. Applied Environmental Microbiology, 2000. 66: p. 1676-1679.

41. Baronian, K.H.R., The use of yeast and moulds as sensing elements in biosensors. Biosensors and Bioelectronics, 2004. 19(9): p. 953-962.

42. Walmsley, R.M., Keenan, P., The eukaryotic alternative: advantages of using yeasts in place of bacteria in microbial biosensor development. Biotechnology and Bioprocess Engineering., 2000. 5: p. 387-394. 
43. Weitz, H.J., Development of a novel bioluminescence based fungal bioassay for toxicity testing. Environmental Microbiology, 2002. 7(4): p. 422-429.

44. Bechor, O., Smulski, Dana R., Van Dyk, Tina K., LaRossa, Robert A., Belkin, Shimshon, Recombinant microorganisms as environmental biosensors: pollutants detection by Escherichia coli bearing fabA\&prime;:::lux fusions. Journal of Biotechnology, 2002. 94(1): p. 125-132.

45. Bending, G.D., Friloux, M., Walker, R A., Degradation of contrasting pesticides by white rot fungi and its relationship with lignolytic potential. Federation of European Microbiological Societies (FEMS) Microbiology Letters., 2002. 212: p. 59-63.

46. Anastasi, A., Varese, G.C., Bosco, F., Chimirri, F., Marchisio, V.F., Bioremediation potential of basidiomycetes isolated from compost. Bioresource Technology, 2008. 99: p. 6626-6630.

47. Reid, B.J., Semple, K.T., Macleod, C.J., Weitz, H.J., Paton, G.I., Feasibility of using prokaryote biosensors to assess acute toxicity of polycyclic aromatic hydrocarbons. Federation of European Microbiological Societies (FEMS) Microbiology Letters., 1998. 169: p. 227-233.

48. McNamara, C.J., Anastasiou, C.C., O'Flaherty, V., Mitchell, R., Bioremediation of olive mill waste water. International Biodeterioration and Biodegradation, 2008. 61: p. 127-134.

49. Meharg, A.A., Dennis, G.R., Cairney, J.W.G., Biotransformation of 2,4,6,-trinitrotoluene (TNT) by ectomycorrhizal basidiomycetes. Chemosphere, 1997. 35(3): p. 513-521.

50. Malaviya, P., Rathore, V.S., Bioremediation of pulp and paper mill effluent by a novel fungal consortium isolated from polluted soil. Bioresource Technology, 2007. 98: p. 36473651.

51. Wilkinson, D.M., Dickinson, N.M., Metal resistance in trees: the role of mycorrhizae. Oikos, 1995. 72(2): p. 298-300.

52. Kelly, S.L., Lamb, D.C., Jackson, C.J., Warrilow, A.G.S., Kelly, D.E., The biodiversity of microbial cytochromes P450. Advances in Microbial Physiology, 2003. 47(131-186).

53. Kohler, S., Belkin, S., Schmid, R.D., Reporter gene bioassays in environmental analysis. Fresenius Journal of Analytical Chemistry., 2000. 366: p. 769-779.

54. King, J.M.H., DiGrazia, P.M., Applegate, B., Burlage, R., Sanseverino, J., Dunbar, P., Larimer, F., Sayler, G.S.,, Rapid sensitive bioluminescent reporter technology for napthalene exposure and degradation. Science., 1990. 249: p. 778-781.

55. Tauriainen, S., Karp, M., Chang, W., Virta, M., Recombinant luminescent bacteria for measuring bioavailable arsenite and antimonite. Applied Environmental Microbiology, 1997. 63(11): p. 4456-4461.

56. Petanen, T., Romantschuk, M., Toxicity and bioavailability to bacteria of particleassociated arsenite and mercury. Chemosphere, 2003. 50: p. 409-413.

57. Ivask A Francois M Kahru A Dubourguier HC Virta M Douay F, Recombinant luminescent bacterial sensors for the measurement of bioavalability of cadmium and lead in soils polluted by metal smelters Chemosphere, 2004. 55: p. 147-156. 
58. Corbisier, P., Ji, G., Nuyts, G., Mergeay, M., Silver, S., luxAB gene fusions with the arsenic and cadmium resistance operons of Staphylococcus aureus plasmid pl258. Federation of European Microbiological Societies (FEMS) Microbiology Letters., 1993. 110(2): p. 231-8.

59. Bontidean, I., Lloyd, J.R., Hobman, J.L., Wilson, J.R., Csoregi, E., Mattiasson, B., Brown, N.L., Bacterial metal resistance proteins and their use in biosensors for the detection of bioavailable heavy metals. Journal of Inorganic Biochemistry, 2000. 79: p. 225-229.

60. Harkins, M., Porter, A.J.R., Paton, G.I., The role of host organism, transcriptional switches and reporter mechanisms in the performance of $\mathrm{Hg}$-induced biosensors. Journal of Applied Microbiology., 2004. 97: p. 1192-1200.

61. Eason, C., Sodium monofluoroacetate (1080) risk assessment and risk communication. Toxicology, 2002. 181-182: p. 523-530.

62. Environmental Risk Management Authority of New Zealand (ERMA)., New 1080 Controls Announced. Perspective, 2007(33): p. 12.

63. Kurihara, T., Yamauchi, T., Ichiyama, S., Takahata, H., Esaki, N., Purification, characterisation and gene cloning of a novel fluoroacetate dehalogenase from Burkholderia sp. FA1. Journal of Molecular Catalysis B: Enzymatic, 2003. 23(2-6): p. 347355.

64. Eason, C.T., Frampton, C.M., Acute toxicity of sodium monofluroacetate (1080) baits to feral cats. Wildlife Research, 1991. 18: p. 445-449.

65. Atzert, S.P., A review of sodium monofluoroacetate (Compound 1080) its properties, toxicology and use in predator and rodent control. United States Department of the Interior Fish and Wildlife Services Special Scientific Report. Wildlife No. 146, 1971.

66. Mcllroy, J.C., The sensitivity of Australian animals to 1080 poison:The sensitivity of feral pigs (Sus scrofa) to 1080 and its implications for poison campaigns. Australia Wildlife Research, 1983. 10: p. 139-148.

67. Bell, J., The acute toxicity of four common poisons to the oppossum Trichosurus vulpecula. New Zealand Veterinary Journal, 1972. 20: p. 213-214.

68. Kawasaki, H., Tsuda, K., Matsushita, I., Tonomura, K., Lack of homology between two haloacetate dehalogenase genes encoded on a plasmid from Moraxella sp. strain B. Journal of General Microbiology, 1992. 138: p. 1317-1323.

69. Janssen, D.B., Oppentocht, J.E., Poelarends, G.J., Micriobial dehalogenation. Current Opinion in Biotechnology, 2001. 12: p. 254-258.

70. Kurihara, T., Esaki, N., Soda, K., Bacterial 2-haloacid dehalogenases: structures and reaction mechanisms. Journal of Molecular Catalysis B: Enzymatic, 2000. 10(1-3): p. 5765.

71. Walker, J.R.L., Bong, C.L., Metabolism of fluoroacetate by a soil Pseudomonas sp. and Fusarium solani. Soil Biology and Biochemistry, 1981. 13(3): p. 231-235. 
72. David, W.A., Gardiner, B.O., Persistance of fluoroacetate and fluoroacetimide in soil. Nature, 1966. 209: p. 1367-1368.

73. Lien, B.C., Cole, A. L. J., Walker, J. R. L., Peters, J. A., Effect of sodium fluoroacetate (compound 1080) on the soil microflora. Soil Biology and Biochemistry, 1979. 11(1): p. 13-18.

74. Eason C, Sodium monofluoroacetate (1080) risk assessment and risk communication. Toxicology, 2002. 181-182: p. 523-530.

75. Liu, J.-Q., Kurihara, T., Ichiyama, S., Miyagi, M., Tsunasawa, S., Kawasaki, H., Soda, K., Esaki, N., Reaction mechanism of fluoroacetate dehalogenase from Moraxella sp. B. Journal of Biological Chemistry, 1998. 273(47): p. 30897-30902.

76. Kamzolkina, O.V., Bekker. Z.E., Egorov, N.S. , Extraction of the luciferin-luciferase system from the fungus Armillaira mellea. Biol. Nauki 1, 1984: p. 73-77.

77. Airth, R.L., Foerster, G.E., Behrens, P.Q., The luminous fungi. Bioluminescence in Progress, ed. F.H.H. Johnson, Y. pp.203-223. 1966, Princeton, N.J.: Princeton University Press.

78. Merck \& Co., I., The Merck Index: An Encyclopedia of Chemicals, Drugs and Biologicals. Twelfth ed, ed. S. Budavari, O'Neil, M.J., Smith, A., Heckelman, P.E., Kinneary, J.F. 1996, Whitehouse Station, NJ, United States of America.: Merck Reserach Laboratories, Division of Merck \& Co., Inc.

79. Hernando, M.D., De Vettori, S., Martinez Bueno, M. J., Fernandez-Alba, A. R., Toxicity evaluation with Vibrio fischeri test of organic chemicals used in aquaculture. Chemosphere, 2007. 68(4): p. 724-730.

80. Strachan, G., Preston, S., Maciel, H., Porter, A.J.R., Paton, G.I., Use of bacterial biosensors to interpret the toxicity and mixture toxicity of herbicides in freshwater. Water Research, 2001. 35(14): p. 3490-3495.

81. Hewitt, A.E., New Zealand Soil Classification. Second Edition ed. Landcare Research Science Series No.1. 1998, Lincoln: Manaaki Whenua Press.

82. Barnes, M., Correll, R., Stevens, D. A simple spreadsheet for estimating low-effect concentrations and associated logistic dose response curves. in The Society of Environmental Toxicology and Chemistry Asia/Pacific - Australasian Society of Ecotoxicology. 2003. Christchurch, New Zealand.

83. Smolders, E., Buekers, J., Oliver, I., McLaughlin, M.J., Soil properties affecting toxicity of zinc to soil microbial properties in laboratory spiked and feild-contaminated soils. Environmental Toxicolgy and Chemistry, 2004. 23: p. 2633-2640.

84. Haanstra, L., Doelman, P., Oude Voshaar, J.H.,, The use of sigmoidal dose-response curves in soil ecotoxicological research. Plant and Soil, 1985. 84: p. 293-297.

85. Speir, T.W., Kettles, H.A., Parshotam, A., Searle, P.L., Vlaar, L.N.C., A simple kinetic approach to derive the ecological dose value, $E D_{50}$, for the assessment of $\mathrm{Cr}(\mathrm{VI})$ toxicity to soil biological properties. Soil Biology and Biochemistry, 1995. 27(6): p. 801-810. 
86. Weightman, A.J., Topping, A.W., Hill, K.E., Lee, L, Sakai, K., Slater, J.H, Thomas, A.W., Transposition of DEH, a Broad-Host-Range Transposon Flanked by ISPpu12, in Pseudomonas putida Is Associated with Genomic Rearrangements and Dehalogenase Gene Silencing. Journal of Bacteriology., 2002. 184(23): p. 6581-6591.

87. Sambrook, J.R., David W, Molecular Cloning: A Laboratory Manual. 3rd Edition ed, New York: Cold Spring Harbor Laboratory Press.

88. Hill, P.J., Rees, C.E., Winson, M.K., Stewart, G.S., The application of lux genes. Biotechnology and Applied Biochemistry., 1993. 17 ( Pt 1): p. 3-14.

89. Pennycook, S., Personal Communication, in Landcare Research, New Zealand. 2007, Landcare Research, New Zealand.

90. Miranda, C.D., Rojas, R., Copper accumulation by bacteria and transfer to scallop larvae. Marine Pollution Bulletin., 2006. 52: p. 293-300.

91. Gordon, A.S., Howell, L.D., Harwood, V., Responses of diverse heterotrophic bacteria to elevated copper concentrations. Canadian Journal of Microbiology, 1994. 40: p. 408-411.

92. de Lorenzo, V., Herrero, M., Jakubzik, U., Timmis, K.N., Mini-Tn5 transposon derivatives for insertion mutagenesis, promoter probing, and chromosomal insertion of cloned DNA in gram-negative eubacteria. Journal of Bacteriology., 1990. 172(11): p. 6568-72.

93. Vollmer, A.C., Belkin, S., Smulski, D.R., Van Dyk, T.K., Larossa, R.A., Detection of DNA damage by use of Eschericheria coli carrying recA'::Iux, uvr'::Iux or alk $A^{\prime}:$ :lux reporter plasmids. Applied and Environmental Microbiology, 1997. 63: p. 2566-2571.

94. Topping, A.W., Thomas, A.W., Slater, J.H., Weightman, A.J., The nucleotide sequence of a transposable haloalkanoic acid dehalogenase regulatory gene (dehR) from Pseudomonas putida strain PP3 and its relationship with $\sigma^{54}$-dependent activators. Biodegradation, 1995. 6: p. 247-255.

95. Jacques, P.E., Rodrigue, S., Gaudreau, L., Goulet, J., Brzezinski, R., Detection of prokaryotic promoters from the genomic distribution of hexanucleotide pairs. BioMed Central (BMC) Bioinformatics, 2006. 7: p. 423-436.

96. Barrios, H., Valderrama, B., Morett, E., Compilation and analysis of $\sigma^{54}$-dependent promoter sequences. Nucleic Acids Research, 1999. 27(22): p. 4305-4313.

97. Rombel, I., North, A., Hwang, I., Wyman, C., Kustu, S., The bacterial enhancer-binding protein NtrC as a molecular machine. Cold Stream Harbour Symposium on Quantitative Biology, 1998. 63: p. 157-166.

98. Lenz, O., Strack, A., Tran-Betcke, A., Friedrich, B., A hydrogen sensing system in transcriptional regulation of hydrogenase gene expression in Alcaligenes species. Journal of Bacteriology., 1997. 179: p. 1655-1663.

99. Genschik, P., Drabikowski, K., Filipowicz, W., Characterisation of the Escherichia coli RNA 3'-terminal phosphate cyclase and its sigma54-regulated operon. Journal of Biological Chemistry., 1998. 273: p. 25516-25526. 
100. Poggio, S., Aguilar, C., Osorio, A., Pedrajo, B.G., Dreyfus, G., Camarena, L., Sigma54 dependent promoters control expression of genes encoding the hook and basal body complex in Rhodobacter sphaeroides. Journal of Bacteriology., 2000. 182: p. 5787-5792.

101. Gorski, L., Gronewold, T., Kaiser, D., A sigma 54 activator protein necessary for spore differentiation within the fruiting body of Myxocus xanthus. Journal of Bacteriology., 2000. 182: p. 2438-2444.

102. Weiner, L., Brissette, J.L., Model, P., Stress-induced expression of the Escherichia coli phage shock protein operon is dependent on sigma54 and modulated by positive and negative feedback mechanims. Genes and Development, 1991. 5: p. 1912-1923.

103. Wiles, S., Whitely, A.S., Philip, J.C., Bailey, M.J., Development of bespoke bioluminescent reporters with the potential for in-situ deployment within a phenolicremediating wastewater treatment system. Journal of Microbiological Methods, 2003. 55: p. 667-677.

104. De Paolis, F., Kukkonen, J., Binding of organic pollutants to humic and fulvic acids: Influence of $\mathrm{pH}$ and the structure of humic material. Chemosphere, 1997. 34(8): p. 16931704.

105. Spiehler, Clarke's Analysis of Drugs and Poisons. 3rd ed, ed. M.D.O. A.C. Moffat, B. Widdop 2004, London, UK: Pharmaceutical Press.

106. Yamazaki, M., Terada, M., Kuroki, H., Honda, K., Matoba, R., Mitsukuni, Y., Pesticide poisoning initially suspected as a natural death. Journal of Forensic Sciences, 2001. 46(1): p. $165-170$.

107. Ballantyne, B., Comparative Acute Toxicity of Hydrogen Cyanide and its Salts, in Proceedings of the Fourth Annual Chemical Defence Bioscience Review, R.F. Linsdtrom, Editor. 1984, Research Institute of Chemical Defence: Maryland, United States of America.

108. Weitz, H.J., Naturally bioluminescent fungi. Mycologist, 2004. 18: p. 4-5.

109. Weitz, H.J., Personal Communication. 2006.

110. Wilkinson D.M., D.N.M., Metal resistance in trees: the role of mycorrhizae. Oikos, 1995. 72(2): p. 298-300.

111. Chiu, S.W., Ching, M.L., Fong, K.L., Moore, D. , Spent oyster mushroom substrate performs better than mushroom mycelia in removing the biocide pentachlorophenol. Mycological Research, 1998. 102: p. 1553-1562.

112. Stutter, M.I., Lumsdon, D.G., Thoss, V., Physico-chemical and biological controls on dissolved organic matter in peat aggregate soil columns. European Journal of Soil Science, 2007. 58: p. 646-657.

113. Krosshavn, M., Steinnes, E., Varskog, P., Binding of $\mathrm{Cd}, \mathrm{Cu}, \mathrm{Pb}$ and $\mathrm{Zn}$ in soil organic matter with different vegetational background. Water, Air and Soil Pollution, 1993. 71(12): p. 185-193. 
114. Vaughan, D., Lumsdon, D.G., Linehan, D.J., Influence of dissolved organic matter on the bio-availability and toxicity of metals in soils and aquatic systems. Chemistry and Ecology, 1993. 8: p. 185-201.

115. Lewenza S., F.R.K., Winsor G., Gooderham J., McPhee J.B., Brinkman F.S.L., Hancock R.E.W., Construction of a mini-Tn5-IuxCDABE mutant library in Pseudomonas aeruginosa: a tool for identifying differentially regulated genes. Genome Research 2005. 15: p. 583-589. 